Florida International University FIU Digital Commons

$11-23-2004$

\title{
Women graduates' academic resilience and their personal strategies for doctoral success
}

Alice S. Culpepper

Florida International University

DOI: $10.25148 /$ etd.FI14061564

Follow this and additional works at: https://digitalcommons.fiu.edu/etd

Part of the Higher Education Commons

\section{Recommended Citation}

Culpepper, Alice S., "Women graduates' academic resilience and their personal strategies for doctoral success" (2004). FIU Electronic Theses and Dissertations. 2688.

https://digitalcommons.fiu.edu/etd/2688

This work is brought to you for free and open access by the University Graduate School at FIU Digital Commons. It has been accepted for inclusion in FIU Electronic Theses and Dissertations by an authorized administrator of FIU Digital Commons. For more information, please contact dcc@fiu.edu. 
Miami, Florida

A dissertation submitted in partial fulfillment of the requirements for the degree of DOCTOR OF EDUCATION in HIGHER EDUCATION by Alice S. Culpepper 2004 
To: Dean Linda Blanton

College of Education

This dissertation, written by Alice S. Culpepper and entitled Women Graduates' Academic Resilience and their Personal Strategies for Doctoral Success, having been approved in respect to style and intellectual content, is referred to you for judgment.

We have read this dissertation and recommend that it be approved.

Greg Dubrow

Bryan Moseley

Judith Slater

Janice R. Sandiford, Major Professor

Date of Defense: November 23, 2004

The dissertation of Alice S. Culpepper is approved.

Dean Linda Blanton

College of Education

Dean Douglas Wartzok University Graduate School

Florida International University, 2004 


\section{DEDICATION}

To the women who shared their stories with me and to those who will follow.

Hopefully this will be an inspiration for them to complete the journey. 


\section{ACKNOWLEDGMENTS}

Women Graduates' Academic Resilience and their Personal Strategies for

Doctoral Success indicates that age does not have to be a barrier in being successful at the doctoral level. When I started my journey, I had not been to school in over 30 years and had not taken a mathematics course in 40 years. I thought ERIC was the librarian. Because of caring professors and a university program geared to the working professional, this dissertation is testament to the saying "where there's a will, there's a way."

"Get the union card and then set the world on fire," Dr. Leonard Bliss tells students. And I was no exception. His words are the theme for this dissertation, and I want to thank him for his encouragement and assistance. Both he and his wife, Dr. Linda Bliss, helped me to find my way through the hazy map of statistics-all five courses.

I owe a very special debt of gratitude to my major professor, Dr. Janice Sandiford, whose never-ending enthusiasm and knowledge of the university's policies helped me weave my way through the intricacies of the doctoral process. Because of her belief in me and in the significance of this study, I did not pause at the ever-present rest stops, which tempted me along the way. Her presentation of this research in Portland, was the turning point of my journey. I want to thank my committee, Dr. Greg Dubrow, Dr. Bryan Moseley and Dr. Judith Slater, for helping me organize and polish my academic writing.

But most importantly, I want to thank my family: my husband for his continual reassurance that I could make this trip successfully and my parents for instilling in me the idea that true education is lifelong learning.

My trip was not completed in isolation, nor were the trips of these successful women. 


\section{ABSTRACT OF THE DISSERTATION \\ WOMEN GRADUATES' ACADEMIC RESILIENCE AND \\ THEIR PERSONAL STRATEGIES FOR DOCTORAL SUCCESS \\ by}

Alice S. Culpepper

Florida International University, 2004

Miami, Florida

Professor Janice R. Sandiford, Major Professor

This study explores women's perceptions of what made them successful doctoral students and what strategies they used to cope and succeed in the academic environment of an off-campus program in South Florida. The study's theoretical framework was built on Bandura's (1997) theory regarding ways self-efficacy influences choices made and effort expended; and Gilligan (1982), Belenky et al. (1986) and other feminists' theories concerning how women learn.

The study included data obtained from individual, semi-structured interviews with 10 participants, documents spanning the 10 years of the program and interviews with founding faculty members. For each, academic resilience was built on (a) viewing that working on the degree was personally fulfilling, (b) believing she possessed a strong sense of academic confidence; (c) priding herself on having self discipline; (d) seeing herself as a role model; and (e) being motivated by a personal or career goal.

Strategies the participants used to overcome roadblocks included (a) time management-finding time for personal, professional, and academic duties; (b) focus-- 
making the dissertation a priority; (c) collaboration-utilizing both personal and programmatic assistance; (d), and advocacy-acting on their individual needs.

Results of the study indicated that the program at the satellite campus provided structural resources that satisfied basic needs and strengthened the students' self-efficacy. This helped them become successful doctoral graduates. The women had personal fortitude and strong self-efficacy to complete the doctoral journey. They understood that their success was primarily based on the support they received from people: families, peers, and their major professors. Participants suggested that successful women students ascertain whether they have time and resources to devote to an extended study, an understanding family, and the resilience to overcome roadblocks along the way. 


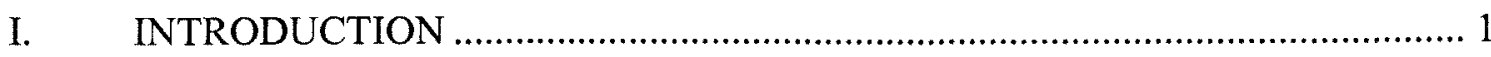

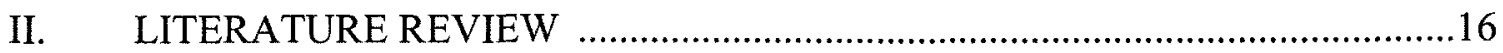

Pattern of Women's Participation in Doctoral Study ...........................................17

Women in the Classroom ...................................................................................19

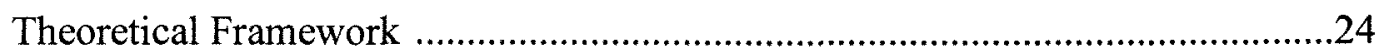

Success of Women in Advanced Graduate Study ...............................................28

Strategies of Women and Institutions Affecting Success ......................................41

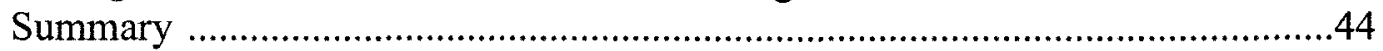

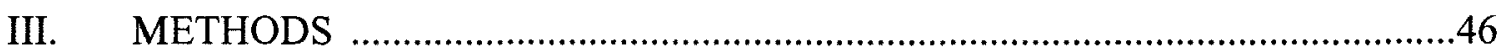

Rationale for Qualitative Case Study ...............................................................47

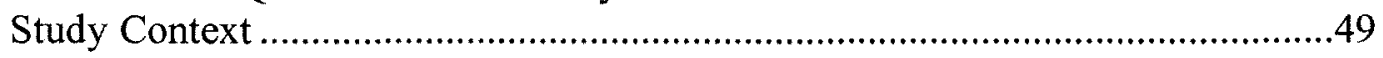

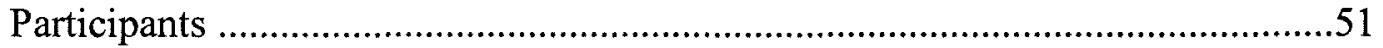

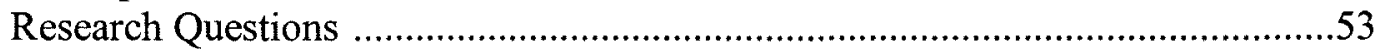

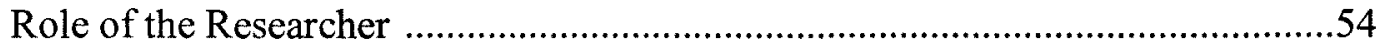

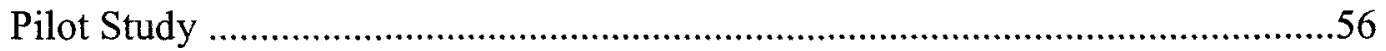

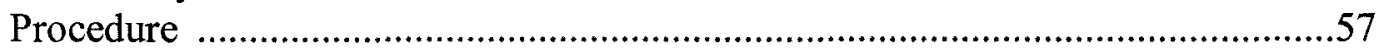

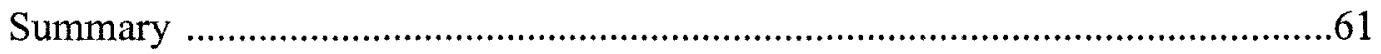

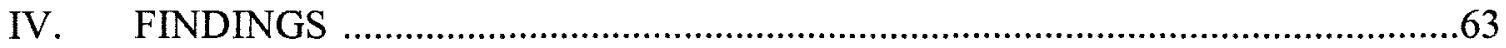

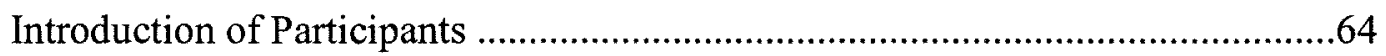

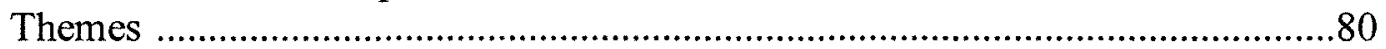

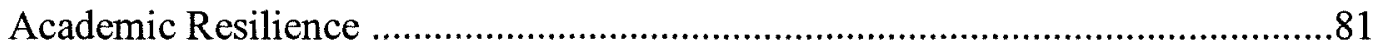

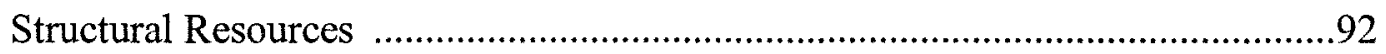

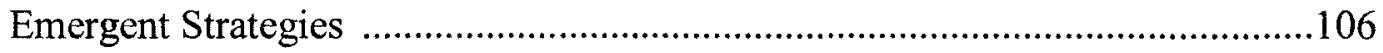

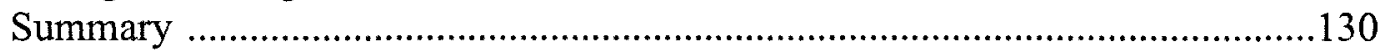

V. SUMMARY, DISCUSSION AND RECOMMENDATIONS _........................133

Summary of the Study .....................................................................................133

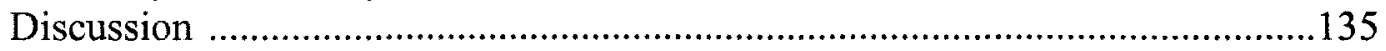

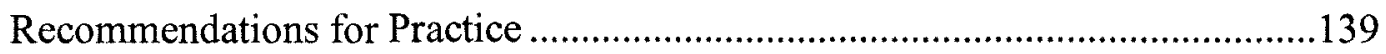

Recommendations for Future Research ........................................................143

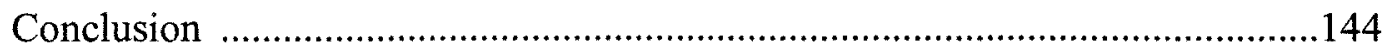

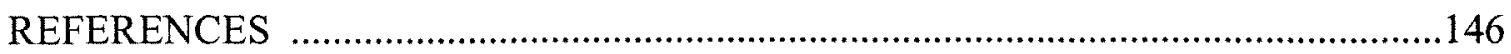

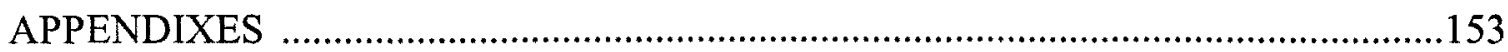

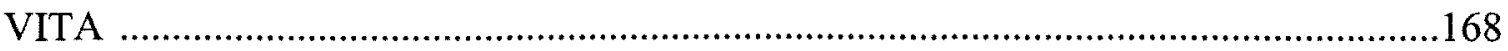




\section{LIST OF TABLES}

TABLE

PAGE

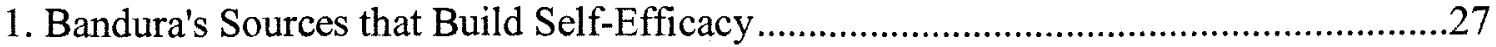

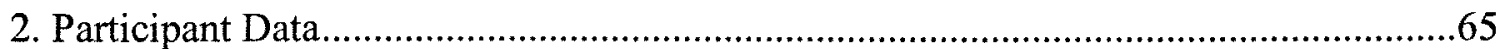

3. Academic Resilience Characteristics of the Participants .............................................82

4. Strategies the Women Used to Prioritize their Responsibilities .................................115

5. Strategies the Women Used to Focus on the Dissertation .........................................121

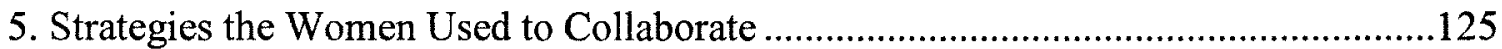

6. Strategies the Women Used to Express their Gender Advocacy ...............................130 


\section{CHAPTER I}

\section{INTRODUCTION}

While the destination for students who choose to undertake the journey through advanced academic studies is graduation, the detours along the way may lead them to a $A B D$ rather than an EdD. The success of a doctoral program at any university is usually measured by the number of students that graduate, so it is in the best interest of an academic institution to provide support that will enable its students to attain their degree. This partnership between a university and its students requires the concerted efforts of both if the culminating success is to be achieved by either: the opportunities provided within the structural resources of the university and the application of internal characteristics to develop personal success strategies by the students.

Personally, I would have to say, that it has been a mind... how can I put it... explosion for me. It's like I had all these ideas in my head, and I couldn't quite figure out how everything fit together.... It has just changed my whole frame of reference. It's all come together intellectually and even spiritually. I really feel how everything works and fits together in a way that I know what my role in the universe is. (Margo, a doctoral completer)

Maybe if all doctoral candidates had experiences similar to Margo's, then more would be successful in completing their degrees. The doctoral program from which Margo graduated was established on a satellite campus in order to serve the local population by offering convenient opportunities to earn advanced graduate degrees.

This study included data obtained from interviews with 10 women who had graduated from the satellite campus, from university documents from the 10 years the program has been operating, and from personal communications with faculty members who helped establish the program. This triangulation of sources enhanced the quality of data collected. The faculty members and documents provided information about the 
program, such as its original mission and structure. The interviews revealed the personal characteristics and strategies of these successful dissertation completers. During one hour, semi-structured individual interview sessions, the women reflected upon their doctoral study, and shared their thoughts and experiences as to what factors they believed made them successful graduates and what others could do to be successful.

\section{Purpose of the Study}

For many graduate students, success is defined as the academic achievement that is associated with receiving a doctoral degree. Candidates agree that the most challenging portion of the doctoral process is the completion of the dissertation. Overcoming this obstacle is critical to personal as well as academic success. The purpose of this study was to explore the perceptions and personal strategies employed by women who attended a satellite program and subsequently successfully completed their dissertations. Much of the literature on successful graduate students examines the programmatic, external factors that influence a candidate's successful completion of a doctoral program. The internal characteristics that contribute to achieving this goal are often minimized.

In addition, historically women have been missing as participants in research; even from the formative stages of psychological theories. There has been bias in the selection of male samples for research (Belenky, Clinchy, Goldberger \& Tarule, 1986; Gilligan, 1982). "This omission of women from scientific studies is almost universally ignored when scientists draw conclusions from their findings and generalize what they have learned from the study to the lives of women" (Belenky, et al., 1986, p.7). This study focuses solely on successful women and their perceptions of how their school and home experiences affected their academics, with the intention of supplementing the 
current literature on academic success. This study is important to current and future doctoral candidates as well as to faculty who want to understand what women perceive helped them be successful. The long-term goal is to enhance the climate of graduate school for women, while the short-term goal is "to help women now enrolled, survive and succeed" (Johnsrud, 1995, p. 77).

\section{Background of the Study}

At a symposium in November 2003 celebrating the 10 years of the satellite program, one of the original faculty members spoke about the program. He said that the original purpose was to provide a doctoral program at an alternative campus in a county that had no public 4-year university, to give working professionals the opportunity to earn an advanced graduate degree and to increase the number of doctoral degrees conferred by the university headquartered in the adjoining county. While the graduation rate has varied over time, after 10 years the first cohort reports a $100 \%$ candidate completion rate.

Studies have indicated that students without close access to university facilities and personnel, such as the library and professors, face additional barriers as they cope with the academic demands of college (Jacoby, 2000; Kluever, 1997; Tinto, 1997; Wilson, 2003). The satellite-based EdD program originally had five features that helped students to cope: (a) cohorts (groups of students admitted at the same time), (b) the Saturday Continuous Integrated Seminars (CIS) "cross fertilizing" students from various programs, (c) a focus on action research, (d) faculty team teaching courses, and (e) a fullservice administrative center on site (C. Divita, personal communication, September 2002). 
The program might be best considered as an evolving one, however. Through the years, the faculty underwent major changes; several of the original cadre of professors left the university as retirement and "new opportunities" sent instructors on other journeys. The location of the satellite campus moved from an urban location to a suburban one. While these moves have affected the original curriculum, providing graduate students with a base outside of the university's main campus continues to be the focus of the program.

As part of this focus, the professors have often reevaluated the program and offered opportunities to help the students graduate in a timely fashion: support groups, workshops and specialty personnel. Currently, one instructor provides students with two kinds of support groups free of charge: a peer group seminar-discussion and a 10-day "boot camp" for proposal writing. The Dean of the Office of Advanced Graduate Studies in the College of Education also provides another type of support: workshops each year to help in writing the dissertation proposal and another in writing the actual dissertation. The university also has hired personnel to help with the writing phase of the dissertation and employed statisticians to assist dissertation-level students with analyzing research data. Still, at this study's point in time, the typical satellite doctoral student's journey to complete the advanced degree moves at a slow pace and major professors have more students to advise each term as more pass the comprehensive exam than complete the dissertation.

Research Focus

The success of doctoral students is being investigated because of the low number of students who have completed this program since its first cohort. After 7 years the 
Admission/ Enrollment Summary of the program (10/9/00), indicated that in Cohort 1 (Fall 1993), 18 students matriculated to the dissertation stage (passed the comprehensive exam and admitted into candidacy) and 16 graduated by 2000 . However, for Cohort 2 that started the year after Cohort $1 \mathrm{did}, 13$ matriculated, and only 3 of those received degrees (none of whom were women). Succeeding cohorts have each had fewer individuals receiving degrees (see Appendix A). None of the later cohorts have approached the success rate of the first. It is recognized that later cohorts have had less time to finish, this pattern is still a cause for concern.

While completion of the dissertation is challenging for everyone, this study focused on the particular challenges that female candidates overcame to achieve success. This study explored the lived experiences of those women who have graduated. By participating in a doctoral graduate program, these women had already experienced personal and academic success through the completion of a master's degree. This study focused on how their academic resilience and personal strategies contributed to their continued success: defined as the completion and successful defense of their dissertation at a satellite facility.

\section{Issues Pertaining to Success}

The conceptual framework of this study integrates Bandura's (1986) self-efficacy model that successful people have a belief in their own capacity to organize and execute actions they need to manage difficult situations and Belenky et al.'s (1986) theory that women learn better in relational rather than solitary situations. This study is grounded in the understanding that motivation plays a part in successful endeavors (Maslow, 1943). A 
reasonable assumption might be that most doctoral students are highly motivated individuals with high expectations because of prior academic success.

The successful women in this study managed their careers and family obligations, in addition to attending school. They demonstrated their commitment as well as their selfefficacy, or their "beliefs about their capabilities to produce designated levels of performance that exercise influence over events that affect their lives" (Bandura, 1994, p. 71). If people believe they have no power to produce results, they will not attempt such a complex project such as an advanced degree program. Self-efficacy can influence choices made and effort expended (Bandura, 1997).

Bandura included both men and women in his studies. However, Belenky et al. (1986) focused exclusively on women and how they learn. Their women who succeeded in education were excited about learning, cared about the lives of people around them, were aware of their own thoughts, judgments and moods, and recognized the inevitability of conflict and stress (Belenky, et al., 1986). Other feminist theorists who emphasized the importance of collaboration, cooperation, caring (Chodorow, 1972; Gilligan, 1982; Noddings, 2003) had an impact on the Belenky and others' theory and were used in this study that explored how women students were successful in advanced degree programs.

\section{Historical Role of Women in Higher Education}

Although current levels of participation by women in doctoral programs are notable, historically, women were hindered in their efforts to excel in higher education through the absence of social and legislative support. Initially, higher education in the United States was available only to men who were taught by men. Although women were teachers in the schoolhouse, it took many years for them to arrive at the university campus 
both as student and as professor. It was not until the Civil War, when men were in battle, that women prepared for roles other than professional domestic or schoolhouse teaching (Rudolph, 1990). Years after they were admitted to the university, the idea that women might have different academic needs was still not taken into consideration.

Even girls' schools and women's colleges have been modeled after male institutions to give women an education "equivalent" to men's. Relatively little attention has been given to modes of learning, knowing, and valuing that may be specific to, or at least common, in women (Belenky, et al., 1986, p. 8).

A century after the Civil War, Title IX of the Education Amendments of 1972, provided more opportunities to women in academia as well as in athletics. Throughout the United States, the number of women who have reached their degree destination has changed since United States legislators passed Title IX. In 1997, Richard Riley (secretary of the U.S. Department of Education at the time) wrote in Title LX:25 Years of Progress, "The greatest untold story of success that resulted from the passage of Title IX is surely the progress that has been made in education" (U.S. Department of Education, 1997, Introduction, para. 4). While Title IX is not the only reason that more women are participating in higher education programs, the availability of more scholarships providing easier access to college and advanced study certainly has been a contributing factor to the increased enrollment.

"Between 1977 and 1994, the number of U.S, women earning doctoral degrees almost doubled, from just over 7,500 to almost 14,000 . This represents a jump from $25 \%$ in 1977 to $44 \%$ in 1994 of total doctoral degrees conferred" (U.S. Department of Education, 1997, Part 4, para. 10). As more women have earned bachelor's and master's degrees, more have continued into doctoral programs. 
The success of women doctoral students is of particular interest because of their growth in numbers, especially in the years after the passage of Title IX. According to the National Center for Education Statistics, more women now earn doctoral degrees than in the past. In fact, women earned $46.3 \%$ of all degrees in $2001-2002$ (U.S. Department of Education, 2003) compared with 14\% in 1970-71 (U.S. Department of Education, 2001). In education, women earned $64.9 \%$ of the doctoral degrees in $1999-2000$ but their registered time increased from 6.9 years in $1979-1980$ to 8.1 in 1999-2000 (U.S. Department of Education, 2003).

As the length of time to complete the degree lengthens, the need to understand the factors that influences completion arises so students who are having difficulty completing the advanced degree can utilize the structural resources and strategies others have used to be successful. This study explored personal factors because prior studies have not focused specifically on the success of women in a doctoral program at a satellite campus.

\section{The Role of Women at the Satellite Campus}

Women have been a majority in this doctoral program since its inception. Because much of the published research focuses on why students do not complete the dissertation, this study explored what motivated those who did finish. By creating a dialogue with women who earned the doctoral degree, information can be obtained to help others better understand the strategies these women used to succeed in this academic environment.

It is important to make this knowledge available because the doctoral degree is essential for professorships at universities and leadership positions in the non-academic world as well, and women (who are presently in the minority at those levels) need to explore what strategies can help them earn this crucial degree. At the satellite campus, 
which is dominated by female students and male professors, only two women faculty members have been consistently employed. This is unfortunate because "the dearth of women faculty at the decision points simply lessens the chances of finding same-sex role models, mentors or sponsors to ease their way into graduate programs" (Johnsrud, 1995, p. 72). Universities today need women as professors and mentors, and the doctorate is a prerequisite to employment in faculty positions, especially at major research universities where doctoral programs reside and where there are few minority men and fewer women of all races and ethnicities (Turner \& Thompson, 1993).

Research Questions

The research questions center on the lived experiences of women doctoral graduates at an evolving satellite university campus in Florida. The overarching research question that drove this study was "What do women students perceive made them successful in completing an advanced graduate degree at a Florida DRU-E satellite campus?" In addition, the study was also guided by three related questions:

Question \#1 What are the characteristics that define academic resilience for women in a doctoral program?

Question \#2 What are the structural resources within an advanced degree program that influence success?

Question \#3 What personal strategies do women develop to complete their dissertations?

By exploring these strategies, this study offers insight, from the participants' points of view, for other doctoral candidates to use to help them be successful on the journey to earn the EdD. At the same time, it provides personnel at institutions that offer 
advanced graduate degrees a road map from insiders' points of view they can draw on to develop and provide opportunities that help other students achieve success.

\section{Rationale/Contribution to Theory and Practice}

To be successful one needs to develop the skills and beliefs to obtain a designated performance (self-efficacy) which can determine how much effort a person expends when encountering a difficult task (Bandura, 1986). Bandura's research is important to any study on the achievement of success, particularly his theory on sources that influence self-efficacy: mastery experience, vicarious experience, verbal persuasion and physiological needs.

At the same time, although many theorists have emphasized women's apparently inborn needs (i.e., Chodorow, 1972; Gilligan, 1982, Noddings, 2003) that influence how they learn (Belenky, et al., 1986) they have not been sufficiently explored as they apply to women who are doctoral candidates. Belenky, et al. (1986), Chodorow (1974), Gilligan (1982), and Noddings (2003) have written of characteristics that women are likely to posses that enhance their chances for success such as their being cooperative and process minded. This study explored how the theories of feminist researchers might be integrated with those of Bandura to better explain the success of women dissertation completers than has been done previously.

Studies of doctoral success that include women (Berg \& Ferber, 1983; Bowen \& Rudenstein, 1992; Burnett, 1999; Clark \& Watson, 1998; Conrad \& Philips, 1995; Ellis, 2001; Golde \& Gore, 2001; Green, 1997; Heinrich, 1995; Kluever, 1997; Kluever \& Green, 1998; Le-Doux, 1996; Lenz, 1997; Mariano, 1993; Nerad \& Miller, 1997; Neumark \& Gardecki, 1998; Rode, 1998; Schroeder \& Mynatt, 1993; Shelburn \& 
Lewellyn, 1995; Smeby, 2000; Turner \& Thompson, 1993; Ulku-Steiner, Kurts-Costes, \& Kinlaw, 2000; Weil, 1990), did not address the contributions of the theories of Bandura or of Belenky et al. However, some studies did mention the importance of collaboration and cooperation, which helped the participants overcome the feelings of isolation during the dissertation process. The influence of the family was mentioned as a benefit and a detriment.

In her research on women's academic careers, Carole Pistole (1994) explained how the family relationship can affect a woman's success in an advanced degree program.

Women's development and identity exists within the context of attachment and family, and family is an acknowledged female domain. A focus, therefore, on parallels between professional and family development might enable women to be less aware of feeling they are not equipped to "play the game" and more aware of how to achieve success. (p. 30)

It is appropriate that this study was particularly focused upon women's perceptions because women are the majority in this satellite graduate facility. As women increase in number, the necessity to accommodate their needs arises. According to the National Center for Educational Statistics (U.S. Department of Education, 2001) many women earn an $\mathrm{EdD}$ (the type of doctoral degree awarded in this study) rather than a $\mathrm{PhD}$. Often, the degree is not granted immediately after the master's degree; women often take time off to raise a family (U.S. Department of Education, 2002). Women are inherently loyal to family relationships, and they put the needs of the family before their own concerns (Baird, 1998; Belenky, et al., 1986; Chodorow, 1972; Gilligan, 1982; Johnsrud, 1995; Noddings, 2003; Titone \& Maloney, 2002). The program of this study was created specifically to accommodate these women seeking an EdD so it is imperative 
to determine what factors contribute to their success because studies that focused on PhDs may not adequately reflect their experiences.

In a related vein, researchers indicate a need for more studies about women. In his study about the strategies women superintendents use to be successful, Brunner (1998) wrote that although there is a body of literature focusing on men and how they attain success, there is little specifically about women. Conrad and Phillips (1995) reported that efforts must be made to ensure that postgraduate research provides a climate appropriate for women.

Proponents of the feminist phase theory indicated that focusing on women in research is important because the theory shows how women have been reflected in the academy. The stages have evolved from a male scholarship (womanless) category to multifocal scholarship (Tetrault, 1985). Academics of feminist theory indicate that research needs to concern women and their scholastic perceptions. "Higher education is the home to feminist scholars who generate much of the new knowledge about women" (Twombly, 1991, p. 10). As a female participant in a doctoral program I am interested in how women students in higher education achieve success.

Concerning the personal factors affecting advanced degree success, Green (1997) indicated that further study of the "dissertation delay and personality measures is warranted by the sparsity of work in this area" (p. 64) in the conclusion of her study of psychosocial factors affecting dissertation completion. Kluever and Green (1998) suggest developing a study to further probe the relationship between responsibility and selfesteem, which affect dissertation completion. 
This study makes a contribution to the academic community in several ways. First, students who have completed the course work and are now struggling with the culminating paper can explore the strategies successful students used to complete the dissertation within the time frame suggested by the off-campus program, and adapt the strategies to their needs even as the program changes. As the students' time-to-degree lengthens, their financial responsibility increases while their morale and competitiveness on the job market decreases (Maher, Ford \& Thompson, 2004; Weil, 1990).

Second, this study should also help faculty members in developing curriculum and strategies for their students to utilize during their academic endeavors. "Failure to complete the dissertation is expensive and painful for the student, discouraging for the faculty involved, and injurious to the institution's reputation" (Green, 1997, p. 57). The number of doctoral graduates is relevant to the success of a doctoral program (including off-campus centers) and the reputation of the university as it influences enrollment, faculty, and economics. University faculty and administrators regret when doctoral students do not complete advanced graduate degrees (Lenz, 1997). Attrition is expensive for the university. "Notre Dame would save \$1-million a year in stipends alone if attrition went down by 10 percent (sic) because programs would not over-enroll students to compensate for attrition" (Smallwood, 2004).

By examining the lived experiences of women who have completed their dissertations, this study offers insights for others faced with the same obstacles. In exploring the strategies these women used to cope with the rigors of an advanced graduate degree, other students can adapt the strategies that relate to their needs, and thereby create a successful situation for themselves and their universities. 
Weil (1990) indicated that the number of delayed completers diminishes the ability of the university's program to attract new students and the faculty can be overloaded with more students to assist and advise. More students will need financial assistance through fellowships and assistantships, which may be limited by the university's economic constraints and availability of funding. As the number of students who complete the degree increases, so does the attractiveness of the university to future advanced degree students.

\section{Terms Defined}

For the purpose of this study the following terms gathered from the literature as well as documents and brochures of the off-campus program will be used:

Academic Resilience. Achieving success in school despite the risk (factors that increase the chance of school failure and limited academic attainment ( $\left.\mathrm{O}^{\prime} \mathrm{Connor}, 2002\right)$.

All But Dissertation (ABD). Student who has completed the coursework and has passed the qualifying exam. (Also known as Doctoral Candidate.)

Cohort. A group of graduate students admitted into a program and expected to proceed as a group through completion. The use of cohorts was discontinued in 1997.

Continuous Integrated Seminar. A one-credit course offered on one weekend a month during the semester. All doctoral students met in a large group to study a current theme such as urban or multicultural issues until they earned the required.

Doctoral Research University-Extensive (DRU-E). Classification by the Carnegie Foundation for the Advancement of Teaching categorizing institutions of higher learning. The DRU-E institutions typically offer a wide range of baccalaureate programs, and they are committed to graduate education through the doctorate. During the period studied, 
they awarded 50 or more doctorate degrees per year across at least 15 disciplines. Only $7 \%$ of American universities are classified DRU-E.

Self-Efficacy. The belief in one's capabilities to organize and execute the sources of action required to manage prospective situations (Bandura, 1986). He explains that self-esteem is an evaluative judgment of self-worth attributed by individuals to themselves, and is different from self-efficacy, which is the belief one can accomplish the task at hand.

Success. The completion of the doctoral dissertation.

Organization of the Study

Women Graduate's Academic Resilience and their Personal Strategies for Doctoral Success explores the personal and structural factors women doctoral graduates perceive helped them be successful in achieving an EdD. Following this introductory chapter, Chapter II includes a review of the relevant literature focusing on feminist theories as well as the internal characteristics and external factors that have been identified as influencing completion of the dissertation. In Chapter III, the methods used to conduct the study and the role of the researcher are presented. The data for this study are the words of the participants and the content found in university documents spanning the 10 years of the program. Chapter IV includes a description of the participants and the data findings. The data analysis here identifies the factors that the women believe are important to being successful graduates and the strategies they used to successfully complete the dissertation. Chapter $\mathrm{V}$ includes a discussion of the findings and implications for practice and future research. 


\section{CHAPTER II}

\section{LITERATURE REVIEW}

In this chapter, the research that provided a background for this study is presented. For more than two decades, scholars have documented the problems students have had in completing the dissertation (Baird, 1997; Berg \& Ferber, 1983; Bowen \& Rudenstein, 1992; Cesari, 1990; Ellis, 2001; Garcia, 1987; Golde \& Dore, 2001; Johnsrud, 1995; Kluever \& Green, 1998; Le-Doux, 1996; Lenz, 1997; Maher, Ford \& Thompson, 2004; Mariano, 1993; Nerad \& Miller, 1997; Neumark \& Gardecki, 1998; Rode, 1998; Schroeder \& Mynatt, 1993; Shelburn \& Lewellyn, 1995; Sternberg, 1981; Turner \& Thompson, 1993; Ulku-Steiner, Kurts-Costes \& Kinlaw, 2000; Witte \& James, 1998). National records are kept as to the number of candidates who receive their degrees, but according to the National Center for Education Statistics, few national records have been kept as to the time it takes to complete the dissertations after a student has completed the comprehensive exam. "Exact statistics concerning terminal ABD [All But Dissertation] status persons are hard to find because of the understandable reluctance of departments, colleges and universities to publish such information" (Monsour \& Corman, 1991, p.180).

Bowen and Rudenstein (1992) provided an additional explanation.

A main reason for the lack of regularly published national data is presumably that completion rates can be calculated only if records are maintained for all students who begin doctoral study, whereas the practice has been (for understandable reasons) to concentrate on those students who actually earn doctorates, allowing those who drop out to disappear from sight. (p.107)

A national survey in 2001 by The Pew Charitable Trusts solicited the point of view of doctoral students about their doctoral preparation and their career goals. The 
more than 4,000 respondents from 27 universities indicated they did not understand what doctoral study entailed (Golde \& Dore, 2001). The participants said they entered their doctoral programs unaware of the time and energy required to complete the advanced degree. The findings indicated that many students do not understand what doctoral study entails, how the process works and how to navigate it effectively. The studies that have been reported in the literature are organized into these areas: Pattern of Women's Participation in Doctoral Study, Women in the Classroom, Theoretical Framework Success, Success of Women in Advanced Graduate Study, and Strategies of Women and Institutions Affecting Success.

\section{Pattern of Women's Participation in Doctoral Study}

This study focused on women who have reached their destination, the successful completion of the EdD at the satellite campus of a Florida Doctoral Research UniversityExtensive. Because women made up $80 \%$ of the enrollment in the doctoral program at this campus, the study specifically explored their experiences in obtaining a doctoral degree. Often researchers used gender as a variable because it was easy to determine and factor, but it is a useless variable unless it is studied for a particular reason (Twombly, 1991). In this study gender was important.

The program at the satellite facility awards the education doctoral degree, the EdD. The Condition of Education indicated that in 2000 only a $16 \%$ of the EdD students are enrolled full time, for a full year, and most of those $(82 \%)$ considered themselves primarily employees (U. S. Department of Education, 2002). The program in this study was created to accommodate working professionals, the same type of student. 
According to the Condition of Education 2003, by 2000 women represented $70.8 \%$ of the persons receiving doctoral degrees in education (U. S. Department of Education, 2003). However, their time to earn the doctorate also increased. The Condition of Education indicated that on an average in 2000, women earned the degree in 8.1 years, up from 6.9 years in 1980 (U. S. Department of Education, 2002). This is problematic because it makes earning the degree less attractive, delays the opportunity to earn at her full potential, and may hinder future job opportunities (Maher et al., 2004; Mariano, 1963; Rode, 1998).

At the satellite campus, all the women in the first cohort received their degrees within the first 10 years of the program, yet only one in the second cohort was successful in 10 years. Because women are actively involved in graduate programs, gender should be a factor worthy of consideration in a study of doctoral students, yet earlier studies have identified the barriers that have precluded this type of research.

In spite of the increase in the number of women students in higher education and professional schools, faculties usually are predominately male, argue against a special focus on women students and resist open debate on whether women's educational needs are different from men's. (Belenky, et al., 1986, p. 5)

Even women's colleges were modeled after male universities to provide women an education that was equivalent to men's. "The socialization process at most universities has failed to take account of the new realities of older, part time female graduate students. Professors use the model in which they were socialized-typically young, full-time male students" (Johnsrud, 1995, p. 73). However, women do have different styles of learning as reported by feminine researchers. 
In Women's Way of Knowing, Belenky et al. (1986) shared their findings about how females learn. "Relatively little attention has been given to modes of learning, knowing and valuing that may be specific to, or at least common, in women" (p. 6). This is still partially true today at some universities. "Most women still suffer from the chilly climate in higher education, as well as from the burden of family responsibilities" (Cooper in Koch \& Irby, 2002, p. 75). Women traditionally are more responsible for family and home concerns and how this impacts their academic progress is important.

The rate of success for women, however, is not continuing to increase as rapidly. In fact, the annual Survey of Earned Doctorates produced by the National Opinion Research Center for the National Science Foundation shows that the number of doctorates earned by women rose in 2000 but dropped in 2001 by $1.1 \%$ (Fogg, 2002). The drop in numbers may indicate several factors. Some women with families can be turned off by the time commitment, and students in general are looking at the financial impact and choose to go into law or business rather than to graduate school (Fogg, 2002). In order to encourage women to undertake the journey, identifying the factors that contributed to the academic resilience and their strategies for successful completion becomes increasingly important.

\section{Women in the Classroom}

While attaining success is important for all doctoral candidates, the style of learning can be different for women who are relatively new to the advanced degree picture. Pertinent to their success is how they juggle their roles and how they are taught.

Because of the way the culture constructs gender, we women carry a lot of "baggage." By this I mean that, in the past, Western culture attributed to us-and quite possibly still does attribute to us-the body of knowledge, the network of 
skills, and the various sets of tasks, duties, and traits that the culture associates with the institutions of home and family and with the "reproductive processes" of society that are housed therein. So that when women go unseen in the educational landscape, this constellation of knowledge, skills and activities is also rendered invisible. (Martin in Titone \& Maloney, 2002, pp. 151-152)

Martin adds that "reproductive processes" is not just biological reproduction but includes all areas of running a household and serving the needs of all family members, young and old. It is important to include women in educational discussions because they do offer a different viewpoint from traditional philosophical theories and analysis of education.

\section{How Women Learn}

In Women's Way of Knowing, Belenky and others (1986) categorized how women learn: (a) silence, a position in which women experience themselves as mindless and voiceless and subject to the whims of external authority; (b) received knowledge, a perspective from which women conceive of themselves of receiving, even reproducing, knowledge from external authorities but not capable of creating knowledge on their own; (c) subjective knowledge, a perspective from which knowledge is conceived of as personal, private and subjectively known; (d) procedural knowledge, a position in which women are invested in learning and apply objective procedures for obtaining and communicating knowledge; and (e) constructed knowledge, a position in which women view all knowledge as contextual, experience themselves as creators of knowledge, and value both subjective and objective strategies for knowing. "Belenky explored women's different patterns of knowing and learning, particularly her concept of 'connected knowing,' which suggests that women learn better in relational rather than solitary situations, from contextualized rather than isolated information, and by cooperation rather than competition" (Marshall University, n.d. para. 4). 
Constructivist learning is not gender specific. However, Belenky et al. (1986)

reported that their women constructivists not only made connections that tied together knowledge, but also were excited about learning. "We found the opening of the mind and the heart to embrace the world was characteristic only of the women at the position of constructed knowledge" (Belenky et al., 1986, p. 141). Their women constructivists embrace all pieces of the self, try to be inclusive rather than exclusive, and want to improve the quality of life for everyone. "Because constructivists understand that knowledge is always in the making and is always situated, they see development of ideas is a highly collaborative and open endeavor. Everyone has a contribution to make" (Belenky, Bond \& Weinstock, 1997, p.63).

\section{Women Juggle Roles}

The woman constructivist is concerned with the issues of inclusion, doing it all, and she recognizes the inevitability of conflict and stress but lives with it (Belenky et al,, 1986). This juggling act can affect the woman's time-to-degree, which is longer than her male counterparts (Johnsrud, 1995). When Johnsrud examined women in graduate education, she provided some explanations.

Women attempt to juggle conflicting roles as employees, mothers, wives, lovers, daughters, friends, and students in a climate that demands focus on the intellectual domain. They complain more than men do about the lack of time, leisure, and support... Given the personal challenges faced by many women returning to graduate and professional school, it is not surprising that their attrition is higher and their time to degree is lengthened. Success requires a level of commitment beyond that demanded of their male peers. (Johnsrud, 1995, p. 75)

Connection, collaboration and socialization are important for women to succeed as they multitask throughout their degree program. Clark and Watson (1998) explored academic collaboration in their qualitative study $(n=11)$ that was grounded on Gilligan's 
(1982) theory of women's psychosocial development. They found that all of the women

they interviewed had intensely busy lives and juggled multiple professional and personal responsibilities which points to the central importance of connection for women. They spoke of it as if the collaborative process was a "living thing, a multidimensional, dynamic, energizing reality that has the potential to enrich their lives" (Clark \& Watson, 1998, p. 72).

How Women Are Taught

As women entered the collegiate classroom, the men continued to teach the women as they had previously taught men, which influenced the success of the women. "The socialization process at most universities has failed to take account of the new realities of older, part time female graduate students. Professors clung to the model in which they were socialized - typically young, full-time male students" (Johnsrud, 1995, p. 73). The satellite campus in this study consistently maintains a majority of women candidates who, at the time of the study, were taught by more men than women professors.

Women's educational development may be inhibited by groups that operate on the basis of the conventions common in male interaction. This suggests that every effort must be made to ensure that postgraduate research groups provide a climate appropriate for women's education. (Conrad \& Phillips, 1995, p. 317)

The two British researchers focused on gender-related communication and collaborative learning to enhance the success of postgraduate study for women as well as men, and they recognized how women exemplify the ethic of caring and cooperation.

The interpretation of much of the research into gender and communication is consistent with stereotypical differences between men and women generally. Men's groups are characterized by competition, hierarchical organization, a 
focus on information that has little to do with themselves personally or emotionally, humour in which they do not serve as the butt of the joke, abrupt moves from topic to topic, a style that is straight forward and confrontational with strongly expressed opinions, and the use of silence as a self-defense mechanism. Women's groups, on the other hand, are described as being cooperative, laterally organized, self-disclosing, using self-depreciatory humour, attempting to make transitions between topics by showing respect for previous speakers before moving to an individual's own points, and by taking turns in speaking, often using silence to allow others to speak. (Deakins as cited in Conrad \& Phillips, 1995, p. 316)

How women are taught is pertinent to their success as advanced graduate students. "Isolation may be a particular problem for women... Group settings, such as the traditional lecture or tutorial classes, have frequently been a mechanism of women's oppression" (Conrad \& Phillips, 1995, p. 313).

Other researchers wrote about this need for socialization. In a qualitative study ( $n$ $=11$ ), Lenz (1998) studied non-traditional women (over 35 years of age) in graduate study and reported that simply having a close relationship is not enough for female development; those relationships must be supportive in order for the female to grow. Her findings are important because her participants did not pursue the doctoral degree immediately after undergraduate school, similar to the participants in this study. Lenz found that successful women have strong support structures in place as well as positive self-in-relation input (how one works in a relationship) developed by Chodorow (1972).

Chodorow (1972) and Gilligan (1982) theorized that women have more social roles than men and that attachment is inborn in women.

Given that for both sexes the primary caretaker in the first three years is typically female, the interpersonal dynamics of gender identity formation are different for boys and girls. Females experience themselves like their mothers, fusing the experience of attachment, while boys, defining themselves as masculine, separate from their mothers. (Gilligan, 1982, p. 7) 
These childhood experiences can even influence the self-efficacy of women, their belief that they can accomplish a task. Self-efficacy affects how they learn and should be taught. In their study of women's success in male-dominated fields such as mathematics and science $(n=15)$, Zeldin and Pajares (2000) explained that because of the different sex-type experiences in childhood, women are less exposed to the type of information necessary to develop strong self-efficacy perceptions in traditionally male arenas.

Although more women study education, they are taught more often by male professors than female ones. Zeldin and Pajares (2000) found that women typically have higher selfefficacy for tasks associated with working with people than for tasks associated with working with things.

How women learn and are taught influence their educational experiences. "Various hypotheses have been formulated to explain the phenomena that more women than men drop out before completing the doctoral degree but implicit in all of them is that the women's graduate experiences differ from those of men" (Schroeder \& Mynatt, 1993, p. 555). In their study $(n=151)$ of student-professor interactions at three Midwestern universities, they found that women students felt overlooked, unsupported and even neglected, factors explored in this study.

Theoretical Framework

In addition to Belenky and others' theories of how women learn, Maslow's (1943) studies on motivation and Bandura's (1986) model on how self-efficacy affects persistence in the accomplishments of difficult jobs contributed to the theoretical background for this study. In integrating the concepts, it appears that the constructivist 
woman (Belenky et al., 1986) and the self-actualized person (Maslow, 1943) seek

knowledge and embrace the world around them. Both groups exhibit strong self-efficacy.

Known for his research on successful people, Maslow (1943) believed that as

people satisfied certain needs, they moved toward self-actualization and wisdom.

Although his research, which was not separated by gender, he developed a five-level hierarchy of needs that influenced motivation. Once people satisfied the lower levels, they could advance to the self-actualized stage.

Even if all these needs are satisfied, we may still often (if not always) expect that a new discontent and restlessness will soon develop, unless the individual is doing what he is fitted for. A musician must make music, an artist must paint, a poet must write, if he is to be ultimately happy. What a man can be, he must be. This need we may call self-actualization. (Maslow, 1943, p.382)

Self-actualized people focus on concerns outside themselves, have a sense of responsibility and seek knowledge and self-fulfillment, personal traits of the successful doctoral student reported in the literature.

Maslow's self-actualized person (unisex) and Belenky et al.'s constructivist woman both exhibit strong self-efficacy, share several characteristics including being excited about learning, caring about others, being goal oriented and being aware of their own thoughts and feelings, characteristics that could be included in a study about doctoral success. Belenky et al. (1986) studied women and how they learn. Relevant to doctoral study are constructivist women who are creators of knowledge and are excited about learning. They care about the lives of people around them. They are similar to Maslow's self-actualized people who are not ego-centered but focus on problems outside themselves. They are mission-oriented, often on the basis of a sense of responsibility, duty, or obligation rather than personal choice. 
Characteristics of these women that relate to successful doctoral study include their recognizing the inevitability of stress but living with it, having a high tolerance for internal contradiction, sharing and listening in conversations, having an awareness of their own thoughts and desires. They embrace all parts of themselves - mother, daughter, student, and mate. The theories of Gilligan (1982), Chodorow (1972), Noddings (1984) all had an impact on the Belenky's et al. (1986) research and were used in this study.

Women who are self-actualized and are constructivists have high self-efficacy. Self-efficacy is not high self-esteem but a belief that one has the skills to accomplish a given task. People with strong self-efficacy undertake realistically challenging tasks and provide motivation for progressive self-development of their capabilities (Bandura, 1986, 1997). "In social, intellectual and physical pursuits, those who judge themselves highly efficacious will expect favorable outcomes; self-doubters will expect mediocre performances of themselves and thus negative outcomes" (Bandura, 1986, p. 392).

Self-efficacy can determine how much effort people will expend and how long they persist in the face of obstacles. "Individuals' beliefs about their competencies in a given domain affect the choices they make, the effort they put forth, their inclination to persist at certain tasks, and their resiliency in the face of failure (Zeldin \& Pajares, 2000, p. 215).

Table 1 indicates the sources of self-efficacy: performance attainment (mastery experiences), vicarious experiences (judging the performance of others), verbal persuasion and allied types of social influences, and physiological states (Bandura, 1986). Enactive attainment is the most influential source of efficacy because it is based on a person's authentic experiences. "People who are assured of their capabilities are more 
Table 1

Bandura's Sources that Build Self-Efficacy

\begin{tabular}{lll}
\hline Source & Definition & Effect \\
\hline Mastery Experience & Success in past performance & Raised efficacy \\
Vicarious & Seeing others perform same task & $\begin{array}{l}\text { Depend on modeling if little prior } \\
\text { experience }\end{array}$ \\
Experience & & Greater sustained effort \\
Verbal Persuasion & Telling people they are capable & Stress/tension negative effect \\
Physiological State & Physical/mental well-being & Pto
\end{tabular}

likely to look at situational factors, insufficient effort, or poor strategies as the causes for failures" (Bandura, 1986, p. 399). The vicarious experience is seeing or visualizing other people perform a similar task successfully. The observers believe that they, too, possess the capabilities to master a comparable activity (Bandura, 1997). Verbal persuasion is used to encourage people to believe they possess capabilities that will enable them to achieve. "People who are persuaded verbally that they possess the capabilities to master given tasks are likely to mobilize greater sustained effort than if they harbor self-doubts and dwell on personal deficiencies when difficulties arise" (Bandura, 1986, p. 400). People rely partly on their physiological state in judging their capabilities and are more inclined face a difficult challenge.

In their qualitative study of women $(n=15)$ in mathematical, scientific and technological careers (male-dominated fields), Zeldin and Pajares (2000) found that vicarious experiences and verbal persuasions were critical sources of the women's selfefficacy beliefs. "These findings suggest that the perceived importance of these sources of self-efficacy beliefs may be stronger for women in male-oriented domains than for the majority of individuals operating in traditional settings" (Zeldin \& Pajares, 2000, p. 1). 
Motivation is governed by three types of self-influence: perceived self efficacy for goal attainment, evaluative self-reactions, and adjustments of personal standards in light of one's attainment. The more people bring these self-influences to bear on themselves, the greater the effort they exert and sustain to accomplish what they seek. (Bandura, 2000, p. 134)

Self-actualized and constructivist women have goal attainment within their grasp and can make adjustments to be successful. This characteristic of a high degree of selfefficacy motivates them to be successful. As women travel the road to dissertation completion, the combination of their mastery and vicarious experiences through their coursework strengthens their efficacy. They are able to face obstacles with more persistence and intensify their efforts when their performance falls short. They expect favorable outcomes from the beginning of their journey. Their self-efficacy is instrumental in their academic resilience.

\section{Success of Women in Advanced Graduate Study}

Although women have a different style of learning that may not fit the graduate school norm, they can be successful in their pursuit of academic success. The completion of the degree has been the topic of many quantitative studies, but few specifically zero in on how women successfully overcome the traditional roadblocks. Doctoral success depends on internal characteristics work with external or structural resources.

From her study of 18 women in positions of academic leadership at a Latin American university, Twombly (1998) formulated two frameworks that influenced the women's success: (a) individual perspective and (b) structural source. Common arguments from the individual perspective include the ideas that "women lack sufficient experiences or educational degrees, women fear failure, women can't make decisions or women are socialized to be caring instead of competitive" (Twombly, 1998, p. 269). She 
reported that the women drew strength from the family unit. She also found that institutional patterns such as entrance requirements, well-defined career ladders, tradition, colleague groups, and mentors have the potential to restrict or enhance women's roles and thus shape the choices individuals make.

Researchers have noted that the key to becoming a successful completor in a doctoral program is being able to overcome the following personal roadblocks:

(a) isolation (Boes, Ullery, Millner \& Cobia, 1999; Burnett, 1999; Conrad \& Phillips, 1995); (b) lack of moral support or understanding from families and spouses (Berg \& Ferber, 1983; Louque, 1999; Monsour \& Corman, 1991); (c) inability to manage time pressure because of a multitude of tasks (Johnsrud, 1995; Kluever, 1998; Ulku-Steiner et al., 2000); (d) procrastination stemming from self-esteem deficits and dependency (Green, 1997; Kluever \& Green, 1998; Maher, et al., 2004; Ulku-Steiner, et al., 2000). Internal Characteristics - Personal (Individual Perspective)

The personal factors from the studies that contribute to the completion of the doctoral degree for women include emotional support from family and friends including peer collaboration; and internal characteristics of motivation, persistence, time management and self-concept (see Figure 1). Although emotional or personal support is

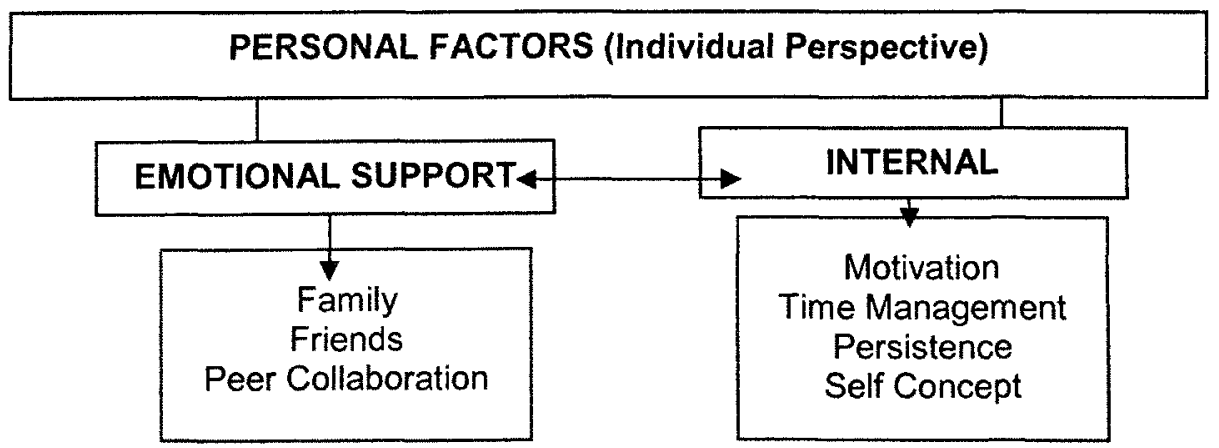

Figure 1. Personal factors affecting doctoral completion. 
different from the internal characteristics, both contribute to the individual perspective of the doctoral student.

In their study of men and women graduates $(n=459)$ at the University of Illinois Urbana-Champaign, Berg and Ferber (1983) found that moral support from family was important for $60 \%$ of the women and $40 \%$ of the men. They added that "women may be more willing to acknowledge support because they are more accommodating to the families' and spouses' preferences" (p. 635). In the field of education, $73 \%$ of the women reported a great deal of moral support, different from the $16 \%$ in the physical and biological sciences. These results are important for this study because it explores the factors pertinent to women earning the doctorate in education.

In Lenz's (1997) study to determine the factors that promote or inhibit the completion of a dissertation by non-traditional aged women, the 11 participants, both completers and All But Dissertation (ABD) students, spoke again and again of wanting a network of support and nurturing throughout the process. Lenz found that successful women had strong support structures from their peers and families as well as positive self-images. The women said they needed a nurturing environment to progress and succeed because they experienced stress and emotional involvement during the dissertation process. Lenz's study included an important conclusion: strategies for the female student, her family, her committee and the university to incorporate in their advanced degree programs.

Additional studies that had a qualitative component gave the participants an opportunity to express individual responses to questions about their doctoral process. The following research related to academic resilience, included motivation, time management, 
persistence and self-concept. Most of the internal characteristics were only one part of the study; external factors were also included.

Motivation. The Maher et al. (2004) study of early- and late-finishing women doctoral students $(n=160)$ from Stanford University, found women who take less time to complete the degree have a strong commitment to finish in a timely manner. These women reported they were goal oriented and disciplined. The late-finishing women in the study reported their family responsibilities and other constraints set the pace for their completion overriding their focus on completing in a timely manner. In fact, they reported they did not have a plan to finish in a timely manner (Maher, et al., 2002). This study was interesting because it divided its participants into early- and late-finishers.

Time management. The ability to be organized and juggle a family, job and university demands is not an easy task. Monsour and Corman (1991) reported that motivation is a continual battle especially in managing the multitude of tasks and time pressures. "The tension generated by the multitude of required tasks may be overwhelming. In order to manage these time pressures an individual must be well organized and have a reasonable work plan" (Monsour \& Corman, 1991, p.183). They promoted the use of a dissertation partner to furnish emotional support by attending workshops, spending time on research and celebrating small accomplishments. They added that there is no one solution to the loneliness of the dissertation process. However, they provided one strategy that could alleviate the isolation and help manage pressure.

In a study about attitude and personality factors at the University of Denver, respondents $(n=239)$ indicated they had difficulty in time management, an inability to plan ahead and problem setting time aside for the dissertation (Kluever, 1998). Although 
the study was not limited to women, $72 \%$ were female. In utilizing the Help-Hindrance scale, the major hindrance was time pressure and financial or family concerns. The major help was the students' persistence (Kluever, 1997).

Late finishing women in the Maher et al. (2004) study indicated their respondents had problems in managing time for their employment and family responsibilities. They indicated their slow progress was due to child-care responsibilities or family related obstacles. Early finishers reporter fewer constraining factors (Maher, et al., 2002). Those results are similar to those in Rode's (1998) study at the University of Maryland College Park. She found that the demands of parenting, caring for parents with health problems, marital tension and illness were hindrances to completion for the 24 participants in her study. In fact, $40 \%$ of the study population reported that internal factors hindered the process for completion of the doctoral degree versus the $25 \%$ who reported external factors (Rode, 1998). All of these studies are important in exploring what characteristics contribute to one's academic resilience in handling the demands of an advanced degree program.

Persistence. The dissertation process may be a more complicated process for women than men, according to Green (1997). In a Denver study with graduates and All But Dissertation (ABD) students $(n=239)$ about the psychosocial factors affecting dissertation completion, she found that the ABD students blamed themselves for their procrastination. Graduates had lower scores. Green (1997) found procrastination could stem from self-esteem deficits and dependency. She reported that since procrastination is associated with negative academic achievement, overcoming procrastination needs to be 
nurtured. She suggested that universities incorporate a group research project into the program to develop a support network and positive research habits (Green, 1997).

Self-concept. Lenz (1997) found that a positive self-image enabled the nontraditional women in her study to finish the degree. In using Chodorow's (1972) theory of relationships, she reported that relationships for the non-traditional women in her study remained important to all the participants who were successful in attaining the degree and created positive self-in-relation support. Lenz (1997) found that just having relationships was not enough; those relationships must be supportive.

Students' perceptions of their own abilities influence other dimensions of student functioning, including their attitude, motivation, and stress which may affect their commitment (Ulku-Steiner, et al., 2000). In their study of gender experiences in doctoral study at a large, southern state university $(n=474)$, the researchers found a lack of status, competition, financial duress, high workload, and performance anxiety contributed to the stress of women. The women who reported greater support also had a higher selfconcept.

In a study about African-American women $\mathrm{PhD}$ recipients $(n=5)$ Louque (1999) found said their feeling of self-worth was a factor in their personal and academic success. They attributed their family and community involvement as being instrumental to their feelings of self-worth and ability to be successful in attaining the doctoral degree. "Success to these respondents meant contributing, using resources, developing opportunities and making themselves available to others" (Louque, 1999, p. 105).

An interesting study by O'Connor (2002) found academic resilience or the success in school despite the risk of inadequate achievement was not solely dependent on 
inherent traits. Through interviews with 19 African American women (and 3 in-depth), she reported that constraint and opportunity affected their individual resilience to academically succeed. Doctoral study has risks, and university personnel provide opportunities for students to negotiate through the barriers. The O'Connor study found that resilience factors are highly adaptive to the opportunities provided.

The Zeldin and Pajares (2000) study on women in male-dominated careers also covered academic resiliency. The 15 participants reported that they were resilient and persistent as they turned difficult situations into temporary setbacks. The women developed strong beliefs that they were competent and this carried them through their tough times in their academic and career history (Zeldin \& Pajares, 2000). All of the studies about self-concept and the doctoral process had women participants so the findings are especially relevant to this study. However, other factors also are important, and often studies focused primarily on the external ones. The comprehensive Golde and Dore (2001) study $(n=4,000)$ is especially interesting because it reported that many students do not know what doctoral study entails, how it works or how to navigate it successfully.

\section{External Characteristics - Programmatic (Structural Resources)}

Students can arrive at the dissertation stage at different levels of readiness for the task, due to personal choices or department practices. In their study of 10 universities, Bowen and Rudenstein (1992) found that students leave programs of their own volition or because of university policies. The researchers stated that faculty must accept collective responsibility for the results achieved by the graduate program. "The design, oversight, evaluation and careful monitoring of graduate programs make an enormous 
difference in the quality of the educational experience, the moral and progress of the students and the extent to which human and financial resources are used effectively" (Bowen \& Rudenstein, 1992, p. 67).

Figure 2 summarizes the literature that included studies about how the program itself can affect doctoral achievement. The learning environment includes peer or cohort and adviser/faculty/committee, which are parts of the university program. Other programmatic factors include the discipline of the degree, the convenience and environment of the program, research experiences provided, financial opportunities and policies for completing the degree.

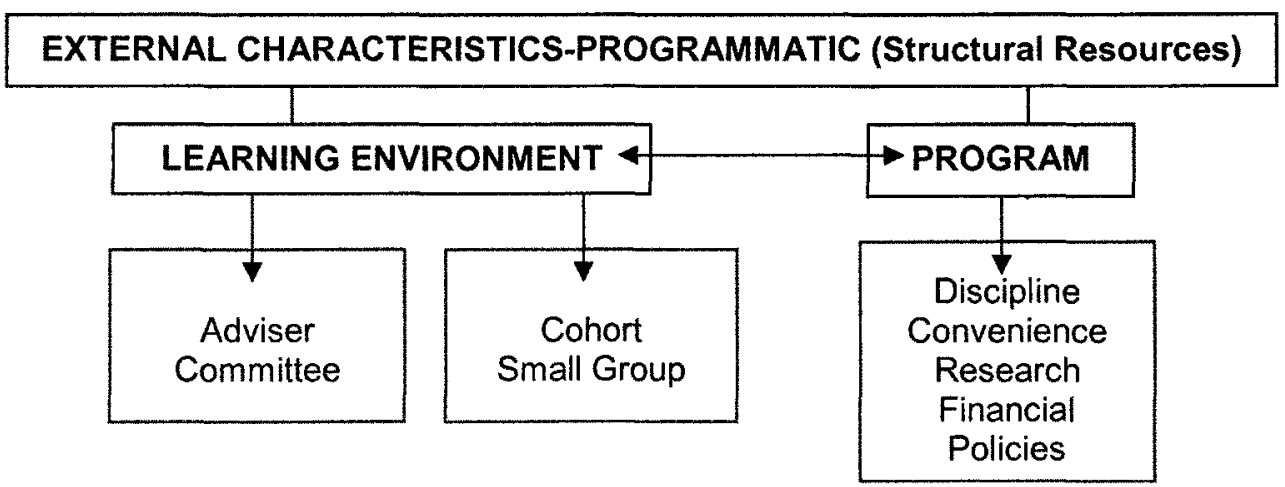

Figure 2. Programmatic factors affecting doctoral completion.

Some students take a dominant role in meeting the requirements and others assume that the university (advisor/committee) will provide the initiative for completing each task. It is important for students undertaking an advanced graduate degree to have a good understanding of their role and the university's role in completing each task associated with the dissertation (Kluever \& Green, 1998; Maher et al., 2004).

Adviser/committee. Successful completion of a dissertation is partly the result of the student's motivation along with family and work/financial circumstances, but it is 
particularly influenced by the quality of the supervision and mentors (Burnett, 1999;

Heinrich, 1995; Smeby, 2000). Professorial expertise extends beyond teaching and includes knowledge of university policies and deadlines and assuring research rigor in the classroom and for the dissertation (Monsour \& Corman, 1991; Witte \& James, 1998).

Successful graduates establish a professional relationship most often with faculty of the same sex (Bowen \& Rudenstein, 1992; Green, 1997; Heinrich, 1995; Kluever, 1997; Kluever \& Green, 1998; Monsour \& Corman, 1991; Neumark \& Gardecki, 1998; Schroeder \& Mynatt, 1993; Smeby, 2000). However, in universities that have fewer women professors, a potential problem could exist (Berg \& Ferber, 1983; Heinrich, 1995; Johnsrud, 1995; Schroeder \& Mynatt, 1993; Turner \& Thompson, 1993). "Evidence suggests that the relative unavailability of female faculty members may be more than a mere inconvenience to female graduate students" (Schroeder \& Mynatt, 1993, p. 556). In their study, women $(n=151)$ with female major professors perceived their interactions more positively than those with male professors and gave higher ratings in the concern for student welfare category. They reported that there is evidence that the presence of female faculty enhances the success of female students (Schroeder \& Mynatt, 1993). Similarly, Berg and Ferber (1983) reported that their 459 participants interacted more comfortably with faculty of the same gender. Heinrich (1995) studied doctoral advisement relationships of women $(n=22)$ and reported that the participants wanted advisors to assume mentoring roles and they were disappointed when advisors were not mentors. Neumark and Gardecki (1998) reported in their study of 709 women, that female faculty serving as dissertation chairs would be positive role models and mentors for female students. 
Cohort support. Advisers are certainly a part of the support network, but "there is reason to believe that social support is most effective when it comes from peers" (Monsour \& Corman, 1991, p. 182). Advisers are supervisors rather than peers and no longer share the same reality as graduate students. "If students gravitate to one another, and we believe they do, it appears that the formation of groups, either formal or informal, is a natural by-product of the educational process" (Witte \& James, 1998, p. 53).

Nerad and Miller (1997) explored dissertation completion at Berkeley and asked doctoral students in monthly focus groups what that institution could do to help them complete the degree. The university personnel added collaborative activities, financial support and programmatic workshops. As a result, the retention rate improved and the time-to-degree lessened.

The use of cohorts can provide the framework for mutual learning and allow the professor to move from the "sage on stage" to the "guide on the side" (Witte \& James, 1998, p. 56). In a study with doctoral students at the University of South Florida, they created a cohort that increased productivity, provided a support system, and enhanced skills for the 6 participants. The cohort worked together on a "group dissertation" to learn the process of completing the terminal paper before each had to write one alone. The researchers found limitations such as conflicting personalities, but reported that the benefits outweighed the problems (Witte \& James, 1998).

Financial responsibilities and university support. Financial responsibilities and opportunities also can affect the attainment of an advanced graduate degree (Bowen \& Rudenstein, 1992; Johnsrud, 1995; Kluever 1997; Maher et al., 2004; Nerad \& Miller, 1997). Earning money while working on a dissertation can be a concern. Doctoral 
students who support themselves take the longest to complete the degree (Johnsrud, 1995). Because the satellite program in this study was created for working professionals, the students had to balance their employment and academic responsibilities. "Financial needs may determine how much time students spend on dissertation versus the time they devote to daily survival.... Employment is undoubtedly related to students' financial concerns. Although it provides needed income, it detracts from the time spent on the dissertation" (Kluever, 1997, p. 55).

The Condition of Education 2002 (U.S. Department of Education, 2002) indicated that most students working toward the EdD considered themselves full-time employees and part-time students. Some factors in attrition and time-to-degree involve students' employment status, whether that includes full-time work outside the university, assistantships or fellowships inside the department, or full or part-time attendance. Those who are part-time students, have other responsibilities that compete for their energies.

Studies have indicated a negative relationship between hours worked and persistence (U. S. Department of Education, 2002), and consequently, students must find an appropriate balance between working and studying. While borrowing to pay for education can leave students with a large debt, working long hours reduces how much time students have for studying and may decrease the likelihood that these students will finish their postsecondary education. Teaching and research assistantships can take away from study time. Bowen and Rudenstein (1992) reported that students relying on their own resources have higher attrition rates and a longer time to degree than do those with financial aid. 
Few research assistant positions are available for EdD candidates so the students must rely on their own resources and employment. The significantly smaller proportion of women than men who hold research assistantships may contribute to the difference in the completion rates and time-to-degree. "Given the well-documented disparity in women's earnings and the greater probability that single women will be the sole support of dependent children, such policies many serve as barriers to women more often than men" (Johnsrud, 1995, p. 72). However, assistantships do provide more than just monetary support because they allow students to interact with other graduate students and to have academic collaboration with faculty (Smallwood, 2004).

Universities can provide other alternatives. In focus groups at Berkeley, students said they wanted a full year to work solely on the dissertation. The university responded by providing fellowships for this purpose. This was one of the factors that improved doctoral retention and reduced the time-to-degree at Berkeley (Nerad and Miller, 1997).

Research training. Training to complete the dissertation involves research skills. In the Pew Charitable Trust survey, research training consumed the bulk of the 4,000 students' lives; $72 \%$ felt they were prepared (Golde \& Dore, 2001). Laboratory-based sciences most readily lend themselves to structuring research opportunities because students are in labs from the onset of their degrees.

The Cuetera and LeCapitaine (1991) study on research training found a doctoral student's interest in research and the content of research courses were significant to dissertation completion. Their 3-part study of psychology students $(n=192)$ used the (a) Training Environment Scale to evaluate coursework and exposure to research as well as the advisor-advisee relationship; (b) Dissertation Implementation Scale to measure the 
student's dissertation writing skills; and (c) the Multiple Affect Adjective Check List to measure anxiety, depression and hostility.

Respondents emphasized the practical and clinical applications of research should focus directly on the dissertation writing process, and that research design and statistics should be more thoroughly integrated.... When students were well prepared by research experiences (and by coursework and adviser relationship) the dissertation writing experience stimulated research interest. When ill prepared, the experience had a depressant effect on research interest. (Cuetera \& LeCapitaine, 1991, p. 237-238)

They found that the quality of research coursework and the exposure to research influenced the interest and success of doctoral students. The quality, quantity and timing of the research impacted the dissertation-writing experience of the students. The relationship between the advisor and advisee affected the anxiety level of the student.

Research activities provide more than just skills. "Students need experiences that promote a shift from an adviser's direction to collaboration, from dependency to independence.... Students need to be socialized to doing active research as much as they need to learn objective skills" (Green, 1997, p. 64). She suggested in her study at the University of Denver $(n=239)$ that students could be required to undertake a research experience, probably in small groups, that continued for one to two years and which could instill persistence and increase independence and personal control. A cohort study at the University of South Florida utilized this idea and student achievement improved.

Discipline makes a difference. The discipline in which the degree is studied makes a difference (Baird, 1997; Berg \& Ferber, 1983; Boes et al., 1999; Bowen \& Rudenstein, 1992; Nerad \& Miller, 1997). In the hard sciences and mathematics where research and experiments are the mode, the time to degree (TTD) is shorter. More time is required for the fields (such as humanities) which require theoretical, abstract analysis, 
have a prevalence of collaborative research, and generally have a need for travel and use of archives (Bowen \& Rudenstein, 1992; Baird, 1997). In the humanities and social sciences, the student is often a lone researcher who works independently and has less frequent interaction between adviser and peers. This can lead to a longer TTD or noncompletion especially for women who need cooperative experiences.

The physical sciences also provide more financial aid, including grants and assistantships (Bowen \& Rudenstein, 1992) and more opportunity for structuring research opportunities (Cuetera \& LeCapitaine, 1991) which are important for dissertation completion. However, women are more represented in the social sciences and humanities (Bowen \& Rudenstein) and thus have fewer opportunities for this kind of financial help.

Strategies of Women and Institutions Affecting Success

The review of the literature on successful women and doctoral completion revealed that academic authorities focused more on the "why" of what leads to success rather than on the "how" success was achieved. Theoretical discussion often outweighed practical strategies However, Brunner (1997) and Wolf-Wendel (2000) offered specific strategies women and institutions used to be successful. Figure 3 summarizes the strategies of those researchers from the literature: (a) personal from Brunner (1998), and (b) structural from Wolf-Wendel (2000).

\section{Brunner-Internal (Personal)}

The literature establishes that women in their quest for a doctoral degree are taught and supervised by more men than women. In his qualitative study of female school superintendents who have succeeded in their male-dominated positions, Brunner (1997) identified seven gender-specific strategies that the 12 women used to be successful in 


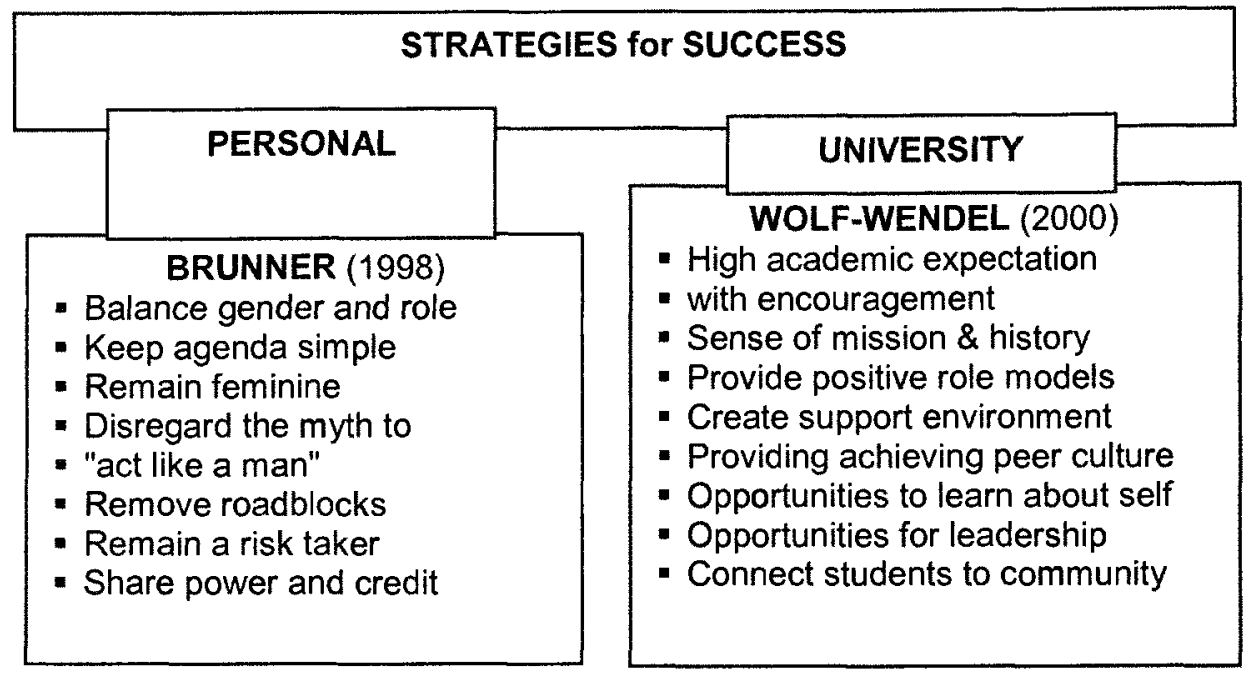

Figure 4. Strategies for successful achievement.

their superintendent roles. The underlying strategy is that they needed to learn how to balance two sets of expectations, role related and gender related. However, he found the women often could not separate the two. At one time the expectations co-existed while at other times one expectation took precedence over the other.

The remaining strategies that women superintendents needed to employ were to (a) keep their agendas simple to focus on their primary purpose, the care of children; (b) develop ability to remain "feminine" in the ways they communicated and still be heard in a masculine culture; (c) disregard the myth to "act like a man" and care for their employees and children; (d) remove what blocks success even close relationships;

(e) remain fearless, risk takers, "can do" people who can retreat when necessary; and (f) share power and credit (Brunner, 1997). What is interesting is how these strategies are related to the traits of women constructivists (Belenky, et al., 1986) and to the importance of caring, relationships and responsibility to women (Chodorow, 1972; Gilligan, 1982; 
Johnsrud, 1995; Noddings, 2003). Since Brunner's strategies are related to gender they are relevant to a study about women.

\section{Wolf-Wendel-External (Institutional)}

Wolf-Wendel (2000) reported how five universities who have graduated a large number of women doctorates and women listed in Who's Who in America are friendly to women. She spent four days at each college and held approximately 30 , one-hour interviews with students, faculty and administrators asking why they thought their institution produced successful women graduates. Her results indicated eight ways that the institutions have created environments that nurture women students: (a) have high expectations and continually encourage student achievement; (b) have a sense of mission and history; (c) provide positive role models; (d) create a supportive environment; (e) provide an achieving peer culture; (f) have opportunities for leadership; (g) provide opportunities to learn about oneself; and (h) connect students to the community.

What is interesting about her study are the elements that relate to cooperation and support, factors that other researchers have indicated are important to the success of women in an academic setting. The opportunities to learn about oneself are important to the person who is self-actualized and to the woman who learns through constructed knowledge. Since only a few of the prior studies specifically explored how universities work with successful women, Wolf-Wendel fills the void with the results of her study. Her findings exemplify the sources that build self-efficacy influencing persistence and success: (a) mastery attainment - success in past experiences, (b) vicarious experiences seeing role models perform and succeed; (c) verbal persuasion - telling people they are 
capable; and (d) physiological - physical and mental well being. The universities worked toward educating the total woman, which in turn made them successful.

\section{Lenz-Women Doctoral Students}

Of all the research studies reviewed, Lenz's (1997) findings about non-traditional women in advanced degree programs offer the insight and strategies for women doctoral students at the satellite campus because the populations are similar. In her conclusion, she suggested personal and programmatic strategies to help women complete the dissertation. She separated her strategies into student, family and friends, adviser, and university. Both personal and programmatic support is the underlying theme that crosses all areas. Her study included a perfectionism instrument, and she found that women needed to let go of their perfectionism to succeed. Family and friends need to help her not feel guilty for not spending as much time with them. The adviser needs to encourage collegial partnerships and be prompt in returning drafts, and the university should provide research opportunities as well as small group support. The major internal component of her study was the inclusion of a perfectionism element. Women who were successful were able to put aside their tendencies to be perfectionists in order to complete the dissertation.

\section{Summary}

In reviewing the literature about success and advanced degree completion, the themes for successful attainment of the doctorate included internal characteristics influencing persistence, external factors creating structural resources and specific strategies women students could use in their advanced degree program. Studies that focused on women (Brunner, 1998; Clark \& Watson, 1998; Ellis, 2001; Heinrich, 1995; Le-Doux, 1996; Lenz, 1997; Louque, 1999; Maher, et al., 2004; Tetrault, 1985; 
Twombly, 1998; Ulku-Steiner, et al., 2000; Wolf-Wendel, 2002; Zeldin \& Pajares, 2000) include a strong component of cooperation and personal and programmatic support. Women who are self-actualized or constructivists, have high self-efficacy. They have an ethic of caring and responsibility both as a caregiver and a care receiver. They learn better by cooperation rather than by competition, and in relational rather than solitary situations. The university personnel can answer these needs with the support factors they put in place to help the woman doctoral student complete her degree.

However, the studies do not tell the personal stories women used to cope and succeed at a satellite campus of a research university. There appears to be a lack of information focusing solely on women's experiences at a satellite campus, particularly from the viewpoint of successful women doctoral students. This study explored how women were able to successfully juggle these roles and the impact of their personal characteristics of persistence, determination to complete the dissertation. This study examined the hows and whys, qualitative variables, in order to provide possible strategies for women to employ while they are seeking their degree and for university personnel to consider when examining their programs for student success. Although this study does not compare men and women scholars, it is important to note the differences because women are relatively new to the advanced graduate degree picture.

The literature presented in Chapter II served as a guide in planning for the interviews and a basis for the analysis of the participant responses. Chapter III includes an overview of the research design, the participants, role of the researcher, the pilot study, procedures, and methods used that ensured credibility. 


\section{CHAPTER III}

\section{METHODS}

The literature in the previous chapter provided the theoretical framework and a discussion of the research for this study. This chapter outlines the methods used in this qualitative study including research questions, program setting, participants, pilot study, role of the researcher and procedures followed for data collection, data management, data analysis, and quality control. The purpose of the study was to explore the perceptions of successful women doctoral students as they demonstrated their academic resilience with structural resources to create and apply strategies they used to succeed in the academic environment of an EdD program on a satellite campus. The demographic data of the population were known from university documents. However, not known were the perceptions of the women as to how they were successful or what personal strategies they used to be successful. This inquiry was undertaken to better understand both.

In semi-structured individual interviews based on findings from the literature, women graduates of a doctoral program were asked to describe their personal thoughts, beliefs, and experiences as they traveled the road to the completion of the degree. Using Maslow's (1943) motivational theory, Bandura's (1986) self-efficacy model, and Belenky et al. (1986) theory of how women learn, I explored through their personal reflections how they thought they were successful completing a doctoral degree. They identified strategies in balancing careers and family obligations in addition to graduate school commitments.

Administrators at the university established a 24-credit requirement for dissertation completion, and documents suggest the dissertation can be completed in four 
semesters while earning these credits. However, this had not been happening, as seen in the completion statistics of the program (see Appendix A).

\section{Rationale for a Qualitative Case Study}

"The qualitative researcher's goal is to better understand human behavior and experience" (Bogdan \& Bicklen, 1998, p. 38). This study examined doctoral study at a satellite facility from the perspective of the women who successfully completed the degree. "If you want to understand the way people think about their world and how those definitions are formed you need to get close to them, to hear them talk and observe them in their day-to-day lives" (Bogdan \& Bicklen, 1998, p. 32). As a woman doctoral candidate, I wanted to know how other women who had professional and personal responsibilities coped with the rigors of doctoral study and became successful graduates. Only the women involved in the process could reflect upon and describe the personal strategies they used to cope and succeed in this academic environment. I chose qualitative inquiry for this study to obtain the rich description that emerges when participants explore their own histories. I wanted to be an active learner who could tell their stories (Creswell, 1998).

Qualitative researchers seek answers to questions that stress how experience is created and given meaning. Denzin and Lincoln (2003) explained that a qualitative case study method allows a researcher to analyze a phenomenon in terms of its specific as well as generic properties. Creswell (1998) wrote that a case study is "an exploration of a bounded system or a case (or multiple cases) over time through a detailed, in-depth data collection involving multiple sources of information" (p. 61). The boundaries of this research study reflect both time (from 1993-2003) and location (the university's 
downtown and suburban sites). The women graduates explored their success during this time frame in their doctoral program. The case study method provided detailed data on how the women participants perceived their success in order to shed light on the phenomenon of advanced graduate study at a satellite facility.

Robert Stake (in Denzin \& Lincoln, 2003) wrote that the study may be interested in a phenomenon in a series of cases rather than in an individual case, because one cannot fully understand the phenomenon without knowing other cases. In a collective case study, researchers study a number of cases jointly in order to understand a phenomenon (in this study, the phenomenon of women's journeys to complete the dissertation). Even when studying a phenomenon, research gains credibility with a broader range of cases within the study. With a repetition of responses these recurring themes strengthen the study.

Because this study focused exclusively on women, Creswell's (1998) view about gender domination in current research is relevant. "In feminist research approaches, the goals are to establish collaborative and non-exploitative relationships, to place the researcher within the study so as to avoid objectification, and to conduct research that is transformational" (p. 83). He encourages feminist researchers to foster a sense of collaboration through self-disclosure, to be self-reflective as they conduct the research, and to negotiate meanings of results with the participants that provide opportunities for deeper probing and reciprocal experiences. As a woman who is enrolled in the program, I monitored my reflectivity as I documented the research through journal entries and included the participants in the analysis of data. Throughout the study I tried to foster their collaboration through self-disclosure. 


\section{Study Context}

The participants in the study were graduates of a program at a satellite campus of a 4-year state university in Florida. The off-campus program was established over 10 years ago, when university administration focused on earning the Carnegie title of Doctoral Research University-Extensive. The campus is located in an adjacent county, away from the university's main library, and provides an EdD program as well as several masters' programs. Currently there is no public 4-year university in the county of the satellite campus.

At a symposium celebrating the 10-year anniversary of the program, one of the founding faculty said the program was for working professionals in an urban setting who wanted to earn an advanced degree. "It was a marriage between work and study. The students would use the workplace environment as part of their doctoral study," he said (G. Morrison, personal communication, November 14, 2003). Students could center their research study around a phenomenon in their work thereby creating a solution to a problem that would benefit their employer and them as individuals (earning the degree).

When it was established in 1993, the program had five components: (a) cohorts; (b) the Continual Integrative Seminar (CIS) which met once a month usually on Saturday (but one semester it met on Sunday); (c) a full-service administrative center on site; (d) an Action Research component (a study at the workplace); and (e) a full-time faculty using a team approach. The founding faculty member explained at the symposium that the original professors actively recruited working professionals for the first cohort. Many were employed at local schools, one that was a research and development public school in the county where the satellite campus was originally located. 
The first courses actually took place at that public school. After the first year, however, as the enrollment in the program grew, the location was moved to a downtown site, close to a public library with a limited university collection. Because the "tower" as it was called, was the home for the county community college, socialization opportunities and parking facilities were limited for the doctoral students. At that location, the faculty's major focus was on students in the satellite program.

In 1996, the founding professors began to retire or leave for employment at other universities. By 1999 , most had left the program or relocated to the main campus. The national search to find permanent replacements extended over a year for each professor. (Even replacements did not remain long and left for other job opportunities.) Current students were encouraged to meet with the applicants when they came to Florida for interviews to give them ownership of the process. Because the cohort format, which kept a group of students together throughout their coursework, was difficult to maintain, it was discontinued in 1999. Since that time students have been admitted on a rolling basis every term.

In 2001 , the location of the campus changed again, this time to a western suburb with ample parking. For the first two years at this location, the satellite program shared a building with a local community college but then moved into a new building constructed for the university. Although this site was adjacent to a regional public library, much of the research material needed for doctoral study was housed in the university's main campus library in the adjoining county about 25 miles away. The focus of the faculty was now on the main campus with the satellite campus as a part-time commitment. Permanent offices were located on the main campus. More space became available for the 
administrative duties of the satellite campus for registration and photocopying in the new building and teaching faculty shared offices.

Since its inception in 1993, the satellite curriculum has changed. The Action Research component has been dropped and instead students take only the required four research and statistics courses. The Continuing Integrative Seminar (CIS) was renamed the Continuous Integrated Seminar, and then ultimately was deleted from the Program of Studies. The CIS concentrated on a variety of topics from research to urban issues, depending on who facilitated the class. During the first two years of their coursework, all doctoral students met together for the class, which was held once a month for four hours on a Saturday or Sunday. During the years of the CIS, each semester different professors presented a problem to the students who, in return, worked toward a solution.

\section{Participants}

Women have always been the majority of the students in the program, and they have a variety of societal roles in the workplace and at home. Graduate school is an additional role. This case study examined how successful women at the satellite campus balanced those roles, and I needed women who could reflect on how they were successful in that area.

In case study research the sample is a major issue (Creswell, 1998; Denzin \& Lincoln, 2003; Merriam, 1988; Patton, 1987). For an in-depth study, I realized I needed information-rich cases of graduates cognizant of their strategies for success so I began with a purposeful sample that allowed me to learn a great deal about the central issues of importance in this study. "Purposeful sampling is based on the assumption that one wants to discover, understand, gain insight; therefore one needs to select a sample from which 
one can learn the most" (Merriam, 1988, p. 48). The women graduates were chosen from the 2002 directory of the program, which provided current addresses and telephone numbers. The directory listed the 21 women who had completed the degree and were still available to be interviewed. Thirteen of those were from Cohort 1. For the initial group sample of participants, I purposely selected women from the first cohort because that group presented the highest number of women graduates during the 10-year study time frame realizing, of course, that time would impact graduation rates. After I considered their cohort, I looked at their area of study for their degree. Initially, I wanted to study women who were in the Higher Education Instruction program, but there were insufficient numbers to conduct a thorough study. During our conversations, the participants mentioned women who had unique stories about their dissertation journey. I added the women they suggested to my study. As my study progressed, I realized I needed the viewpoints of both earlier and later women since the changes in the program environment may have affected their strategies for success so I expanded the sample to other cohorts. I contacted 13 women and interviewed 10 when three did not respond.

Creswell (1998) wrote that it is important to have different perspectives on the problem, process or event as well as cases that are ordinary, accessible or unusual especially in collective case studies. For my study, I found accessible women who were both ordinary and unusual. The women started at different times; I did this not as a comparison, but to explore a variety of women's perspectives of the changing program environment.

The participants in this study graduated with a wide variety of dissertation credits. Five completed the degree within the 24 -hour credit minimum required by the university 
in the Program of Studies, finalizing the dissertation in four terms. Four were from the first cohort but they completed in different years because of a variety of reasons they explained during their interviews. Almost half (14 of 29) of the women who have graduated from the program were in the first cohort so almost half (4 of 10) of the women in my study were from that cohort. At the time of the study no woman from Cohort $2 \mathrm{had}$ completed the degree but since then two have, however, one does not live locally, and the other is coping with a critically ill child. All participants were given pseudonyms.

\section{Research Questions}

By creating a dialogue with women who were successful in attaining the EdD, it is anticipated that their experiences will inform others about the process of being successful. I examined, through their words, the women's experience in obtaining an advanced graduate degree. Over 10 years, the university program has helped shape their history through its changing environment and personnel.

Creswell (1998) suggests one overarching question with several sub-questions. The overarching question in this study was: "What do women think made them successful in completing an advanced graduate degree at a Florida DRU-E satellite campus?" Several other questions guided this study:

Question \#1: What are the characteristics that define academic resilience for women in a doctoral program?

Question \#2: What are the structural resources within an advanced degree program that influence success?

Question \#3: What personal strategies do women develop to achieve doctoral completion? 
These were not the actual questions asked in the interview. The questions for the interviews I used were open-ended and can be found in Appendix D.

\section{Role of the Researcher}

Because of my time spent in the doctoral program I brought to this study an intimate understanding of the logistics and requirements of the off-campus program as determined by the university. Personally, it took me more than 66 dissertation hours to complete the degree perhaps because of my change in employment and length of time since I received my master's degree (more than 30 years ago) which affected my academic writing style and research skills.

I was able to ask meaningful questions based on my own knowledge of the program. After being involved in the doctoral program and reading the published literature on doctoral students and then later on women academics, I developed ideas as to some of the factors contributing to success, so it was essential that I be cognizant of these and my subjectivity as the interviews progressed. Although I asked meaningful questions, I was cautious about prompting the participants in an unbiased manner.

By starting with broad-based questions, I let the participants share their feelings about the doctoral degree program and process. In addition, I took careful measures to monitor my subjectivity, including keeping a reflective journal and sharing the interpretation of data with the participants and an outside reader to see if my findings were clear.

By interviewing the successful graduates of the program, I explored their views on how to complete the degree, which was important to me since I was a current doctoral candidate. Although I earned my master's degree nearly three decades before becoming a 
doctoral candidate, I quickly became entrenched in the research process and the use of the computer for locating sources at a multitude of libraries across the nation. After two years of coursework, I sat for and passed the candidacy exam. I enrolled in both quantitative and qualitative research courses. In the qualitative class in which I enrolled during my dissertation proposal-writing stage, I began the groundwork for this study.

While I was researching and writing my dissertation, I joined two support groups for doctoral candidates: one with my major professor and another with a librarian who specialized in doctoral research. Additionally, I participated in two Saturday workshops with the director of advanced graduate studies; one in writing the proposal and the other in writing the dissertation. I also attended two research seminars: (a) one on qualitative inquiry using computerized data coding and analysis, and (b) a conference showcasing student and faculty research in the university's College of Education. Throughout the 6 years I attended four dissertation defenses at two different Florida universities.

During the past 38 years, I have been a journalism instructor in a public high school and an assistant professor at a private university in Florida. One of my prime responsibilities has been training students to be effective interviewers. Because of my experience being a teacher and a doctoral student at the same time, I was able to "empathetically don the shoes of another" (Eisner, 1998, p. 37) as I interviewed the women to explore aspects of their life histories that were related to their doctoral study. I was interested in how they dealt with the various responsibilities in their personal and professional lives; how they juggled the roles. As the researcher, I too, was employed full-time and was married with grown children. I was able to connect more easily with the participants in this study because of our similar situations. In fact, I found I began to 
employ some of their strategies as my study progressed. However, I continued to be cautious and monitor my subjectivity.

\section{Pilot Study}

Creswell (1998) suggests that researchers engage in a small pilot study to see if they are at ease with the ambiguity and decision process involved in a qualitative study. So in the fall of 2001 , I conducted a pilot study on the perceptions of women graduates as to what helped or hindered their success in completing the dissertation. Single interviews were conducted with three women from different cohorts. When presenting the results to a focus group of eight doctoral students, it was evident by the comments of both men and women in the group that the perceptions of the women were interesting to all doctoral students.

In the pilot study, several themes emerged which were followed up in this study. The most important was the theme of support, both personal and professional. The women in the pilot study were all married and said that their husbands took control of the household and constantly urged the women to isolate themselves and finish their dissertations. Professionally, the women said that support from their major professor and methodologist was critical to their completion. Two of the three women completed a qualitative study and said that the qualitative research class specifically helped them complete in a timely manner. The women in the pilot study downplayed the impact of financial issues during their doctoral study. Three said they received a paid sabbatical for one term during their dissertation period and four received tuition reimbursement.

The pilot study revealed the existence of both personal and external themes. It left me wondering about the strategies these and other successful women graduates had used. 
This study more formally explored the strategies successful women doctoral candidates deemed critical to their completion of the degree. After seeing a memorandum charting the number of completers in the program (see Appendix A), I wanted to investigate this more extensively.

\section{Procedure}

I began this case study with a single focus: What did women think made them successful in completing an advanced graduate degree? My study used multiple sources of data, some of which were historical in nature. Each of the women gave me permission to cite from their dissertations, and I actually used a citation from Savannah's.

\section{Data Collection}

First, I interviewed three of the founders of the program. Then I studied documents about the origin of the off-campus program including original brochures and data provided by administrators and professors involved with the program since its inception. The data provided information about cohort admission (beginning with the first one in 1993) as well as post-cohort individuals.

The bulk of the data was obtained over a year through 60-90 minute individual interviews. I selected the participants from the Doctoral Program Directory (2003), which listed telephone numbers and email addresses for both current students and graduates. First, I focused my search on women, and I met with the registrar and searched original documents to find out when the women started the degree. I then contacted 13 women by email or by telephone to ask if they were willing to participate in the study and followed up with a letter. Three women did not respond to my initial contact. 
The interviews were conducted at the participants' convenience and at the location of their choice (home, workplace or campus). I felt it was important to meet them at a place where they would feel comfortable speaking with me since I was basically a stranger to all but one. Eight of the participants were interviewed at their workplaces, and two were interviewed at their homes (and one of those was not employed). During the dissertation writing process the participants continued to be involved if they wished. Four women continued to personally encourage me throughout the dissertation process, as we would meet socially or professionally. One emailed me on a regular basis and encouraged me "get something on paper to all your committee members."

For the actual process of interviewing, Creswell (1998) suggests asking the participants grand tour questions followed by subquestions. The grand tour opening question I used was "Discuss what was happening in your life when you decided to pursue a doctoral degree." This question could provide insight as to why or how the participant completed the program. Another grand tour question was "Walk me through your degree program from the coursework through the dissertation." In response, the participant explained which factors helped and/or hindered her completion of the doctoral degree. A third question was "What about you personally made you believe you could complete the degree?" Based upon the theory that these women had achieved Bandura's (1986) level of self-efficacy, each participant discussed her motivation, persistence, personal circumstances and strategies she employed that contributed to her completion. If the participant, while answering the grand tour question, did not cover the related issues, I prompted her with follow-up sub questions such as what influence did your work/job 
responsibilities have on your completion? (See Appendix D). Throughout the process I continued to review the data until I eventually reached the saturation point. After the ninth interview, the answers began falling into the same patterns, and I interviewed one more person with the same results.

\section{Data Analysis}

After each of the interviews with the participants, I made notations in my journal. I personally transcribed the interview and wrote in the margins for personal-internal (left) and external-programmatic (right) as the beginning of chunking the data into major categories. Then I reduced each side separately into patterns or themes using a color coding method into the factors that the women said were pertinent to their success (see Appendix F). When a new idea emerged, I reread transcripts already coded to see if a new theme was present. For instance, May brought up the health issue which earlier participants had not mentioned, so I went back and found one other reference to health, Savannah's childbearing. Although Savannah did not have a negative experience with having a child, Maher et al. (2004) classified childbearing under health issues.

While each participant had a different perspective, I found patterns of internal and external factors. Then I broke each of those into sub themes. Personal notations included family; goals/why undertaking the program; job (time off, supervisor support, financial assistance); perseverance; personal finances; health; self-concept; pride-ego; role model; and academic ability. Subsidiary themes included: support of the family and work; academic resilience factors (personal fulfillment, motivation, self-concept, self-discipline, role model, time management); goals for having the degree, and physical needs (health). Programmatic notations included convenience, cohort, committee, coursework/CIS, 
dissertation, financial, major professor, research, topic, and university policies. External themes became the university program (policies, location), personnel (major professor/committee/on-site staff), financial support, small group and peer support (cohort) and research opportunities. Finally, I tabbed with bright yellow postits, the strategies each woman said she used to overcome the roadblocks and her suggestions for other students and university personnel to consider.

I was able to bring back the internal and external themes which I then included in a narrative integrating the perceptions of these participants on what facilitated or brought about their success with the key attributes of successful people described in the literature. Additionally, the data obtained from the documents supported what the founders said about the purpose of initiating the program and the cohorts in which the students were enrolled. The narrative concluded with the women discussing their strategies for successful completion of the doctorate.

\section{Ensuring Quality and Credibility}

I used several methods to enhance credibility of the research. For "data triangulation - the use of multiple sources of data" (Creswell, 1998; Denzin \& Lincoln, 1998), I used several sources of data. In addition to interviewing the women who had different perspectives, I spoke with two members of the faculty who helped develop the doctoral program at the satellite campus. I also reviewed university documents from the 10 years of the program. Then I employed member checking (Creswell, 1998; Denzin \& Lincoln, 1998), and I shared the transcriptions and coding notes with the participants so they could make additions or clarifications they remembered after I left. One participant requested more time and I interviewed her for an additional 30 minutes. Three of the 
participants made incidental corrections to the transcriptions because they wanted to sound more academic. After I completed the first draft of Chapter 4 - Findings, I sent each participant a copy electronically or by U.S. regular mail. Eight of the 10 participants provided feedback after I sent them the chapter, and they said I had captured the essence of their journeys. No one suggested additional themes or alterations.

Throughout the process I kept a journal to reflect upon the interviews, distinguishing my perceptions from the participants' as well as the progress of the study. I found the journal most helpful when I made entries immediately following the interviews. Although I had the tape, the journal allowed me to reflect upon my interpretation of body language, eye contact or other non-verbal impressions I may have derived from the interview. Also, an outside reader, a former professor, reviewed my writing to see if I clearly conveyed the information in my study in a scholarly yet understandable manner.

Janesick (1998) explained that transferability is also important in a qualitative case study. It is the "ability of the case study to describe a setting so others may use it as a source of comparison" (Janesick, 1998, p. 119). I used detailed descriptions of these participants and their journey so readers could transfer the information to other settings if the characteristics are shared. This study was based on exploring the insights of 10 women graduates of a satellite campus doctoral program in South Florida, and readers may connect their stories to those of the participants to better understand their journeys.

\section{Summary}

This qualitative case study allowed me to collect and analyze data from women graduates of a doctoral program offered at a satellite facility in order to determine what 
they felt allowed them to cope and succeed in this academic environment. Through personal interviews, successful women shared aspects of their life histories concerning the phenomenon of completing the journey to a doctoral degree. The analysis of data presented in Chapter IV describes the themes that relate to the academic resilience, structural sources and personal strategies that influenced the success of these women in the Florida program. Theories pertaining to the success of the participants' motivation (Maslow, 1943), self-efficacy (Bandura, 1986) and way of learning (Belenky, et al., 1986) were considered in identifying the traits of academic resilience. This served as a starting point in tracking the journey of these women to successfully complete the doctoral degree. 


\section{CHAPTER IV}

\section{FINDINGS}

This chapter includes the data and results of this study that investigated successful women doctoral students and the road they took on their academic journey. The doctoral completion model illustrates the personal characteristics of academic resilience in female students, which are identified as they encounter the available structural resources that helped to ultimately define the specific strategies employed by the participants in this study. Descriptions of the participants are included to distinguish and clarify their experience in the doctoral process. Continued discussion of the factors that define the academic resilience of these women is explored through their internal perspective including: (a) viewing that working on the degree was personally fulfilling, (b) believing she possessed a strong sense of academic confidence, and (c) priding herself on having self-discipline. Two other academic resilience components identified by approximately half of the women were (d) seeing themselves as role models, and (e) being motivated by either a personal or career-related goal. The structural resources through which the participants filtered their academic study are identified as: (a) peer group/cohort, (b) faculty/committee, (c) financial, (d) research, and (e) accessibility. The final stage of the completion process includes the strategies that the participants in this study utilized, adapting their academic resilience factors to the structural sources: (a) managing their personal, work and academic responsibilities; (b) focusing on the dissertation, (c) sharing and collaborating; (d) advocating their needs.

In both my pilot and this study, the overarching question that drove my research was "What do women students perceive made them successful in completing an 
advanced graduate degree at a Florida DRU-E satellite campus?" Through the pilot study, I discovered that the importance of support, both personal and programmatic, helped female doctoral students achieve successful completion of their advanced graduate degree. However, in this expanded study, the participants focused on additional indicators: (a) their academic resilience, and (b) their personal strategies for success. Other related research studies centered on the programmatic support and why people do not complete the degree, so the personal theme of success became the focus of this study (Berg \& Ferber, 1983; Boes et al., 1997; Bowen \& Rudenstein, 1992; Burnett, 1999; Conrad \& Phillips, 1995; Cuetera \& LeCapitaine, 1991; Green, 1997; Heinrich, 1995; Kluever \& Green, 1998; Johnsrud, 1995; Lenz, 1997; Maher et al., 2004; Monsour \& Corman, 1991; Neumark \& Gardecki, 1998; Schroeder \& Mynatt, 1993; Shelburn \& Lewellyn, 1993; Smeby, 2000; Turner \& Thompson, 1993; Ulku-Steiner et al., 2000). I felt it was important to add to this body of work by exploring and defining the personal strategies of those who successfully completed their degrees rather than those who did not. The participants in both the pilot and actual study agreed that possessing and applying the characteristics of academic resilience is what initially brought them to this process, and in many cases, helped them to achieve completion.

\section{Introduction of the Participants}

As I examined the data, I found that the women graduates had interesting experiences to share with others in doctoral study. They entered the satellite program with the belief they had the skills to complete the degree. While each of the 10 women in this study seemed to share this common characteristic, the following description of each participant indicates that they also come from varying personal situations. 
Ten women who graduated with doctoral degrees from the satellite campus of a South Florida university participated in this study. While they pursued their degree, all of the participants were married (one became married during her program of studies), and all have remained married. Relevant data about each participant is provided in Table 2.

Table 2

\section{Participant Data}

\begin{tabular}{llllll}
\hline Name & $\begin{array}{l}\text { Diss. } \\
\text { Terms }\end{array}$ & Area of Degree & $\begin{array}{l}\text { Employment } \\
\text { During Degree }\end{array}$ & $\begin{array}{l}\text { Began } \\
\text { Cohort }\end{array}$ & Ended \\
\hline Cate & 3 & Higher Ed. Admin. & University Admin. & NA-1998 & 2001 \\
Elly & 4 & Higher Ed. Admin. & University Admin. & NA-1998 & 2002 \\
Jackie & 6 & Higher Ed. Admin. & Com. Col. (CC) Admin. & $4-1996$ & 2002 \\
Lil & 6 & Higher Ed. Instruction & High School Teacher & $4-1996$ & 2002 \\
Lynn & 11 & Curriculum/Instruction & Reading Teacher & $1-1993$ & 2000 \\
Margo & 4 & Higher Ed. Instruction & CC Professor & $1-1993$ & 1997 \\
May & 7 & Curriculum/Instruction & Elementary Teacher & $1-1993$ & 1998 \\
Nora & 4 & Curriculum/Instruction & Elementary Principal & $1-1993$ & 1998 \\
Sally & 4 & Higher Ed. Instruction & CC Adjunct & $3-1995$ & 1999 \\
Savannah & 9 & Higher Ed. Instruction & Unemployed & $4-1996$ & 2003 \\
\hline
\end{tabular}

Data were obtained during 60-90 minute interviews with each participant. Since the original purpose of the satellite program was "a marriage of work and study," I included their employment during degree study. At the start of their journeys all were working; one participant ceased working at the onset of the dissertation phase. A brief description of each participant is included. Pseudonyms were selected to protect their anonymity. No one from Cohort 2 is listed because at the time of my study, no woman from that cohort had completed the degree. Since then, two women have finished. The participants are listed in alphabetical order. 
I met Cate in one of my classes but actually did not have a conversation with her until our interview. In fact, since she was one of the first women I interviewed for the pilot study, I actually spoke with her twice because I wanted to ask her additional questions to explore how her personal coping skills contributed to her success. Cate is an administrator at a four-year university and has no children.

We first conversed at the college satellite campus and then a few months later in her office on the main campus. She began her doctorate when she was 33 years old and 7 years after she received her master's degree. Cate had personal and professional reasons for beginning the journey that stemmed from her educational experiences and eventual career goals.

I really enjoyed the experience of being in the classroom. After a few years I started to miss that. I had taken a couple of classes to kinda (pause) of testing the waters and really enjoyed those interactions with students and faculty. So that was part of it. I just think to get to some of the professional goals that I have as well. I realize that it will make me much more marketable.

She said she chose the satellite program after taking classes on the main campus but "there wasn't a sense of connectiveness to me between the students, at least in those classes I was enrolled in. And as I began to talk to people I gathered the impression that would be more the case with the satellite campus with the cohort system."

Although the official cohort system had been disbanded by the time she enrolled she said "it more affected my satisfaction while I was in the courses in terms of having similar people in my classes; it made the classes a little more enjoyable. But, beyond that, I did not have regular contact with anybody." 
She completed the dissertation in the least time of all the participants in this study. "I had very clear goals, and in the beginning I established a general time frame." After taking one semester off before beginning her degree, she earned her 24 dissertation credits within three terms taking 6 credits, 9 credits and 9 credits. During the spring semester, she received a professional grant and took a 16-week sabbatical from work. Once she defended her dissertation she said it was "like a 500-pound weight has been lifted off my shoulders. I'm excited for the opportunity to go out to dinner with my husband or plant flowers (laughing) or watch TV." Because Cate worked at a university, she said people placed a high value on the doctoral degree and she was concerned that once she received it, people would have a "different set of expectations." Just after she received the degree, she attended a meeting and shared this story.

It was a committee that I had been serving on for a while. In the beginning, the chair made an announcement that I had completed. And everybody said, "Do you have anything you'd like to say?"

And I said, "No, but I will try to contribute to the conversation intellectually today" (laughing).

Reflecting back on the process, Cate said the doctoral process provided more than a sheepskin, especially since she completed a qualitative dissertation that provided her the opportunity to reflect on the process.

How l've completed this just makes me aware that I must have something intellectually that allowed me to get to that point. So I think just a chance to reflect on where I have come and how did I get through that process. Just kind of more an awareness of my own talents, I guess that you don't always think about, in terms of yourself.

Cate says she has a responsibility now that she's a member of "this community of scholars" within the student affairs field. She is on the editorial board of a journal in her field and she wants to "stay connected and active in that area" and is not sure what her 
next study will entail. She also received a promotion within the university after she received her degree.

Elly

I met Elly during one of my doctoral help sessions in the summer. She announced to the group that she was going to graduate in December, although she had taken a 10year hiatus between first enrolling in classes and graduation. It took a special visit to get the 51-year old administrator back on track.

Let me tell you the funniest story. I was in my office on the third floor when this older gentleman came in. And he said, "I'm ..., and I would like to talk to you about finishing your degree."

And I said, " How nice of you to come here." Oh, my goodness, I was so overtaken by it. And honestly, that made me start to think. I plunged right into working on the degree full force. I made up my mind that day. I was going to finish and I did with a little nudging from Dr.....

At the time of her degree work, Elly had one grown daughter and another entering high school. "I felt I was in the best position that I could be to get this done." During our interview at her four-year university office, she explained that she set a time to finish because her boss who was on her committee was getting ready to retire. She, too, had a one-term sabbatical that helped her complete the writing phase of the degree.

Elly was one of three participants who spoke about how her spiritualism affected her completion.

As a Christian... I knew God was with me. I acknowledged him in the acknowledgment section of the dissertation. I had to thank Him. During those times, honestly, when I was wondering what should I do, I just know that he helped me. I had so many epiphanies in that little cubby in the library. I sat there often and prayed. I don't share this with people very often, but I want to share it with you because it made all the difference. He was the source that strengthened me. I immersed myself into the work and at times just lost touch with everything. I set everything aside and made it my priority because I knew it would only take a finite period of time to get it done. 
At her dissertation defense, Elly said being called doctor was "anticlimactic" because people already called her doctor because of her age and position. "But to see it written was more profound and had a greater impact than just hearing it."

Once she had her degree, she received a raise, but she said that was not the most important factor of her accomplishment.

The most wonderful thing is the new feeling of confidence I felt. It wasn't just that I knew that much more, and yet I did. If somebody had told me I would learn as much as I did writing my dissertation, I would have laughed. But I learned so much while writing the dissertation, not just about the subject matter, but also about myself and how focused I can be in achieving a goal. I am pretty easy going, but I was so determined. I would not let anything stand in my way.

She said the one significant event that let her know she would finish was not until the end when the dean signed the form. "I realized the degree provides me with the opportunity to work as long as I choose to work. It gives me credentials; it certifies me as a person that has something worthwhile to say. I can legitimately teach others what I know while continuing to learn from them as well." After our interview, when we would meet at academic functions such as the 10-year symposium, Elly continued to tell me, "If I can do it, you can do it."

Jackie

While I waited for my interview with Jackie, a busy community college administrator, I observed her interactions with her students - firm but polite since they had missed their registration deadlines. She had two middle-school-aged children at home who were the reason she began the doctoral program, because she felt she was wasting time in the library while they were doing homework. 
There was no other reason in the world. There was no monetary raise. I have no more status at the college. It's not on my business cards. It is not on my door, not on my letterhead. So it was just personal. So why not?

She entered the satellite program because it was convenient, and said the degree probably only cost her $\$ 500$ (and that was just for graduation expenses) since her college paid for her doctoral study. But her graduation wasn't smooth.

I felt like a bride who eloped. December graduation was on Monday and I found out at 3 o'clock on Thursday that I was graduating. It wasn't until then. I did not think they were going to let me graduate and that caused a lot of anger because I had defended in October so I wouldn't get into that. I had lots of time to make the changes, lots of time to get everything done. I could relax. I could enjoy, like when you're getting married: like a celebration. And I could think about what I was going to wear and get my nails done. But that was not the way it turned out.

Although the final days were not positive, earning the degree was. "When I look back to when I started nursing school at 17 or 18 , I never would have thought that all these years later I would be here, never in a million years." She keeps her diploma on a table to the side of her desk because she had no time to frame it.

And I look at it, and I think about it. I think it is really an accomplishment when you look at the number of people I started with that never finished the program, that never got very far in the program, or stressed themselves out taking seven credits a semester for two and a half years until they went nuts. And then never got anywhere with it. I just think you know it's an accomplishment that I've done this.

Jackie took one class at a time except for the 18 consecutive hours that satisfied the university's residency rule. She said it was an adjustment to return to her regular routine.

You 're so used to getting on the computer for three or four hours every night or reading an article or proofing or critiquing or doing something. All of a sudden having that three or four hours (pause), you think, "Oh, that would be wonderful." And it's wonderful for about a week. But you've been so productive and now you have nothing, you're in limbo. You have to come up with something. 
Jackie did. She took up quilting and showed me an example on the wall that she had created. After our conversation, she went to quilting class that evening.

\section{Lil}

I actually interviewed Lil twice, once for my pilot study and again for the extended study. Originally I just asked her questions about the program and a few about her strategies. But I needed to know more about the personal factors that led her through the degree process. This 46-year-old high school teacher encouraged me to begin the doctoral degree. She has a grown son with a wife and two children who live in central Florida, and she thought she might move there when she retired.

I'll be 53, and I can have a whole other career. So I really like teaching, I mean, that's what I do, so I thought it best to go into the teaching field. I've been an adjunct at the community college. I really like that, and I thought I could teach at a 4-year university. I thought, well, if I have my doctoral degree, it's just another thing. It just adds to what I can do. I just wanted to give myself choices.

She said completing the first three chapters made her feel confident she was going to make it to graduation. "That might be why they make you do that because you are really, really committed. It's like, okay, I'm halfway there. I could see the ending. I could see it. Just do it." During her dissertation she became a National Board Certified Teacher and said that detoured her for almost a year. But she was proud she never took time off from her teaching to complete the doctoral degree.

I used to think that the people who insisted on being called doctor, "Get over yourself!" But now I understand. It's so much work. I know a professor who got a tattoo on his shoulder the day he got his degree (laughing). It's so cute. Again, I had him for the first course, so I thought, "Oh, come on." But now, man, I could get tattooed all over.

Outcomes for Lil included "just getting it done" and the "personal satisfaction" she was "helping education by giving other people the straight view" in her dissertation 
on lesbian teachers. She added, "Going through this process is never wasted. I am a research animal. I help my students be research animals. I will continue this in maybe writing articles about other things. "Lil helped me throughout the entire dissertationwriting process. She was my cheerleader and my sounding board, my shrink and my unofficial adviser. Her sense of humor guided her and me through this dissertation phenomenon. She never got a tattoo. Lynn

One woman from the first cohort who thought she would never finish was Lynn, a public school administrator who needed 60 dissertation credits to complete the degree. When I interviewed her at her office the first thing she said was "You do not want to talk with me." But I did because her story was just an important as the woman who graduated with 24-dissertation credits.

When she started the journey, she was at the public research and development elementary school where the first classes of the satellite program were held. She was in the first cohort, a group of professionals who attended classes together throughout most of their doctoral program.

We were going to innovate and change the face of education forever. So when the proposal came for this program, it was a good time. We were all very busy. It wasn't like, gee, we have nothing to do today. We were all very busy but it just seemed like it was what we were doing already.

Lynn said she wanted the degree for the knowledge she was going to gain because she was not looking for a new career. "We were in a place where education was important, for the future of the country, for the future of the individual." She enjoyed the coursework the most. 
We were exhausted. But the fact is once you got there, there was an energy level, and the people I was with were a very bright group of people. In some cases the professors took a step back and the discussion was the group. It was energizing. I really liked those three years in the coursework. I did not like working in isolation. I found that difficult.

The dissertation was her Achilles' heel because she was one of the last in her cohort of 15 to graduate. She explained that there were two significant events when she finally believed she would finish. The first was when the committee called her "doctor" at her defense and the second was when she walked across the stage at graduation because of the protocol of getting the dissertation approved for printing was really trying for her.

It was like two or three weeks of pure hell. We were driving, and my husband was driving at this time because I was a basket case... But even after the committee said I was a doctor, there is a gentleman down there who says we have to fix this and you have to fix that." And I'm thinking once you have written the dissertation, your committee accepts it, you've defended it, they've called you a doctor, who's this gentleman anyway?

However, Lynn made all the corrections and did march across the stage to complete her journey. She said that she doesn't know if she had to do it all over again if she would.

Now that she has the degree she said that "perhaps the people above me take a little bit more notice because now I'm a doctor; maybe I seem to speak with a little more authority" (laughing). She still has the same position but planned to retire in 2004 for a month and then return to work.

\section{Margo}

When I met Margo at her place of work, she was a professor at a local community college. Her office was filled with awards certifying her academic and community achievements. When she was a doctoral student, she had no young children at home. She said she always valued education; that she was one of those rare students who loved 
learning. "I always knew, oh, someday, I would love to have a doctorate. But it seemed like a dream that I didn't know if I ever would have the opportunity to pursue. I feel it is the culmination of becoming a very well-educated person."

She decided to earn an EdD instead of a PhD because her master's was in zoology. "I learned early on in my graduate work that research is not my forte. I would rather work with people, and I learned I liked to work with students." Margo shared with her students that she was in school too.

And I think that helped them understand that I was able to relate to some of the problems they had. When they sat in a night class and their eyes closed, I didn't get angry at them because I sat in some night classes absolutely exhausted from teaching all day and going to school, and I knew exactly how it felt. And I think they appreciated and responded to the fact that I understood where they were because I was walking the same path that many of them were.

She said the experience made her a better teacher "because I think there's no better way to relate problems somebody is facing than to face the same problems yourself."

Margo entered the satellite program because the location made it easier for her to attend classes and the cohort system kept people together. "The thing I most feared about the whole program was doing the dissertation. And this is why I put off pursuing a doctorate for 30 years after completing my master's degree." She said that she completed her quantitative study quickly because of the "great support" she received from a statistics faculty member on her committee as well as her chair.

Margo exemplifies Maslow's (1943) self-actualized person. "I feel I have a calling. That's why I say it's almost like a spiritual thing; it's my calling to help people understand they are connected with the natural environment. How to accomplish this was the transformational insight I gained as a result of my dissertation research." 
During my dissertation process, Margo was the participant I met most frequently at different academic activities. She even accepted my invitation to become a member of the environmental magnet advisory board at my school. She always asked how my dissertation was progressing and offered encouragement.

May

Another member of the first cohort was May, who is now a public school program facilitator. At the time of her study, she was a teacher at the research and development school where the initial satellite course was held. She took her first class because she had a certificate for a free course at the university, but she continued on "because once I start something I feel like I need to finish. And I think the first semester was wonderful in the bonding with the other students."

In our interview at her workplace, she said that she had three surgeries while working on her degree but still finished. She had two children who were in college and said one of the values of the degree was to be a model for her children. "I was working but I was pursuing my education; I was supporting education." She was a fourth grade teacher at the school when she was completing her coursework, and later taught kindergarten at another school. Throughout this process, May noted how cohort collaboration was important to her.

We developed relationships, bonded and connected and developed trust, knowing that we would help each other, looking forward to see someone familiar the next evening.... It was wonderful to have these conversations on academics with people that had read the article or who had a similar purpose to reading it for a course. That was very exciting or interesting, and made professional growth toward learning. 
May's committee altered midway through her advanced degree program. Her first professor did not like the focus of her study, so she changed her topic. "But that was not agreeable with him either. I didn't feel I was getting the support I was hoping for, needed and expected." Her second major professor liked both topics and told her to work with the one she wanted. Because that professor became ill, May then had to add two more to her committee.

She said having the degree has helped her to "look at the big picture in education." As a human resources facilitator, she is responsible for staff development throughout the district. "I feel more comfortable with research and practice lifelong learning. We cannot be a stick in the mud; we need to be aware of what's going on." Actually I interviewed her twice; because the first time she had a meeting date that was changed and she rushed out to her appointment. We met again for another 30 minutes. Nora

Another member of the first cohort, Nora, was a principal at the time of her study. The satellite faculty asked to use her elementary school as a location for the first class, and she agreed.

I was the principal, and so I thought I had to model a behavior and sign up never knowing how much work it was. I was a principal and a fairly new principal so it wasn't necessarily the ideal time but there never is.

She enjoyed the small classes with 9 or 10 people who met in the conference room next to her office.

It was exciting at first, you know. Getting back into the groove and those intellectual conversations and those books. It gets long after a while. I feel like I am working with people who need those conversations and intellectual dialogue, which sometimes you don't have as a principal because you do a lot of teaching and mentoring. So it was really like energy for me to have it. 
Nora, who became a district administrator during her degree program, squeezed

me between other appointments at her place of work. Her diploma, too, was still on a shelf because she said she did not have time to frame it. When she began to work on her qualitative study, she said her position as an administrator caused her problems because it was difficult to get a school to participate. "It's kind of threatening, you know. The teachers didn't know because I was friendly enough with the principal for the principal to let me in, if they were honest, if I would go back to the principal and say the teachers were unhappy."

Nora was one of the first candidates to complete the degree from Cohort 1 , and she said that surprised her.

The stunning thing is I was one of the first to finish. If you were to take a poll, you would not suspect that because there are some really concrete-sequential, driven kind of people that always had things done on time. And when we were in groups, small groups, I was never the group leader to organize everybody. But those kind of people you just knew that they (pause). I felt they would be done first.

Her personal outcomes from receiving the degree were "the professional

friendships that I've made, and your own confidence that that's a goal in your life that you just wanted to do and you did it." Intellectual she said "I feel confident in what I am saying about anything in my field and where to go for information. If I am working with doctors and professors, I feel equal and I don't feel intimidated." In fact, she even taught a class of doctoral students for one term when her major professor had other commitments. Sally

I met Sally, a community college adjunct instructor, at her home. After we shared a cup of green tea, I found out she earned the doctoral degree for purely personal reasons. 
It was something I wanted to do. If it didn't accomplish anything, if it didn't give me any more money, if it didn't given me any more position, it was just something I wanted to do. The value was solely for myself.

Her children were grown which gave her time to study, but she did become a caretaker of her mother during the dissertation process. She conducted her quantitative study in her workplace, and did not participate in the graduation ceremony because "it was not important to me."

It had been seven years since she received her master's degree from a university in a western state, and she was now a community college adjunct professor. "It was something I wanted to do for me. I wanted to learn. Teaching was great but now I wanted to do something where I could learn something. And I decided I wanted to do this." She said she was confident she could complete the degree because of her "experience before this in school: my undergraduate and graduate work. I knew that I had the drive. I knew I had the ability, and I knew I could do it."

As a teacher she, too, shared her experience as a student with her students. Just after she finished her degree she broke her arm and was unable to do many things.

And I wound up telling my students about it. "You know, last August I got my doctorate," but I connected it to the fact they leave everything to the last minute. If I had left everything I needed to do until the last minute I wouldn't have been able to complete it.

After hearing her name with doctor before it, she said it was wonderful and a great achievement. She also received a pay increase at her job and said earning her degree was important to other people in the business world.

In school people call me doctor all the time. But at home we kind of forget it. I can definitely remember one experience when my husband worked for a bank, and we had been in the company of people with whom he worked on a social basis. And they treated me like everybody else. And then one day it came up and 
oh, everybody was interested. And everybody was paying attention to me. My friends who knew me before and since, there's been no change.

Sally was one early cohort participant who said the cohort arrangement did not

affect her one way or the other. "I know I couldn't say that by watching the others

succeed made me want to succeed. That really wasn't the case."

\section{Savannah}

As I entered Savannah's home and saw the holiday decorations and photographs, I knew she had young children at home. In fact, she had gotten married and had her first child while she was working on her degree. After moving several times, she gave up working outside the home so she could complete the degree and be at home with her children.

At the time she enrolled in the program she was teaching high school English. Even though she scored over 1,200 on the Graduate Record Exam and had a 4.0 grade point average, she was denied acceptance at the university from which she earned her baccalaureate degree. Thus she became a teacher and earned her master's degree in South Florida. "I had always done very well in school, and I was very disheartened when I didn't get into the program." A friend she met while working on her master's degree in education encouraged her to begin the doctoral degree at the satellite campus.

I was very happily soaking in my Roman hot tub, Saturday morning, single in my own townhouse. And my girl friend said, "I've done the research. I found out it's the best one. We'll start next semester. It'll be so much fun."

Savannah wanted the degree "I think just because I've always loved education.

I've always succeeded in it. I wanted to be a teacher." She said her parents' love of education was instilled in her as she attended the private Christian school where they both worked. 
I grew up as a Christian in a Christian home. God can help you through anything. He wants you to do your best. He can help you be the best you can be. It was such a burden on me, and I think God opened up enough doors to let me know this is what I'm supposed to do even if I don't know what I'm going to do with it now.

She said that these beliefs helped her through the program as well as the drive to finish what she starts.

I always feel I am supposed to finish what I start. I just always have been taught that as well. Even if it is a bad book I am starting to read, I just finish it because I started it. Although I have walked out on some bad movies before, I just felt I had to finish this.

The acknowledgment to her dissertation tells her story. "Five different houses, four different cars, three deaths, two children, and one husband later, I can finally say those three words I've waited seven years to say, 'It is finished!"'

\section{Themes}

While the pilot and the follow-up study identified the importance of personal and programmatic support, in the expanded study, the additional themes of personal characteristics that contributed to a woman's academic resilience and the strategies women developed as they utilized the structural resources to complete the doctoral degree emerged. Positively affecting the participants' educational resilience were (a) personal fulfillment, (b) academic confidence, (c) self-discipline, (d) position as a role model, and (e) motivation. Structural resources that helped them through the degree included:

(a) peer group/cohort, (b) faculty/committee, (c) financial, (d) research, and (e) accessibility. The strategies they developed emerged as they (a) managed their responsibilities, (b) focused on the dissertation, (c) collaborated with peers and faculty, (d) and advocated their needs. 
As indicated by others in previous studies, the women in this study said the lack of deadlines and the isolation of the dissertation made the completion more difficult for them than the coursework. They said that although the courses were challenging and the statistics classes difficult, they depended upon the support of others to help them complete the degree.

While each of the participants struggled with the dissertation, each utilized internal characteristics and developed strategies that supported her educational resilience which is why individuals experience success in school despite the risk ( $\mathrm{O}^{\prime}$ Connor, 2002). This is central to the completion of a doctoral degree.

The women in this study possessed the traits characterized by feminine theorists (Belenky, et al., 1986) that align with academic success. They were excited about learning. They not only sought knowledge, but created it. The participants in this study pursued the doctoral degree because they were lifelong learners and enjoyed the academic dialogue. They were aware of their own thoughts, judgments and moods and worked toward self-fulfillment.

Additionally, the participants had academic confidence or strong self-efficacy (Bandura, 1986). Throughout their academic careers they experienced success, both verbally and through mastery attainment. So when risk became a factor, the women intensified their efforts to obtain the designated performance. This self-efficacy also influenced their motivation and persistence (Bandura, 1986). Being goal oriented, these women recognized the inevitability of conflict and stress (Belenky et al., 1986) yet because of their high tolerance for internal contradiction and ability to multi-task, they 
disciplined themselves and were successful in their degree program. Because these women cared about those around them (Chodorow, 1972; Gilligan, 1986; Noddings, 2003), they wanted to be role models for their children, students and peers. They were concerned about connection and wanted to make a difference to others. While the journey for doctoral completion was an academic endeavor, the sense of personal accomplishment was evident in the experience of each participant. Table 3 highlights the five characteristics of academic resilience the participants reported. The columns are separated into those who completed with the minimum amount of dissertation credits required by the university in 3 or 4 terms, and those who earned more than 24 credit hours in more than 4 terms to complete. Since most of the participants in this study possessed the attributes of academic resilience that allowed them to even consider such a complex endeavor as the dissertation process, there is very little difference in the characteristics between those who finished in 3-4 terms and those who finished in more.

Table 3

Academic Resilience Characteristics of the Participants

\begin{tabular}{lcccc}
\hline Characteristic & $\begin{array}{c}3-4 \\
\text { Terms }\end{array}$ & $\begin{array}{c}5+ \\
\text { Terms }\end{array}$ & Total \\
\hline Let their "love of learning" override all obstacles & 5 & 5 & 10 \\
Academic confidence - prior success in school & 5 & 5 & 10 \\
Self-discipline, finish what started & 4 & 4 & 8 \\
Position as a role model for students, children, teachers & 4 & 3 & 7 \\
Motivation - pride, employment opportunity now or in future & 2 & 1 & 3 \\
\hline
\end{tabular}

Personal fulfillment. Each of the participants reported that she had a love of learning and appreciated graduate study for the academic dialogue it allowed her to 
engage in with her classmates and professors. This inner desire to continue her education and grow personally was a strong theme as Nora explained.

It was exciting at first. Getting back in the groove and those intellectual conversations and those books. It gets long after a while. But the first semester I thought this is really great. I feel energized again. I feel like I am working with people who need to have those conversations.

May, a colleague of Nora's, said lifelong learning and interactions in academics were important to her throughout the degree. "These conversations on academics with people who had read the article or who had a similar purpose to reading it for a course were very exciting or interesting and increased learning and professional growth." So May felt that her personal fulfillment came from stretching her academic potential to its realization

The sense of accomplishment was important to all the women as Cate explained.

I think the most significant is the sense of personal satisfaction and accomplishment. In talking with other colleagues who have completed the program, we often talked about it's something you think about a lot. You think about, "I did that. I completed that."

Nora was pleased that she finished. However, she had mixed feelings about the process. She, like other participants, reported she did not know how she finished.

Confidence that that's a goal in your life that you just wanted to do and you did it. Sometimes you look back and think, "I don't know how I did it then." Now it would have been easier because the kids have grown up. But I'm glad I did it because the truth is, I don't know if I have the energy to do it now.

She was one of two women who had second thoughts about embarking on the journey now that they knew what it entailed. Lynn, who needed 60 dissertation credits to finish, also said she was not sure if she would do again.

I am pleased with myself that I got it done. Certainly I would have had a great deal of regret if I hadn't completed it. I know that because that's me. I rarely don't 
finish something. This was the closest I ever came to saying it's over, and that bothered me a lot.

Lynn's resilience drove her to completion even when she felt abandoned by the structural resources with which she was presented. Her entire committee changed midstream.

It was the process that inspired Lil, a high school English teacher who reported that the entire advanced degree program, not just the dissertation, was important.

I've always said to kids try to see the beginning and the middle and the end of something. Follow through to the end. That is success. The process is success. The ending is wonderful but it 's the process that is the real success. Going through the process is what is real success to me.

While pursuing an advanced degree can be a fulfilling endeavor, it is rarely approached without possessing the academic confidence that allows a student to know she has the ability to participant in academic rigor.

Academic Confidence. Each of the participants said they felt they had the drive and intelligence to complete the task when they began the journey since they had earned strong academic evaluations in their master's degree coursework and because others told them they could accomplish the goal, two of the sources for self-efficacy. This is different from ego, which is based on a feeling of worth. "The outcomes people anticipate depend largely on their beliefs of how well they can perform in given situations" (Bandura, 1986, p.120).

Sally explained. "My experience before this in school, my graduate and undergraduate work. I knew I had the drive. I knew I had the ability, and I knew I could do it. And seeing that I was getting somewhere kept me going." Savannah said that she had always succeeded in education and had done well since kindergarten. 
Others said their experience in the coursework was thought provoking but easy

which gave them confidence to complete the degree. Jackie explained.

When I went to the classes I thought they were manageable, other than the statistics and research which were a different topic. The rest of it really was "what do you think, or what are you experiencing on the job or what's a reaction to this or a research paper?" It's not like your first university degree where you are learning the profession. As you get more and more into the graduate degrees, it's more of what you think, what is your position on it. So in terms of the content, I thought it was easy.

Cate added that her confidence was both personal and professional.

I knew it was something I could do because I enjoyed those interactions in the classroom and I enjoyed the process of learning. It was very challenging and I knew it would be very challenging, but I felt it was something I could do so in a way it was a personal goal as well as a professional goal to accomplish that.

Throughout her program Cate had "good, positive feedback about my writing skills and my work in the courses that helped me by giving me the confidence that this was something that I could do." Her words support the results of the Zedlin and Pajares (2000) study that found the participants developed the will and the skills to succeed in mathematical-related careers. They wrote that the most important factor in the enhancement of self-efficacy beliefs of their participants was the confidence that significant others expressed in the women's capabilities. "It was critical that others have confidence in them and express that confidence to them so that women developed confidences in themselves and developed resiliency to the obstacles they were sure to encounter" (p. 242). Their study found verbal persuasion and mastery attainment contributed to the success of the women, which was similar to Lynn's experience of prior achievement.

I knew I could do it because I did have some history of being successful in education. At my school we had written some very large grants and we were the 
prototype of meeting as lateral teams and writing grants and making differences. Individually and as a group member we had a lot of success. Plus I did take courses after my master's, not just to recertify, but to learn more.

For Jackie, the verbal praise during the defense of her comprehensive exam strengthened her belief she could finish the journey and encouraged her to continue.

When I did my comp, I felt very comfortable and confident with what I knew. When I went in to defend it, they were very complimentary and I was told, "you have $50 \%$ of your dissertation written." And I thought, "Wow, I am ready to go."

Margo reported that being called "doctor" at her dissertation defense made an impact on her and strengthened her self-efficacy. She said she was honored to be her committee's colleague now.

When the professors called me "Dr..." after the defense, it was so strange because I have them elevated on a pedestal and then to be welcomed as one of their colleagues was such a great honor, a sense of great satisfaction, pride and relief it was over (laughing).

Cate reflected that her completion of the degree added to her belief that she could be successful in other areas. "If I'm able to accomplish this thing that so few people do, then I must have the skills and abilities to do a lot of other things that I think about doing or want to do. So I think, if anything, it just gives me that sense of confidence." While academic confidence allowed the participants to project their future success, these women still required the self-discipline to sustain their educational journey.

Self-discipline. Because of their ability to persevere, these women overcame the traditional problem of sustaining their academic work and interest. The ability to persist when the task is difficult is another trait of people with self-efficacy as the participants in this study have demonstrated. Cate explained.

You can always find a reason not to write, not to spend time on the dissertation. There's always, always, always going to be something else to do. Just really 
making that commitment that this is what I'm going to spend my time doing.

In her psychosocial study at a western university, Green (1997) examined how the personality factors of perfectionism and procrastination affected dissertation completion.

To counteract the tendency to be a perfectionist, Nora explained what one of her professors told her.

You think it's the most important find that's ever come through humanity, but the truth is it's probably going to sit on a shelf somewhere and very few people will read it. So don't spend years trying to find the perfect topic. Just find something you can do, that you like, that you don't mind living with for two years, and just do it.

The participants in this study reported their persistence was crucial to their success. Because the women in this study had strong self-esteem and good support from their family and peers, they were able to overcome procrastination and complete the dissertation. The strength of their will to succeed (Zedlin \& Pajares, 2000) played a strong role in their success. As Zedlin and Pajares (2000) have pointed out, the ability to persist when the task is difficult is another trait of people with self-efficacy as the participants in this study have demonstrated.

Cate expressed a feeling that most of the participants had. She always knew she would finish; there was never any doubt in her mind.

When I started I had a clear sense of what I wanted to accomplish, what I was doing with the degree, and I had a timeline in my mind that I really adhered to. And I think some of the qualities of me personally and professionally are that I am very focused and very disciplined and very goal oriented. Once I made up my mind to do the degree, I knew I would finish it.

Other participants agreed that they needed to finish what they started as Savannah explained. "Because I started it, I needed to finish it. I felt like I was a failure if I didn't 
finish. I had already put in all this time and this money every semester. I just felt like I would be a failure if I didn't."

Margo had a similar feeling. "I've always been driven to do well, and along the way, I learned I love to learn. I just love education. I feel it [the doctoral degree] is the culmination of becoming a very well educated person." She then added, "It's a sense of great personal satisfaction having achieved the goal, something I've wanted all my life."

Some women said that other factors aided them in their persistence. Lil said she "really wanted the degree and I really wanted to finish it. I guess I have that kind of drive." She added that because people had given her their time to be interviewed for her qualitative study, she owed it to them to finish her dissertation and report their stories.

At the time of her study, Nora was principal of her school, and several of the teachers worked on their advanced degree at the same time. "I just felt it was a persistence issue. I was the leader of the school and I had people under me who went into it with me. So I knew I could do it if they could do it." She added that the hard part was when the structure was off and no one called to remind her about deadlines. "You have to do that yourself. It's all about self-motivation and self-discipline."

The participants said that the dissertation was the culmination of the degree, and they realized it would take time to complete it, but Margo said not to stop along the way.

At the end of the coursework you do not have a clear idea of what direction to go, so you say, "Well, I'll take a little rest," and that's the worst thing you can do because if you don't plow right into it, it's so easy to lose momentum. So I think $99 \%$ of it, in my opinion, is persistence. So I'm not going to stop. I'm so tired. I'm close to the end of the race. Wouldn't it feel good to just walk a little while? But if you can just keep trotting you can get there much faster. If you start walking, you may decide to sit down, and then lay down. And then not finish at all. 
Jackie said that it was "too major for me to give up" even though she was in an isolated process. She said she "just wanted to have some closure."

And then you get so long down the road and think, what the heck am I giving up for? If you look at it on a continuum, you are closer to the end than you are to the beginning. What are you putting all the effort, the sacrifice and the weekends that you could have been doing other things, especially when you're doing the dissertation at the end? That's when you want to give up. That's when I wanted to give up. It's very lonely. I just wasn't going to give up. I wasn't going to let this thing go on and on and on and on.

Other participants reported that they learned from those who did not complete the dissertation such as Lil's principal who was an ABD. May explained it was important to her as well as her family to finish the commitment she began.

I finished something that I started because that was important to me. I had heard of some doing the coursework and never doing the dissertation. I heard of candidates passing the written exam and even starting on their dissertation but and not finishing. I heard of one person who did everything but the oral defense. I instill in our kids that we try. If one makes a commitment, one finishes it.

An interesting result of completing the dissertation for all the participants was that this was not an end process but rather the beginning of a new identity. Completion brought new responsibilities in leadership roles for their peers, workmates, students and children.

Position as a role model. Several women, especially those who were teachers, who felt they were examples for their students, shared the role model route. Other participants said they were models for their children as they were living proof of the importance of education and life-long learning. Lil teaches English and communications.

I'm proud to say I did not take off one minute for this whole process and that has been a badge of honor to do this on top of my job. When my writing kids say they have to work and they have this and that, I say," Well, so do I, and here I am." I've told my students what my topic is. I've shown them the 
process, and I've shown them how I have to rewrite things. It is very helpful to them to see that education is still very important to their instructor.

Lil was the only high school teacher who consistently worked during her degree program. Both Sally and Margo, community college instructors, also used their experiences to model the process for their students. Margo said that working on the advanced degree motivated her and her students to do well.

I think it made me a better teacher because there's no better way to relate to problems somebody is facing than to face them yourself. It sort of motivated me to try and do a good job, to be clear and concise, really let them know exactly what they had to study, things I appreciated myself. I said, "Here is my schedule. I know if I can do it, you can do it," and so it encouraged them that way.

The women with children at home found their experience was important to motherhood and education. May reported that she was a "model to my college-aged children. While I was working full time, I was pursuing a higher degree in education, supporting the importance of education. I was writing papers; they were writing papers.

We were on common ground."

Jackie originally began the degree because she was taking her children to the library. But as she worked on her degree, she said it motivated her as well as her children.

But I just don't give up on very many things. I just see things through. And I had two children I was setting an example for so I couldn't tell two little children that I had been telling you don't give up just because it's tough. Oh, Mom's giving up. (Laughing) I just couldn't do that.

The role model theme continued for the administrators. Nora was an elementary principal when she began her program. She is now a district administrator.

I always knew I was going to finish it. I decided I was going to finish. I just wouldn't have started it. And what kept me going at first was I was the principal. I had 11 people in the master's program and seven people in the doctoral program. In rocky times I said, "I can't quit. I've got all these people." 
Cate, a university administrator, reflected that her role modeling would continue after she received the degree. She is ready possibly to initiate change in her community, which was the goal of the Continuing Integrated Seminar (CIS), the one-credit weekend class. She added that she has published her research once and now is thinking about what

In my final defense, one of the things they talked about how in completing is that you are a member of this community of scholars, and that's something that I think about as well. What is my responsibility now with this knowledge that I have gained, and the skills? By completing, I've been able to think more about how I want to be involved, service, beginning to think about publication.

kind of additional research she can undertake. Being a positive role model motivates others, but also serves as a way to sustain ones own motivation and thus, perpetuating the educational process.

Motivation (pride and ego). Motivation took several different routes from personal pride to future job opportunities. Lil said that she thinks it takes some degree of "ego that makes a person want to finish" and be embarrassed if she did not.

Pride, embarrassment if I didn't go through this because people knew. "You're going for your doctorate. When are you going to finish?" My principal went through a whole doctoral program and did not do his dissertation. So I really did not want to be embarrassed by the fact I hadn't finished. And my students who would ask how far I was. So it would be embarrassing not to finish. So pride got me through the dissertation.

Some participants knew the degree was important for either job advancement, the creation of program within their current position or future employment. Cate explained.

I would like to advance within student affairs. My next move would be to an assistant vice president level. That, at many institutions, would require a doctorate, and certainly anything beyond that nowadays does. And I also wanted the opportunity to be able to teach at the university level. 
Elly said that she wanted to create a master's program in her current job. "And I can tell you, in all honesty, that was the thing that drove me to do this." She is now in charge of the program she envisioned. Lil, on the other hand, said the degree gave her choices for a second career after she retired.

\section{Structural Resources}

Although the women in this study possessed the academic resilience to participate in a doctoral program, they had to adapt their personal characteristics to a particular academic program and institution. This is the filter through which they developed strategies for successful completion. The women in this study reported that completing the dissertation was the most difficult part of their journey to their doctoral degree. They indicated that the structural resources provided by the university helped them succeed, some more than others.

The dissertation-writing stage can be influenced if students work in a collaborative environment, are not left alone in their struggle to progress with their dissertations, interact with advisers, are given information about academic publishing, and have a financial package that fits their individual program and research structure. (Nerad \& Miller, 1997, p. 75)

In an effort to overcome the isolation, collaboration from peers and faculty is important throughout the program. Wolf-Wendel (2000) identified five colleges that had a large number of successful women graduates. The universities in her study provided positive role models, created a supportive environment, and provided an achieving peer culture, factors that women in this study identified as instrumental in their success.

\section{Peer Support - Cohort/Small Group}

Participants in this study indicated that the program provided support from personnel as being the primary external factor that influenced their success. The peer 
support was primarily the cohort organization of the program and small group activities.

Students who are involved with a cohort program are more likely to complete the dissertation (Baird, 1997; Burnett, 1999; Witte \& James, 1999) because cohorts reduce the feeling of isolation.

The use of cohorts at the satellite campus enticed students to begin their doctoral studies. Cate reported she "made a personal connection" to one of the original professors who explained the satellite program to her. She became interested in the program because of the cohorts and the proximity of the campus to her home.

The cohort feature worked especially well for the first class as evidenced by the high success rate of graduated students. Nora explained.

I think you'll find that Cohort 1 did a lot to bond us. They did a lot of simple icebreakers and things like that so they heavily invested on us knowing and caring about each other. They provided a lot of time for that and group activities.

Students in the later cohorts also reported the importance of cooperation and collaboration, which is important for women (Belenky et al., 1986; Gilligan, 1982). Lil, a high school English teacher, explained.

The cohorts really helped. Misery loves company. I'm not really good in math so the statistics courses just about killed me. But I had a friend in the program who was good in math, but she had a problem with writing. So we would help each other. So I would have about five people over to my house and I would cook. Bribery, and they would help me, and we would help each other with studying questions, writing, going over statistics, everything. It was so nice to have everyone there together. That helped a bunch.

Nora explained that the first cohort was especially successful because the university offered the courses in the order the students needed to take them. "And if you signed up as you were supposed to do and if you didn't have to play catch up, you would finish in four years. So that was their promise to us. And it worked pretty well." 
The collaboration of the first cohort built relationships that encouraged continual participation as May, who was in the first cohort, reported.

The first semester was wonderful in the bonding that we all did. During the evening class we took a break. Rather than everyone just going out on their own, we shared snacks, talked and became familiar with each other. We looked forward to seeing someone familiar in the next class.

She added that members of the first cohort continued to get together after the coursework every other month or so "to celebrate wherever we are. That was very helpful." She also said getting together sometimes was not always pleasant. "I was very apprehensive to go, especially when I was in the dissertation stage not accomplishing much. I didn't want to face everyone."

This emotional "support" encouraged others in that first group as Lynn reported. "But I was also with a group of people who told me I could do it. And that I'd better do it. I can say that because it took me so long that towards the end I would have walked away if it hadn't been for that cohort and my husband and my mother." The university dissolved the official cohort program after admitting Cohort 5 in 1997 because students were being admitted into the program every term and it became too difficult to maintain, so women who were admitted later did not have this type of support.

The participants reported the use of small groups in their classes contributed positively to their completion. Lil explained.

A lot of the courses are naturally set up for group work, which I think is a good idea because it really focused on a community of learners and leaders. That's a big deal in this program. To be a good leader, you have to be a good follower. You have to be a good example, and you have to work with people. You can't just be an island in this, especially in education. So the group work came from the courses very often. 
In his study at Memphis State University on study groups, Cesari (1990) said that the sharing of knowledge was "not intended to replace academic adviser's role but designed to supplement that role with tangible coping skills for the completion of the degree requirement" (p. 376). Nerad and Miller (1997) reported that small group workshops for candidates at Berkeley reduced attrition.

Savannah reported that one professor at the satellite program now sponsors a similar-type "boot camp" to help students complete their proposals. She said the "boot camp" should help other students, but it was not available when she was a candidate. She added that group projects in her classes did build camaraderie, which continued even after she received her degree.

We did a lot of group work. At times we stood up and had to teach our own information. I think it helped me build the friendships that helped me through this. There were three or four people who went through the program. Whether they finished or didn't finish it, they helped me finish it just by their support. I would not have gotten to know them as closely if it wasn't such a small group of people.

Since most of the students at the satellite program lived and worked close to the campus, it made it easier to complete the small group projects. Margo said she appreciated the convenience. "You're working with your fellow classmates on many group projects, and for everybody to be in the county was a lot easier than driving to Miami to work on a group project." The benefit of peer and small group interaction was evident in the discussions of most participants. However, all of the women expressed that while peer support was important, faculty support was essential. Adviser/Committee/Faculty

Students rely on the faculty for academic guidance and expect them to have a thorough understanding of university policies. Bowen and Rudenstein (1992) wrote that 
the faculty need to accept responsibility for graduate programs and they need to work together.

The course of study needs to be well defined, with sensible but firm expectations and deadlines at every major point along the way. Most of all, there should be a clear acknowledgement that the faculty members have a joint obligation to run a program - a coherent structured entity- for which they should feel accountable. (Bowen \& Rudenstein, 1992, pp. 266-267)

The ability to nurture the women doctoral students was one of the special traits of the founding professors that Jackie singled out. "The faculty was a very seasoned faculty who had worked in this area and had worked with the educational institutions in South Florida, and was very nurturing."

The faculty of all doctoral programs serve as teachers, advisers and committee members. Many prior studies even focused on the importance of women having same gender advisers (Green, 1997; Heinrich, 1995; Johnsrud, 1995; Kluever, 1997; Monsour \& Corman, 1991; Neumark \& Gardecki, 1998; Schroeder \& Mynatt, 1993; Smeby, 2000; Turner \& Thompson, 1993).

In this study, seven of the 10 participants had women as their major professor. Savannah said that her major professor was "very good as a friend, very good emotional support." She added that her chair kept her going in the beginning of the dissertation writing. Because of the faculty leaving the university, half the participants changed major professors and/or committee members during their doctoral program. Those who spoke about a change in faculty said it distracted from their timely completion. But when Cate got a new adviser before the comprehensive exam she had no problems.

From the very first time I met her, she seemed very supportive and she was very helpful through the comps process. I utilized her a lot as an information source. I was pretty clear with her from the beginning. If this is the goal I have 
to finish, give me a sense of the timeline and the processes. That was what I really wanted. She was very, very timely in giving feedback... She probably gave a lot more feedback in the process itself, and the logistics, and also the expectations about APA and general editorial kinds of things.

One of Margo's committee members changed because he left the university. She said her committee was helpful but the guidance was limited because "my topic really wasn't the area of expertise of the members." She added that her chair was very familiar with the university requirements.

My committee chair was very helpful in making sure that everything was done correctly. There are so many hoops you have to jump through (pause) this paper has to be filed at a certain office and that form by a certain date. It's unbelievable the list of forms, and how you can get confused by what has to be done. She was so good at that, and she was working with so many doctoral students. I always admired her a lot and appreciated what she was doing. So my particular committee members definitely were supportive, but they didn't have a lot of guidance in terms of, "Oh, you're off on the wrong track" or anything like that. I considered it a blessing (laughing) because I was able to pursue what I wanted to pursue and they seemed to think it was okay.

Lynn, who also had new committee members, added that her major professor "just kept telling me I could do it, mainly." She said there was a void when she did not have a committee, but that her new methodologist was "the cavalry that saved me." She added that she observed the people who finished in the shortest time had consistent committee members.

Timely feedback from the committee was mentioned as an important factor in the dissertation phase. Lenz (1997) said it was important for advisers to return drafts promptly, and they should be experts on the university's dissertation process. Cate said she depended on feedback, and got it, mostly for the first three chapters. She said she wished she had used her committee more for the other two chapters. May said she 
sometimes waited three or four weeks after giving drafts to her committee members to get them back.

Reading the drafts and making check marks does not give me feedback and coaching. Feedback needs to be meaningful, to move me to the next step. That does not help me produce quality work. And so if we want quality work from the doctoral students, we need to get quality feedback and coaching from the professors.

Both Margo and May had a committee member who was terminally ill, but they still received good feedback from her. The faculty member would edit their chapters from her bed, and then talk with them on the telephone about their dissertations. Timely feedback can be a major issue to a timely completion of a dissertation. Otherwise, this process can lead to large amounts of frustration, time and money.

\section{Financial}

Financial issues were reported in other studies as being a major issue towards completion (Baird, 1997; Berg \& Ferber, 1983; Bowen \& Rudenstein, 1992; Burnett, 1999; Cesari, 1990; Johnsrud, 1995; Kluever, 1998; Lenz, 1997; Maher et al., 2004; Shelburn \& Lewellyn, 1995); however, in this study no woman had serious problems with money. Several women asked for paid leaves from their workplace and grants for tuition. Three women said they wanted to finish in the 24 credits because that was all that was required and they did not want to pay for more than was necessary.

Nora said she was "very pragmatic when it comes to spending extra money or being in the program longer." She signed up for the minimum of six dissertation credits required by the university instead of trying to get it completed fast and taking nine credits at the beginning. "If you're farther ahead, at the end you can always sign up for nine or whatever." Nora thought she "probably took some loans out." She explained. "As the 
semesters roll along it gets expensive. My son was in a private school. But that's never an issue for me. I can always pay the money back at some time. I would never let money stop me from doing it."

May was specific about her financial assistance, a $\$ 1,000$ scholarship from the university. She said it was helpful because she was paying for two children in private, out-of-state colleges. She also worked one term as a graduate assistant but said it was "very minor. The university just needed someone to help out with the program so they asked me."

Nora reported that the teachers in her school were getting grants to help with tuition and would get a raise when the degree was completed, but administrators got nothing. "Some people deliberately got advancements when they got it or even close to it, especially some of the ones in human resources got big promotions in their companies."

Sally said she was an adjunct professor at two community colleges and because she was not a full time instructor, that neither college gave her money for anything. "So I had to pay. And they kind of knew it, and they worked with me, and that's why I wanted to get through."

Savannah did not receive any financial assistance either during her degree, only from her husband. She said she applied for a couple of scholarships the last semester but did not hear anything even though she attempted to contact the people in charge. "It was only being offered to doctoral students and there weren't that many, so I thought I had a pretty good chance."

Lynn was near retirement when she worked on her degree. She said she would not recover the money she spent on the degree once she became a district administrator. 
From a financial point of view it was draining to the family. When I was school- based I could get the grant, but the minute I came down here I lost it. That idea you had to go every term, you had to maintain so many hours every term was a hardship economically, honestly, which I don't think we'll recoup because down here they don't pay you for your degree. I've got very few years left in the system that I don't think I'll be going back to the school where they'll be paying me for it, so I can say my degree was for the learning.

She added that when others in her first cohort were taking additional courses she felt she "couldn't do one more thing nor could she afford to do one more thing." She did not take a large time off because "I could not afford to not be at the job, so it was just working day and night, and then just towards the end taking the extra time off, just a few weeks off to finish."

The workplace also provided financial assistance in the form of tuition reimbursement, salary increases and paid sabbaticals. Margo got all three to help her pay for the degree.

It wasn't necessary for me to have a doctorate to continue teaching at the community college, but they do pay for your education, and they pay you more when you get the degree. So it seemed a plus in that way too, that you could increase your salary and all that.

Three of the participants had paid leaves from work, one quit her job when she wrote her dissertation and others were able to take time off when they needed it. Lil was the only woman who pointed out that she never took any time off work.

Cate completed the dissertation in one calendar year. She received a grant for a leave during one Spring semester. During that time she wrote her proposal, had it approved and began the interviews with her participants. In the following summer she analyzed the results and began writing the dissertation. 
Four of the participants who worked at institutions of higher learning had their tuition paid for by their employers. Jackie shared a concern that three of the administrators reported.

College supports it. I get college tuition reimbursement for going to school so they support it. You don't get anything as an administrator when you get the degree, which is a source of contention because faculty get a monetary award, and administrators don't so that has been a source of problems for administrators.

Although a salary increase was not the motivation for any of the women to obtain the degree, six women did receive an increase after earning the doctorate. Those who were administrators did not. While the price of their education held some importance for the women in this study, their concern for research experience and understanding the dissertation process was more pressing.

Research

Training to complete the degree involves research skills that directly affect dissertation studies and writing (Bowen \& Rudenstein, 1992; Cuetera \& LeCapitaine, 1991; Golde \& Dore, 2001; Kluever, 1997; Lenz, 1997; Maher et al. 2004; Shelburn \& Lewellyn, 1995). Doctoral candidates beginning the dissertation often feel ill prepared, inadequate, confused and helpless... Research suggests that students' doctoral training programs play an important role in this process and that doctoral programs vary in their ability to prepare students to write the dissertation (Cuetera \& LeCapitaine, 1991, p. 233).

Margo and Lil wrote a thesis for their master's degree, but the other participants earned their master's degree in education, which did not require a thesis. May was a research assistant but did not conduct research in that position, and Sally was a graduate 
assistant for her master's. "I could do extra coursework or do a thesis. I did the coursework rather than the thesis, so I didn't have that experience."

Lil, however, earned her master's degree in English and wrote her thesis using the MLA style. "It was a totally different kind of writing, a totally different kind of research. It was literary research... So I just had to reevaluate and totally change the way I did things." She explained that in her last course, qualitative research, students had to do a mini project. She made her project longer than required and based it on a previous interview from her action research class and that became the topic for her dissertation research. "Students need experiences that promote a shift from an adviser's direction to collaboration, from dependency to independence. Students need to be socialized to doing active research as much as they need to learn objective skills" (Green, 1997, p. 64).

At the satellite campus, the coursework and comprehensive exam provided the only research experiences for the women participants. Three women used pilot studies, developed in their qualitative research class, as the basis for their dissertations. Each of the women reported that most of their research experience came from the classes that were required for the program. Students were given the option of taking a qualitative or a quantitative research class, and two participants enrolled in both courses. Seven of the participants used a quantitative inquiry and three used qualitative inquiry for their studies.

Nora explained that the research experiences for the students in the first cohort were different from those in later cohorts.

We had a lot of research courses. That was part of Cohort 1. I don't know if it's still in the program, but part of the desire was that we would have a lot more research background than most doctoral programs. So I think we had about five research courses and I guess that was unusual, most only have one or two. 
Nora completed a mini-project in her qualitative research class but conducted a quantitative study for her dissertation. "The teacher recommended doing it on the same thing you wanted to do your dissertation on. Smaller sample, shorter project but it gets the kinks out of it, and all the mistakes you make, you make there."

One of the original tenets of the program was action research or using the work place for research to initiate change. In fact, 7 of the 10 participants used their workplace for their dissertation research. (One of the three who did not, was not working when she completed her dissertation.) Sally was an adjunct professor at a community college.

The influence that work had was that I had everything in place for me to do this experiment. So that influenced me to do this, and vice versa. What influence this had on my work was that it made me understand better how the students were learning and what I could do to be a better instructor.

Although May was a research assistant, she did not consider that experience as suitable research preparation for a dissertation. "It was not really research." She said she had research for papers for classes and her strategy was to learn how to use the Internet on her own.

Actually I would not say I had research experience. I was in a teaching situation where I tried to use a lot of creative or critical thought. I would use the discovery method or the scientific process or the plan-do-study-act in order to meet the needs of my students. I tried to be very methodical in how I do my professional work.

Even though the women did not have formal research experience, they were able to use their coursework and comprehensive exams to launch their dissertations. Two participants, however, said they had difficulty in using the library because the downtown facility really did not have enough quality content for their studies. They had to go to 
other college libraries or go to the main campus of the university to overcome this problem created by the satellite delivery.

Cuetera and LeCapitaine (1991) found a lack of positive research opportunities also affected the spirit of the student. "When students were well prepared by research experiences (and by coursework and adviser relationship) the dissertation writing experience stimulated research interest. When ill prepared, the experience had a depressant effect on research interest (pp. 237-238).

While the logical resource for research experience would be the coursework/classroom, five of the participants who finished their dissertations in the shortest amount of time used the workplace to conduct their research. Although researchers caution students about writing in their own backyard (Janesick, 1998) since researcher bias could influence the findings, the participants were able to have their dissertations approved because their studies were worthy of research. Seven of the 10 participants chose topics relevant to their workplace. The five women who completed their dissertations with the fewest credits conducted their studies in their workplace.

Jackie wrote several concept papers on problems in her area. "Things I thought were problems weren't problems according to them [her committee]." She eventually found a topic that was acceptable to her committee and was helpful to her community college. "It wasn't what I wanted to do. Did I love it? No. It was a struggle for me to write it. Everybody says you have to love what you're doing because it's easier for you." Margo 's topic was her passion. "I thought I could include my job and my real passion, because it's something I've always cared about. I had the opportunity to learn more about it myself." Because the students attended classes at the more accessible, 
satellite campus, it was more difficult for them to take part in research activities that were held at the main campus in the adjoining county. Accessibility

Factors that draw or attract individuals to a particular program include convenience, location and opportunities for advancement. Students having contact with their advisers and easy access to the university resources facilitates providing the most support (Kluever, 1997). Each of the participants in this study reported they enrolled because of the "convenience" of the program. Classes were located close to their homes or work and began at either 4:30 p.m. or 7 p.m., after the normal workday.

In addition to the access, students consider educational and employment opportunities, and professional ideologies (Le-Doux, 1996). The body of research indicates support is the most critical factor to the advanced graduate student, and the Florida university in this study organized its satellite program specifically with this in mind. Sally lived and worked in the same county as the satellite campus.

The location (pause) that it was organized and structured and everything was done for you. These are the courses you take, and this is where you go. That was very helpful not having to guess or wonder. So the structure, the location, the accessibility of the professors

She added, "It was so close. I knew if I didn't have to go down to Miami to do anything out of the area, it just sounded so great, so convenient. So when I heard about it, I said 'That's where I want to go."'

Margo, who lives in northern part of the county, said that when the program was announced, it made it easier for her to take classes because she had taken her cognate classes on the main campus. "As far as travel time, it just cut it down, way down, and that 
was one of the big things. Every minute counted in my schedule. And having it convenient was a key issue."

Another convenient factor was that the on-site administrative office maintained a helpful staff who catered to the first cohort. It continues to assist the doctoral students. Nora, a public school administrator, explained.

We negotiated a lot, that first cohort. And they always came in and registered you for the next semester. They walked in your class, and you signed up right then and there. Here's the two new courses you have to take. Here's what you have to do. I'll take your checks right now because most of us were flaky about getting stuff in on time as far as that stuff goes. They kept saying "It's a private school program in a public college." And you would never think you were in a large university the way they babied us. They really did baby us I would have to say.

Jackie, who works in the central part of the county, summed up the program and why she was attracted to it. She said that it was developed in her county for "working educators. They were adult learners, and it was convenient for them. It was in a location that was convenient for them, at times that were convenient for them." For most of the participants, one of the main attractions of this particular satellite program was its convenience. As all were busy with careers and family, they valued their time and preferred to spend it in the classroom rather than on the road getting there so they created and applied strategies to help them complete their academic journey.

\section{Emergent Strategies}

To cope with the traditional roadblocks, the women in this study developed personal strategies to be successful. Johnsrud (1995) says that the long-term goal is to enhance the climate of graduate school for women, while the short-term goal is "to help women now enrolled, survive and succeed" (p. 77), which is the focus of this study. 
Although the participants reported that their personal factors were the most important, they did recognize how the structural sources affected their dissertation completion.

Four strategies evolved from the women's stories: (a) managing the job, family and degree responsibilities; (b) focusing on the destination (dissertation);

(c) collaborating with family and colleagues; and (d) advocating their needs.

Time Management - Making time for the job, family and degree program.

In Brunner's (1998) study about women superintendents, the participants said they need to learn to balance two sets of expectations: role-related and gender-related (but they always were a woman), and this was the overarching strategy that affected the strategies identified by the participants in his study. The women participants in this study were eager to share their strategies for success with me, but similar to the Clark and Watson study (1998) which found women juggle multiple professional and personal responsibilities through their words and interactions, these women had to fit my interviews into their tight schedules. Nora said it best. "But the truth is, life's busy all the time. And it's really procrastination. So I just had to suck it up."

Throughout the doctoral process the women had to balance three roles: employee, student, and mother/wife. All the participants said this was the most difficult to handle. So they all employed strategies to manage their time blending the three roles together. Generally employment came first, studies came second and someone else assumed family duties.

Organization was the key to these participants' success in prioritizing their duties as family member and student. "The tension generated by the multitude of required tasks may be overwhelming. In order to manage these time pressures an individual must be 
well organized and have a reasonable work plan" (Monsour \& Corman, 1991, p. 183).

They said the key to managing time is organization. Nora explained how she handled her time management.

I don't sweat the small stuff. I don't get hung up on details. The big things I stay focused on. There were months I didn't do anything, work just consumed me or I

let myself get sidetracked. But when that countdown begins, you have this many credits left or you'll be paying extra, you know you have to suck it up.

Participants who were teachers reported the strain on their lives and jobs. Margo, a community college professor, said it was "difficult to juggle work and study. It was definitely one of the high strain points in my life as far as time management. I really give a lot to my students, and I did not want to do less for them while I was doing my degree."

Lil agreed that being a teacher was especially difficult because she, too, had multiple responsibilities at her workplace because she was English department chair, an Advanced Placement teacher and a television production adviser who would spend hours after class with her students.

I think if you are a teacher, and I guess for anybody who's working, it's really hard to balance this program with working. Like I said, I took a lot of pride in not taking any time off, but when it comes to the comps and the dissertation, you are in the weeds and it's really hard to balance everything. If you have a demanding job, it's not going to get done quickly either the job or the dissertation.

Cate explained that her job came first while she was at work, and saved academic study for home.

My job isn't one where I could set aside what I was doing to work on my dissertation, or even having the option to spend time at work doing that. I think when your mind's in different places, it does affect your work. When I left work I did my best never to think about work because I had something else to focus on. 
May, who had to travel 40 minutes to class each way from her workplace, said "juggling everything" was her roadblock. She emphasized being flexible to succeed.

People are trying their hardest, with the situations that are occurring, to do their best. We will always probably have the feeling of being overloaded, overworked, things constantly changing. There's always change occurring, and it's not something you can change. But you have to find yourself to be flexible in order to ride the waves.

May added that planning for her classroom teaching was crucial because "You couldn't just say to the kids, "I had a rotten night. I've been in class. Just put your heads down" (laughing).

But the juggling of duties was not limited to their places of employment. The women had to adjust their family lifestyles as well. Margo explained that she had a "high maintenance husband." But they had dated in high school and all through college so he knew what to expect when she began her degree.

He knew that when I started a program that I was going to be totally absorbed in it because that's the kind of person I am as far as devoting myself to it, being highly motivated. And so by taking the classes and teaching full time and preparing for my classes and then doing assignments for the classes I was taking, you know there really was no time. I had no recreational activities for four years. I mean, I didn't even go to the movies for four years. So it was a very big sacrifice but there was always the light at the end of the tunnel.

The women in this study reported their support was especially strong from their families, similar to the findings of Berg and Ferber (1983) at the University of Illinois Urbana-Champion campus who found that moral support from family was important for $60 \%$ of the women and $40 \%$ of the men.

The implication is that women were less likely to embark on graduate studies when these kinds of support are not forthcoming, but it is possible that women are simply more willing to acknowledge support because they are more accommodating to their families' and spouses' preferences. (Berg \& Ferber, 1983, p. 635) 
Individuals writing dissertations need support beyond what is provided by

advisers and committees. "The enormity of the project, and the fact that it is outside the experience of most non-academics, makes support difficult to obtain from family and friends" (Monsour \& Corman, 1991, p. 181). The participants in this study acknowledged the different kinds of support their husbands and children provided.

Jackie explained the support took different routes.

Some times it was just, "I'm not making dinner tonight, you're on your own," and some of it was they understood after a while that if I say I'm not doing something on a Saturday night, then they went and did it on their own and let me be.

Lynn, who eventually graduated with 60 dissertation credits, the most of all the participants, said this about her family. "They didn't let me quit. I mean towards the last year I would have done anything to make it go away (laughing) because it had just hung on me so long, and I wasn't getting to the point that I saw the end in line."

Spousal support was very strong for the women and it was both emotional and practical. During the women's course of study, the family dynamics changed. Supportive husbands took over family chores and childcare duties and even limited the activities for the women. Cate said that her husband "took over a lot of things in the house that maybe no man would have done."

In her study with African-American women doctoral recipients, Louque (1999) found similar responses. Four of her 5 participants said the family was crucial to their success. Husbands and significant others helped children with homework, drove children to sporting events, prepared meals, carried drafts of the dissertation to committee 
members, and offered words of encouragement. In this study, the women reported they had the same type of support. May explained.

But I was very lucky that my husband was very cooperative. He didn't feel like I was neglecting him. I would leave the work on the computer and say "Hello" or visit. He was very good about picking up or doing more laundry. And if he came home and there was no food, he would go out and get groceries. I knew I could not focus on everything I had done before. His support was very helpful.

Lil reported her husband took a similar part in her journey.

We totally changed our family rhythm. My husband, generally the first one home cooked. He's great but he really wanted me to get this. So I had super support. This is unusual I know because a lot of people don't have this. So I am very, very fortunate. And he also grounded me (laughing). He said, "I'm sorry you cannot take on any new responsibilities until this is finished." So he was a constant reminder of how important this was. It was important to him, so he reminded me of how important it was to me.

Lil's husband also became an outside reader for her qualitative study. She said that as he read her paper, he would ask her to explain unclear concepts. Because "he wasn't into educationalese" it helped her clarify her writing.

Emotional support included pressure to complete the degree, which was neverending for some family members, as Lynn explained.

They never felt that I wouldn't get it. As a matter of fact I was thinking, "I wish they'd let me off the hook." Between the family and the cohort that was just so determined, I wasn't going to quit. I thought at this point "You're not my friends (laughing). You are my enemies." They are very proud of me. They are very proud of me.

Some of the women took more drastic steps that paid off in the end for them, even to the point of demanding support from their family as Elly explained.

I neglected them. I declared a moratorium on being a mother and a wife. I said I have to do this. My husband was right there and if I had papers to do he would say, "Do you want me to put stuff on your neck?" My daughter would say, "Do you want me to proofread for you?" And they were just there. 
Children also helped their mothers. Elly's teenagers proofread her dissertation,

and Sally said her children bragged about her being in school in pursuit of her degrees.

Just by being proud. Everywhere we went, everyone one they spoke to, "My mom is going to school, and my mom is doing this or that." But they did this before because my undergraduate degree and graduate work in Nevada was when my children were already old enough to understand what I was doing. And they supported me all through that and in this second phase.

But the family needs to provide more than just encouragement including financial assistance especially while they are fulfilling their residency requirements (Boes et al., 1997). As Savannah continued her program, her husband kept saying, "Your scholarship is going to run out. You need to finish" (laughing). Additional emotional and financial assistance came from the students' workplaces.

Guilt was an emotion some of the participants experienced when there were unable or unwilling to do it all at home. Jackie told this story.

I think you need to get your family to support you, if you're still at that age, and get over the guilt that you can't do whatever it is that has to be done. It took me a while before I just said, "I'm not doing that. If you want supper, you make it when you come home. I'm not making it." But you have to walk away. Or say, "I'm not doing the dishes," and walk away and not be guilty. It took a while not to be guilty because the kids didn't want to do it; they had homework. They were tired. My husband didn't want to do it. Nobody wanted to do it so it sat in the sink. When I got up in the morning part of me was very angry and part of me was guilty. But it took a while to get over the guilt and be tough.

At the anniversary symposium, a founding faculty member explained that the second purpose of the satellite campus was to provide the opportunity for working professionals to earn an advanced graduate degree. All of the participants reported they accessed their support from the workplace, whether it was emotional, financial, or research-oriented. Jackie explained that not all workplaces would be supportive. 
I think you need a work environment that people will support you. And I guess it depends on if you're working with anyone that doesn't want to see a woman succeed because I think there's a ceiling still there. There are a lot of people who don't want to see women succeed.

The women in the first cohort had the most support from their workplace. Many who were involved in that cohort attended their first classes at their place of employment. Other participants reported the emotional support was encouragement for being in the program and continuing through the program, which helped alleviate some of the stress involved with juggling work and study.

During the dissertation phase, Cate did not attend many of the evening functions at her job, and said her friends and colleagues understood.

The people at my work environment were very supportive. Having the leave was a gesture of tremendous support for me to be gone for 16 weeks. My supervisor who also was in the program was very encouraging, and she was also my peer reviewer. She helped a lot when I got stuck on things to talk to. And there was just a lot of support, day to day, from people I work with knowing there were things I might normally be a part of or go to but didn't.

Some supervisors encouraged their colleagues to return to school for the advanced degree. Elly said, "I had a boss who was behind me who kept saying 'You need this. You have to move it. You need to get this.' It wasn't required for my job but she knew it was an important thing I had to do for myself."

In addition to motivation, supervisors helped in other ways as Jackie reported.

At work I certainly got a lot of support from my boss. She encouraged me to go back to school. Yes, yes, that's a great idea. If I had to leave early to go to class, a 4 o'clock class, I had the flexibility to do that. Or if I had to go to the library and get something, she wasn't after me. I never got any pressure from it. She was very good at that.

Basically, the students had to cope with the time required for each of their "jobs."

They each created their own time management strategies. Nora reported she got "highly 
organized" and got up early Saturday morning, went grocery shopping for the week and decided if her "husband was going to cook it or my kids, and if we were ordering pizza." She then went to class. "And when I did that one thing it made all the difference in the world. So I did get some systems to help me."

Sally, on the other hand, said nothing changed in her life. "I struggled to keep up with everything. Maybe didn't keep up as well as I would if I didn't have the dissertation to do. But nothing changed. My day for cleaning, I cleaned. Wash got done."

Stress came with the territory and the women dealt with it in different ways. "Although most graduate students report high levels of stress, women experience stressors unique from those experienced by men, including discrimination, stereotyping, socialization, and marriage-work interface" (Ulku-Steiner et al., 2000, p. 297). In their study at a southern university, they found that a lack of status, competition, financial duress, high workload, performance anxiety and continuous evaluation all contributed to stress. Margo explained that she tried to avoid anxiety by not doing the entire dissertation all at once.

It was stressful in terms of time, not having enough time to get enough sleep, and there were times it was not enjoyable as it would have been had I not been working full time. But the dissertation did not end up being as an overwhelming task as I thought because I did one chapter at a time. I said, "Okay, if I look at the whole project I was going to die, but I can do Chapter 1."

And then she explained that she worked on Chapter 2 and then Chapter 3 and so on.

Elly, who set a distinct timeline for her dissertation completion, said women should be selfish in their pursuit, like she was, because they "owe it" to themselves.

If this is something that is important to you, think of it as a finite amount of time. And if it means a lot to you, then set aside everything and devote yourself to it because you owe it to yourself. So many times I could have been done with my 
degree years before but I allowed myself to get derailed. I was not selfish. I was very selfish during the last three years of this journey. I would not let anything stand in my way. I gave myself a period of time and I just would not be denied.

Managing the time for one's job, family and studies is essential and students have to make conscious decisions before beginning the program as Jackie explained. Before she began the program, she spoke with other students to see if it was "manageable."

I think you have to be honest with yourself that if you're not somebody who's self-disciplined or a completer, chances are you're not going to do it so why bother unless you're doing it to get the credits for your teaching certificate or something like that. Or the time. If you're not going to commit to the time because you're so active or your family situation.

Table 4 includes the specific strategies the women developed to manage their

Table 4

Strategies Participants Utilized to Manage their Work, Family and Academic Responsibilities

Strategies

\begin{tabular}{ccc}
$3-4$ & $5+$ & \\
Terms & Terms $^{1}$ & Total \\
\hline
\end{tabular}

Husband/family assumed childcare, household duties 3

Used a mini project from class to help with topic

Organized/prioritized work, home and study roles

Took no time off work

Related study to workplace to save time

Work provided tuition reimbursement or grant

Made a timeline to determine finish date

Took a paid sabbatical from work

Used advanced degree to motivate own students, children

$\begin{array}{lll}3 & 5 & 8\end{array}$

$\begin{array}{lll}3 & 4 & 7\end{array}$

Put social activities, family outings on hold

Family helped proofread, became involved in process

Employer arranged participant's schedule to meet needs

Left family on own since degree was for finite time

$4 \quad 2 \quad 6$

246

$5 \quad 1 \quad 6$

$3 \quad 3 \quad 6$

$\begin{array}{lll}3 & 1 & 4\end{array}$

$\begin{array}{lll}4 & 1 & 4\end{array}$

$\begin{array}{lll}1 & 3 & 4\end{array}$

$\begin{array}{lll}3 & 1 & 4\end{array}$

$2 \quad 1 \quad 3$

$2 \quad 1 \quad 3$

2

2

Husband hired a maid

Note: ${ }^{1}$ One participant quite her job after she began her advanced degree program. 
work, family and academic . Unlike the themes associated with academic resilience, elements identified with the participants' strategies to achieve success show differences in occurrences between those who completed in 3-4 terms and those who took more time. Those who took sabbaticals from work and those who correlated their dissertation study to an issue in the workplace, completed in the shorter amount of time. One woman who completed in more than four terms quite her job after she became pregnant during her doctoral study. Her husband hired a maid to clean the house after the baby was born so Savannah could study.

Although most the participants in this study identified time management as the greatest obstacle to achieving doctoral completion, they emphasized the necessity of academic focus. They had to revise their internal characteristics and zero in on the primary goal.

Focus on the Dissertation - Keeping their Agenda Simple

While in the Brunner (1998) study women kept their eye on a single goal, the education of children, the participants in this study took a more practical approach. May had a simple goal attached to her computer. "Get it done!" The rest of the women shared her vision.

Each of the participants reported that during their coursework, the advice other students had given them was, "the sooner they decided on the topic the better." The women who completed in four terms followed that advice. Sally explained.

Students from the first cohort would come and talk with us and tell us their experiences. And when I heard that phrase, "Decide early and stay with it," I lived with it. So then everything I did from thereon was geared for it. So all my research was done through my coursework by staying with that one topic. 
Cate determined two areas of interest, and through her course work focused on those areas as she completed required papers and projects." My comps were related to that as well, so by the time I finished my comps I knew I wanted to write in that area."

Elly said that she knew her topic by the time she took the comprehensive exam, and that was helpful to her successful completion.

I pretty much selected my topic when I did my comps. That was the wonderful thing about the faculty. They felt that your comps should really be your dissertation topic, and the questions they ask you that you write on should give you the opportunity to really develop your literature, your chapter two. And while it did not pan out exactly that way, it certainly provided a lot of information.

One of the original goals of the satellite program was to use the workplace for the research study. Nora explained that this helped her complete in a timely manner.

They told me whatever you do, pick do something that you have access to. So I was smart enough to say, "What is it I have to do in this job? Who are the people I have contact with everyday that's part of my work anyway?"

She ended up completing her research study in her new district job when she became an administrator. "And that was a godsend because I got it done on time."

Because Elly worked at a 4-year university, she was familiar with advanced degree programs and said she did not fear the dissertation.

I do not suffer from the fear of this whole mystique of the dissertation. This is hard for people in the outside world because they are not in the academic environment which kind of gives you a sense of this is not all it's cracked up to be. A lot of this is intimidation and scaring you to death. I did not try to make a name for myself in my dissertation. I saw it as a requirement to get the degree and give me the opportunity to do some things I wanted to do.

Nora explained that students should think they are capable of completing the journey if they have advanced into candidacy because that is an accomplishment. 
Be confident enough that you can do it. A lot of people really don't. They make such a big deal of the dissertation that you almost feel intimidated that it's beyond your capability. If you've finished your course work and comps, you can do it.

Several of the women interviewed established a personal timeline that included a projected date for dissertation completion, and in some cases, graduation. Cate used a specific deadline strategy as did other women, but hers was the most specific.

I think what worked for me best was having some very clear goals. My process was at the beginning, I established a general time frame. I said I wanted to graduate next December and in order to do that, this is generally the pace I have to move.

Every week she set goals for herself because she wanted to know if she was making progress. "But I also didn't want to feel as if every single minute needed to be devoted to that dissertation. So it was a way for me to manage the process and feel okay about taking some time off as well." So she made a list of goals and if they were done by Saturday, she took Sunday off and then wrote a new set of goals for the following week.

Jackie set goals also, but ice cream and jewelry were her added incentives to completing the goals she set.

Anytime I got stressed, I went into the kitchen and ate out of the gallon, butter pecan. That was a reward. I am very disciplined, and if I sat there and found my mind wandering, getting distracted, I would say, "You can't leave until you've done five pages. Or you can't leave until it's been an hour. I made myself sit there and do that. And then you can go and have a 10-minute break and have some ice cream."

She also has three "very nice" pieces of jewelry she bought after three major accomplishments: coursework, comps and dissertation. She said she didn't intend to buy them but "I saw and thought I deserved them, so I bought them."

Jackie reported she "worked every single night no matter how tired I was or what I had to do, and at least one day on the weekend. And that was the only way I could do 
it." She tried to get on the computer by 7:30 p.m. and would work until 9:30 p.m. or until she got tired.

And I'm sure I got prematurely tired because it was just such a struggle. Some nights and some days I thought I could write better, I just kept working. When those creative times came, I just took advantage of that. Or if I got in a formatting mood, I just kept formatting until I got tired. Some days I could hardly keep my eyes open so I would just proof maybe just four pages or work for an hour. But I made myself do it every night because it is so easy to procrastinate.

Lil called her strategy to finish getting into her "zone" especially during the dissertation phase. This involved listening to classical music so she could "click in."

I made sure every single day I did at least one thing on the dissertation, whether it was reading something, collecting an article from the Internet or writing one section. But every single day I had to do something. Some days I spent longer, or slapped myself into the "zone," that's what I called it, when I can really write.

But that strategy did not work for everyone. Savannah, who had young children at home, reported that working a little bit each day was "impossible. I mean for me that's impossible. Psychologically, I needed a chunk of time. Not just 10 minutes or 20 minutes when the children were sleeping." Her husband hired her a maid and once a week, for the entire day, she sent the children to her parents so she could go to the library and work. That's actually why she got the maid because at first she spent the entire day cleaning instead of working on her paper. The strategy gave her time to continually revise her dissertation.

You just have to be persistent. When I got my proposal back the first time, there was so much writing on it and the dean tore it apart, and said "this was horrible" and all kinds of terrible things. And then I fixed every single, solitary thing that he wanted, exactly the way he wanted, unless he said, "Just a suggestion would be" or "Maybe you should think about."

Two women selected topics with which their committee was not familiar. They were the first two women to complete their degrees. "When you pick something that 
people don't know a lot about it gives you a lot more freedom. I did pick a topic that my professors didn't know about," Nora said. But once the topic is approved, it is time to move ahead.

Just think of it as a giant term paper, and stay focused. Don't go down those side roads. This is not the time to learn something new, to broaden your horizon. Pick something you already know a heck of a lot about, so that you are the expert. And then you do this work which will expand your knowledge. And then you go into your defense and you know more than anybody else in that room.

Three participants used other dissertations as models because they felt lost when they began the dissertation phase. Margo said to stay focused. "Don't let other forces pull you away. I think it's $99 \%$ perspiration and $1 \%$ inspiration. Don't be overwhelmed by the task. Do one chapter at a time." She was one of the first women from the first cohort to complete the program and earn her degree. She had a writing strategy.

One of my friends, who was a chapter ahead of me, would give me her chapter. So I saw the set up, a specific example, and so I just followed her general guidelines. And I would turn in my work, and they would give me feedback, and I would improve it, and so on.

Sally had a larger vision, one semester at a time. "Don't look way in advance and say, "How am I ever going to do that?" Choose your committee wisely and don't put it off. Don't sit out a semester, one semester can mean a lot. And just keep plugging along, and it will run smoothly."

When beginning the dissertation writing phase, Savannah said she went to the library to read other students' dissertations, especially the ones from the university because the requirements are always changing. Jackie used a different process.

When you're doing the dissertation, you write the title page. I remember doing that (laughing). And then I wrote the Table of Contents. Page break. And then I wrote Abstract. Page break. I can remember doing all of that. I had 10 pages with nothing on them. 
She then put in a disk and wrote Major Heading and went back and cut and pasted from her notes and references and created a shell. "Luckily I didn't have to use old-fashioned index cards."

Specific strategies the women participants in this study developed to focus on their dissertations are highlighted in Table 5. The selections are listed in the total the participants reported during the interviews. The only significant difference between those who finished in 3-4 terms and those who took longer, was with those who planned a topic Table 5

Strategies Participants Reported They Utilized to Focus on the Dissertation

\begin{tabular}{lccc}
\hline Strategies & $3-4$ & $5+$ & \\
& Terms & Terms & Total \\
\hline
\end{tabular}

Took minimum dissertation credits at beginning

\begin{tabular}{lll}
5 & 5 & 10 \\
4 & 4 & 8 \\
4 & 4 & 8 \\
5 & 2 & 7 \\
3 & 3 & 6 \\
3 & 3 & 6 \\
2 & 2 & 4 \\
2 & 2 & 4 \\
3 & 1 & 4 \\
2 & 2 & 4 \\
2 & 1 & 3 \\
1 & 1 & 2 \\
2 & & 2 \\
2 & & 2 \\
2 & & 2 \\
1 & 1 & 2 \\
& 1 & 1 \\
& 1 & 1 \\
\hline
\end{tabular}


and were able to stick with it. This was attributed to a change in advisers and faculty members, which then necessitated shifting the topic focus. Because focus is closely associated with the academic resilience trait of self-discipline, it is logical that there are so few differences between early and later completers. All participants already possessed and knew how to implement strategies related to focusing on the dissertation.

\section{Collaboration - Sharing the Power and Credit}

No matter how individually focused each participant remained, their doctoral process required additional collaboration with peers, family and faculty. In this study, personal and academic collaboration supported the theories of Gilligan (1982), Noddings (2003), and Belenky et al. (1986) on how women succeed better in relational rather than solitary situations, and with cooperation rather than competition. As seen in the literature, collaboration from all sources serves as the backbone which successful graduates reported kept them going throughout their programs.

As women completed the advanced degree journey, they collaborated and shared with family, friends and faculty. The support of the family is crucial to doctoral students (Berg \& Ferber, 1983; Kluever, 1997; Lenz, 1997; Monsour \& Corman, 1991). The women in this study agreed, and their families adjusted to their needs from the very beginning. Sally explained what she did at the first meeting about the satellite program.

I dragged my husband there, and I was the only one to do so, because I felt he was going to be a big part if I was going to do this, his life was going to be affected as well. After the meeting I asked him what he thought. He said, "What do you think?" I told him I wanted to do it and he said, "Fine, do it if you want to."

Brunner (1998) found that successful women shared power and credit with their peers and supervisors, reflecting the ethic of caring and collaboration (Gilligan, 1982; 
Noddings, 2000). Margo said that support from their peers just did not come from the cohort, but also from the activities and projects the professors assigned.

Using the cohorts, I think everyone was together when it came time to study for exams or prepare for our comps. There were a lot of us getting together, working together, quizzing each other, supporting each other. "Okay, I looked up these questions, you look up those. Let's share our answers" and see if they would give you ideas on subjects they would cover. So you really worked together. Then there were courses where you were divided into groups, and I know we did group projects in at least five or six of the classes.

Monsour and Corman (1991) suggest that having a dissertation partner supplements the adviser's role and provides social support in the form of empathy and companionship. Nora was in Cohort 1 with Margo, and said that even with the abandonment of the cohort system, a dissertation partner could help.

I probably did it at the right time because I had a strong peer group. If it was just me, by myself, it would probably be a lot harder to have done it than to know there was some peer pressure there. I think if you go in with a buddy or somebody that can keep you going, it's probably helpful.

Savannah said that only one or two friends in the program could help whether they finished or not.

Forming those few friendships. You're with a group of people but if you can get one or two to become close with, whether they finish or don't finish, they're there for your support, and they've been through what you're going through.

Maher and others (2004) reported that early finishing women had more types of support from family members than late finishers and they maintained a positive working relationship with faculty which is consistent with May's advice.

Assess your family situation so that they [family members] are supporting you even though they don't know what you're going through. Continue to communicate what you are doing. Explain that you need their support and when they give you their support show appreciation. 
Having a working relationship with the faculty was just as important to these women as well. Not only should the faculty members be well versed on university procedures, but they also influence the student's self-concept by the quality of their mentorship (Ulku-Steiner, et al., 2000). All the participants spoke about the importance of the committee. Elly said that choosing the right committee was "everything." In her study of non-traditional women doctoral students, Lenz (1997) found it is important to establish collegial relationships that were kind and caring. Nora said it was important for the committee to function as a team.

The best advice that someone said is make sure your committee members like each other and want to work together because they all have big egos. Let's be honest, and some really don't get along at all and have very different styles so they won't work together as a team.

Her advice was for students to find a major professor who they could work with and then ask the professor who he or she wanted to recommend who they wanted to work with. Her topic was similar to her professor's doctoral study. "When I talked to him about what I wanted to do, his eyes lit up. He said, "That's my passion."

Specific strategies the women developed to strengthen their collaboration are highlighted in Table 6. While it appears incongruous that those who most noted the importance and encouragement from work and family were more than 4-term finishers, this is because they needed the outside encouragement to supplement the void created by shifting staff and program vision. However, it is interesting to note that the later finishers listed peer groups as very important, supporting the original vision of the cohort program. The participants recognized that each had unique needs that affected their doctoral study, some even specific to themselves as women. 
Table 6

Strategies Participants Utilized for Collaboration

\begin{tabular}{lcccc}
\hline Strategies & \multicolumn{3}{c}{$\begin{array}{l}3-4 \\
\text { Terms }\end{array}$} & $\begin{array}{c}5+ \\
\text { Terms }\end{array}$ \\
\hline Husband provided emotional support & 5 & 5 & 10 \\
Made friendships that still exist & 4 & 5 & 9 \\
Utilized cohort, "connectivity," for support & 4 & 4 & 8 \\
Used group work, class presentations for relationships & 4 & 4 & 8 \\
Responded to encouragement of friends & 4 & 4 & 8 \\
Use encouragement from work & 2 & 4 & 6 \\
Had family that was proud, gave emotional support & 2 & 4 & 6 \\
Set up peer support groups in classes that extended past & 1 & 5 & 6 \\
Knew the selection of "right" committee important & 4 & 2 & 6 \\
Avoided conflict with committee & 5 & 1 & 6 \\
Kept in contact with committee & 3 & 2 & 5 \\
Relied on university administrative personnel help & 2 & 3 & 5 \\
Involved family in decision making, to orientation & & 1 & 1 \\
Understood importance of "boot camp" & & 1 & 1 \\
\hline
\end{tabular}

\section{Advocacy - Knowing their needs}

To many of the participants in this study, self-advocacy translated to gender advocacy. Each expressed having to deal with conflict involving guilt for possibly neglecting their "jobs" whether career or family, in order to pursue their goals as well as being self-advocates having to speak up for themselves, and sometimes be strongly assertive.

An educational environment can have an impact on the success of a doctoral student. Several participants in this study recognized gender-bias as affecting their academic experience. Some even indicated that self-advocacy, particularly when it came to the dissertation phase of their degrees, required strong behavior historically associated 
with males. It is essential for a university to create a gender-neutral environment, so students entering graduate programs can better cope with any gender bias if they recognize it as such because bias does exist (Shelburn \& Lewellyn, 1995).

In Brunner's (1997) study, the women superintendents spoke about their femininity and the ability to disregard the myth to "act like a man." Although I did not ask a specific question about gender-bias, three of the women in my study spoke about its existence in doctoral programs. Jackie had a definite opinion.

There are a lot of people that don't want women to succeed. If it's a guy getting his doctorate, that's a whole lot different... But maybe it's South Florida, really very southern, and I think for women to have a doctorate degree is more significant than up north. Maybe up north it's more competitive and everybody would be doing it. Down here if you'd look and see really in the school system how many women have them, not a whole lot.

She said that because she was in the health care field and most of her supervisors and colleagues were women, she personally did not experience negative gender-bias at her workplace.

Many of the participants in this study earned their degree in administration to enhance their administrative expertise or career advancement. Nora, on the other hand, was already a public school district administrator. She explained that just 15 years ago only $5 \%$ of the principals were women but $90 \%$ of the teachers were women. "They never got to the leadership roles. But it's different now." She said with the addition of career ladders there are more avenues for women to become administrators, that women need to climb those ladders and the doctorate is an asset.

I think it's a man's world in a lot of ways professionally, and I think women need more than men to get to the same place men are. So I think if it's about career, maybe a man could get the same job with a master's degree. I think it's smart to say women need to get more to just get the same edge. So I think if women have 
aspirations career-wise in the school system or in the world of education, a doctorate is definitely an asset.

Nora added, "I think women need to be more assertive in certain ways. They are not automatically the ones in meetings to take notes and get the coffee. That still happens."

However, while many women do not wish to be viewed as the feminine stereotype, they do recognize that they sometimes have to deal with emotions that are characterized as uniquely female. Savannah let her emotions get the best of her when meeting with her methodologist.

I think you have to know it's a man's world, and use what you... whether it's emotional.... Unfortunately that's how I became a close friend with my methodologist. The very first time I met with him and he tore my paper apart, I was having a little PMS that day, and I started crying on him, and I think he thought, "Oh, no." I never cried on him again but I think he realized I was an emotional person, and he worked with that.

She added that women have to be themselves. "If you're not a 'stand-in-front-of-yourface' type of person, then don't pretend to be. People accept you for what you are if you're honest about yourself."

As much as the women wished an equal footing with men academically and personally, they still placed themselves into assigned roles and this conflict brought about feelings of guilt. May said she just could not do all the jobs at one time and it made her feel guilty. Her health suffered also as she had three surgeries during her degree program. She added that she wished she had spent more time staying healthy during her studies.

I was the kind, especially with the kids being at home, that I cleaned the house on Saturday. I did the grocery shopping. I prepared the meals ahead and all. During the dissertation I had this fight in myself. I could not do everything I did before. I couldn't clean and do the groceries and do the birthday cards for my family. I could not do that and put time into my dissertation. If I were doing the dissertation, I felt guilty about all the other things, work related or family or personal things that I wasn't doing. 
Only two of the women mentioned health issues in our conversations. Savannah had a baby, and May went through three surgeries that lengthened her time to completion. Maher and others (2004) included childbearing as a health issue. "I think that when there's stress, when you have a lot on your plate, it affects your physical condition and emotional stress. So I would say eat well. Take care of yourself is the most important thing to me," May said.

One of the differences in men and women is that women are generally not confrontational, but cooperative (Belenky et al., 1986, Conrad \& Phillips, 1995). During the time span of their degree program, half the participants reported the need to be somewhat confrontational with personnel, faculty and administrators. After feeling a lack of support May changed her committee, and said she wished she had made the change sooner.

Several participants indicated it was their responsibility to advocate their position and contact their committee. May reported she had to seek change.

It was a lonely thing to complete the dissertation. Little help was offered to solve problems. I made the appointment to see the professor. I initiated the contact with the professors to request feedback. If they were willing to put in the time and willing to discuss it, I could proceed forward with their assistance.

Lil explained that "it's when you don't keep in touch with your professors that they're going to have a surprise for you at your defense." Cate relayed some advice that someone told her along the way.

Never go into the defense, either of the defenses, without knowing what your committee feedback is. Be prepared to respond to it. Make sure that when you submit something, you are always following up to get that feedback, even if it's before the defense. Ask, "Are there any things in particular you want me to respond to in my defense? 
Jackie explained that the strength women show by advocating their academic positions is more than just words.

I think it's important for women, if nothing else, to be role models for younger women. That you can do this and you can accomplish this. That it's not just for guys any more. That you can go to school, that you can do it. That you can get a position that you want. You can have your own career if you are a career woman, which, of course, I am.

In the final stages of the dissertation process, four women ran into roadblocks as they finished the final draft of their papers. A university administrator wanted three of the participants to postpone their graduation to do additional work after their committees had approved their dissertations. They each stated their cases with authoritative and convincing support and ended up graduating on time. Savannah explained her technique.

I think you have to stand up for yourself. You have to not rely on one person's opinion but you have to say, "No, I know this is good enough and someone else has already read it and said it's fine." Don't just take "no" for face value.

Advocacy strategies the women developed and strengthened their resolve to complete the advanced degree are highlighted in Table 7 . The women who needed more time to complete their degrees developed additional strategies to help them on their journey.

As the candidates reached the end of their journey successfully, they changed roles from student to leader. "When doctoral study is 're-visioned' as an initiatory rite of passage in which a woman assumes a new professional identity, the role of advisor becomes that of initiator, guide, and ultimately colleague in the professional world" (Heinrich, 1995, p. 466). The women in this study used their academic resiliency to utilize the structural resources with which they were presented and created strategies to 
Table 7

Strategies Participants Utilized for Advocating their Needs

\begin{tabular}{lccc}
\hline Strategies & $3-4$ & $5+$ & \\
& Terms & Terms & Total \\
\hline
\end{tabular}

Let their "love of learning" override all obstacles

Avoided "doing it all" during process

Depended on relationships for support

Used reflection on process as motivation

Did not let feelings of guilt override personal goal

Spoke up for themselves, even confrontational

Terms Terms Total

Used spiritual belief throughout program

Rewarded self when goals met

Understood their health was important

$\begin{array}{ccc}5 & 5 & 10 \\ 4 & 5 & 9 \\ 4 & 5 & 9 \\ 3 & 4 & 7 \\ 1 & 2 & 3 \\ & 3 & 3 \\ 2 & 1 & 3 \\ 1 & 1 & 2 \\ & 2 & 2\end{array}$

achieve academic success. They are now members of the academy.

\section{Summary}

The 10 participants in this study were determined to complete the advanced graduate degree when they entered the doctoral program at the satellite campus. Their self-efficacy was the backbone that supported their academic resilience as they coped with the traditional roadblocks non-completers were unable to overcome. As Nora said, "You have to keep your eye on the target. What is it you want? You want the doctoral degree. You will get it. You just have to roll with the punches and not let the barriers be insurmountable."

In the beginning, the satellite program provided its students with five structural sources that gave them the support necessary for survival. The participants in this study said they believed some of the original "vision" of the founding faculty had changed over the 10 years of the program, therefore, creating new detours for the students. The 
women's "lived experiences" clarified the personal factors that strengthened their academic resilience. The program's structural sources helped them succeed by earning their doctoral degree within the academic environment of the satellite program. It was clear the women had strong academic resilience that led them over the bumps in the road; however, it was the personal strategies developed by each woman that drove her to her success.

As women constructivists, they acknowledged their quest for knowledge, their need for collaborative learning and their being goal oriented (Belenky et al., 1986). They demonstrated their responsibilities as role models, their caring about the lives of people around them, their having an awareness of their own thoughts and feelings, and their having a moral or spiritual dimension to their lives.

Overall, the study indicated that these women had the will and the skill (Bandura, 1986) to complete the degree by developing strategies to overcome the traditional barriers in their journey to complete the doctoral degree. As I examined the data, the women graduates in this research fit the parameters of Maslow's (1943) self-actualized person and Belenky's et al. (1986) constructivist woman. Commonalties of these two types of people include characteristics of seeking knowledge, caring about the lives of people around them, being goal-oriented, having an awareness of their own thoughts and feelings, and having a moral or spiritual dimension to their lives. As I analyzed our conversations, I realized how their self-efficacy impacted their completion of their degree because they all believed they had the skills and personal discipline to complete the degree from the very beginning of their doctoral program. While other doctoral candidates also initially appear to possess the academic resilience to participate in a 
doctoral program, the participants in this study emerged with a degree because they were able to assess the structural resources available to them and apply the necessary strategies that would adapt their academic resilience into successful completion. 


\section{CHAPTER V}

\section{SUMMARY, DISCUSSION, AND RECOMMENDATIONS}

In this chapter, the study is summarized, the findings are discussed, and recommendations for practice and research are provided. An overview of purpose and methods utilized for this study are reviewed and are followed by discussion of the major and secondary findings. Implications that may provide guidance for enhancing dissertation completion rates of women and recommendations for future research conclude the chapter.

\section{Summary of the Study}

The purpose of this study was to explore the perceptions of women graduates of an evolving doctoral program at a satellite facility as to what they thought contributed to their success in coping and succeeding in that academic environment. The women who were interviewed reported that they lived in this county and had enrolled in this program because of the convenience the satellite location provided. There was no public doctoral degree granting university in this county. The program that they attended was originally developed for working professionals and was designed to ameliorate common satellite campus problems such as limited access to the main research library, the professors, and administrative support. I sought to better understand how these women succeeded even as the program changed location and structure.

To achieve a sample that provided multiple perspectives, women were chosen from all five cohorts and from among those who had not been in a cohort. Early dissertation completers (3-4 terms) and later completers (5+ terms) were likewise 
included. Professors identified some of these women, and participants recommended others during the interviews.

I used several methods to enhance credibility of the research. For triangulation of data sources, in addition to interviewing women who had different perspectives, I spoke with two of the founding members of the faculty. Furthermore, I reviewed university documents from the 10 years of the program. I also employed member checking, sending both interview transcripts and Chapter 4 findings to each of the women interviewed. I incorporated feedback from an outside reader who examined my data analysis. Finally, I kept a research journal to help identify potential bias and organize data from the interviews.

Interviews took place at the participants' homes, workplaces and at the university's main and satellite campuses. To help me analyze what the women said, I transcribed each interview tape recording. Data from the transcripts were organized into emergent themes: five personal themes relating to academic resilience and four strategies the women used to cope and succeed in the academic environment of the satellite campus.

Findings reflected that the women demonstrated academic resilience as they worked with the university's structural resources and developed personal strategies to successfully attain doctoral degrees. For each, academic resilience was built on (a) viewing that working on the degree was personally fulfilling, (b) believing she possessed a strong sense of academic confidence, and (c) priding herself on having selfdiscipline. Two other academic resilience components identified by approximately half of the women were (d) seeing themselves as role models, and (e) being motivated by 
either a personal or career-related goal. As the participants described their doctoral experience, typically they indicated the structural resources that affected their completion included the presence or absence of (a) peer groups/cohorts, (b) financial support, and (c) research opportunities. Other influential structural resources were the (c) consistency of faculty/committee member support, and (d) accessibility of university facilities and personnel. In this setting, the women employed four types of strategies; (a) prioritizing their family, work, and academic responsibilities; (b) focusing on the dissertation; (c) collaborating with peers; and (d) becoming self advocates concerning their needs. Individual participants used varying numbers of these strategies. Table 4 indicates how a woman's characteristics of academic resilience filter through the structural sources so she can create and adapt strategies to fit her personal needs.

\section{Discussion}

In the literature, there is greater discussion of programmatic factors than of personal characteristics that contribute to successful dissertation completion. However, the women interviewed in this study indicated that they believed that their academic resilience was more influential in their completing the dissertation than the structural resources provided by the university. Academic Resilience

While most participants began with the intention of reaching the personal satisfaction of attaining an advanced degree, they also displayed confidence in their academic ability. Self-discipline played a major role for most students in reorganizing their lives to fit the rigor of academic immersion. This process thrust many into the position of role model for their family and students. Surprising, motivation was the least 


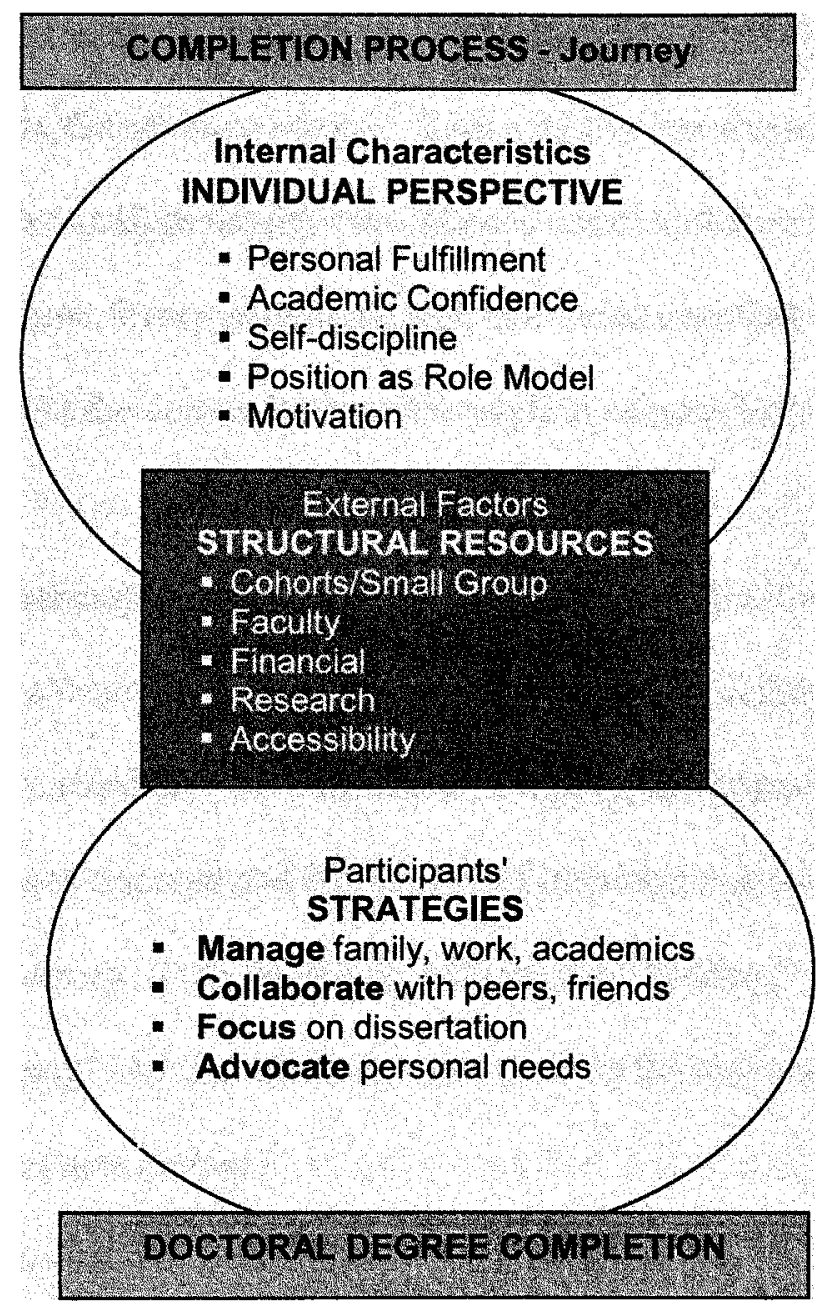

Figure 4. Dissertation Completion Model

mentioned factor to success but this may be that the participants assumed this to be "understood."

The research for this study revealed several interesting findings that related to the theories of success. In the interviews, each of the participants' responses supported Bandura's (1986) theory of self-efficacy. The theory can be used to determine how much effort people will expend and how long they persist when obstacles occur. Most of the women reported that they viewed their prior academic success (obtaining their 
baccalaureate and master's degrees) as indications of their having the intelligence and skills to complete the advanced degree. Each said that her experiences in the doctoral coursework at the satellite facility strengthened her confidence that she had the ability to complete the degree. Every participant said that the coursework was the easiest part of the degree and that the convenience of the satellite campus helped make going to class manageable.

The participants also exemplified Maslow's (1943) self-actualized person, one who focuses on a desire to know and seek wisdom. Each participant said she sought knowledge and wanted the self-fulfillment of earning the degree. The women reported that they were goal-oriented and felt a sense of responsibility to complete the journey, to themselves and others. Two felt the degree was their "calling," and one said it was "a spiritual awakening" and that she "knew her place in the universe" now after obtaining the advanced graduate degree.

\section{Structural Resources}

Armed with the characteristics of academic resilience, the women assessed the structural resources, which they would utilize during an advanced degree program including (a) cohorts and small groups; (b) faculty; (c) financial; (d) research experiences; and (e) accessibility. They reported that the theme of connectivity, which emerged in the pilot study and from the literature, was important to them. Belenky et al. (1986), Gilligan (1986) and Noddings (2003) all theorized that caring, collaboration and cooperation contribute to a woman's personal and professional success.

Supportive elements for this theme included peer, faculty and administrative assistance. From the academic perspective, the participants identified peer support as 
their primary influence, and the cohort system was the vehicle by which most of them received this support. The women reported that committee members who were "timely in their feedback" and who kept them on track about university deadlines were the most helpful. Professors who employed small group work and presentations as part of their curriculum established an atmosphere that was conducive for "bonding" among the students. The personnel in the on-site administrative center added to the convenience of the satellite program by being accessible during the day and in the evenings.

As the women chose a program that fit their academic needs, they addressed their financial considerations. Nine participants were employed during the doctoral program, and one was a research assistant. Several women utilized assistance from their workplaces in terms of paid sabbaticals during the degree programs, tuition reimbursement and grants. Three participants indicated they wanted to finish with only 24 dissertation credits, the least required by the university, so they " would not have to spend any more money than necessary."

Research experience was another structural source. The women reported that they only had research experience from their coursework. Those who selected the "take home" comprehensive exam said that it helped them write in a dissertation format. All but three used their workplace for their research studies, which was one of the goals of the founding faculty of the program at the satellite campus.

Another vision of the designers of the program was to make classes easily accessible to its participants. This was a drawing point for all the students and why they initially applied to the program. They already possessed the resilience to succeed in any program, but the convenience factor is what made this satellite location so attractive. 
The finding that most stood out in this study was the revelation of personal strategies that the participants used to reach the successful completion of the doctoral degree, particularly their dissertation. They developed four personal types of strategies to successfully manage the demands associated with their families, jobs, and university personnel and policies which included (a) prioritize-finding time for both personal and professional duties; (b) focus-zeroing in on the dissertation and making it a priority; (c) collaboration-utilizing both personal and programmatic support; and (d) advocacyworking for their needs. This study provided a glimpse into the graduates' "lived experiences" in order to clarify women's advanced degree-seeking needs.

\section{Recommendations for Practice}

Based on the findings of this study, the following courses of action are offered for potential doctoral students, current doctoral students, and those who work with them. The suggestions include: (a) using their personal characteristics to overcome the obstacles of dissertation completion; (b) prioritizing their responsibilities; (c) becoming a selfadvocate; (c) collaborating with peers and faculty; and (d) focusing on the dissertation.

1. The participants indicated they had personal characteristics that allowed them to persevere when faced with barriers and to finish something that they started. They exhibited strong self-efficacy (Bandura, 1986), the belief they had the skills to complete the dissertation because of their past academic experiences. Once the structured coursework ended, the difficulties began with the open-ended dissertation process.

Doctoral students need to be flexible during the dissertation phase of their degree because changes will occur in the university faculty and policies during their program. 
Students must be willing to adhere to university policies and deadlines, because completing the doctoral degree is the ultimate goal. Students cannot be sensitive as they work on writing and revising their dissertations because a committee of people with diverse viewpoints reads their document. Committee members are experts in their area whether it is methodology or cognate, and they bring to the table a range of experience. Students need to remember that committee members often teach classes in addition to their doctoral responsibilities.

2. The participants reported that to be successful, students need to effectively prioritize their family, job and academic studies effectively. They should ask themselves before beginning a program if they have the time to commit to the task and can put family and non-essential job responsibilities on hold for the duration of the degree. Before advancing to candidacy, students need to discuss with faculty their time commitments during the advanced degree program to ascertain that they can manage the dissertation research and writing.

Several participants who completed the degree with the minimum credits set a timeline to finish their degree. Once students enter candidacy, they should develop a research plan with the committee outlining deadlines for the proposal and chapters of the dissertation. It should include a completion date. The plan would include opportunities for conferences and workshops. The plan would be a work in progress, but it would provide structure the participants said was missing in the dissertation phase.

The participants indicated the need for family support both practical (physical) and emotional as they prioritized their responsibilities. Each needed her spouse and children who were at home to understand the importance of completing the degree to her, 
and to work with her, not against her. The ethic of caring and cooperation (Gilligan, 1986; Noddings, 2003) affected the women as they had to overcome not "feeling guilty" or for the family not to "feel neglected." They needed to allow husbands to assist with childcare and household duties even to the extent of hiring domestic help if necessary. The doctoral journey is only for a period of time.

3. Participants indicated the need to be self-advocates and to speak up for themselves in an assertive, but not confrontational, way to let others know that "they mean business." They need to ask for help and even changes in their committees if they feel it is necessary. The Lenz (1997) study indicated that women should not feel inferior just because they need assistance.

Because the support of university personnel is crucial to the timely completion of the doctoral degree, the participants indicated that it is important for a woman to select an adviser who understands her situation and with whom she can have a good working relationship. The student should remain in contact with the adviser on a regular basis and together the two should have regularly scheduled meetings. Because the participants indicated that timely feedback from the adviser and committee is most important, students need to stay in communication with their professors on a regular basis.

The participants indicated that they had little opportunity for academic collaboration with their advisers. So students should explore opportunities to help in the research process by asking to attend meetings or even gather and analyze data. If this is not possible, students need to access information about university research activities and seminars. Contact with faculty inside and outside of the classroom serves directly to shape learning and persistence and influence the degree to which students become 
involved in learning in and beyond those settings (Tinto, 1997). It is important to establish collegial relationships early in the doctoral experience (Lenz, 1997).

The participants indicated that students should seek opportunities to continue academic collaboration that would help during the "isolated" dissertation phase. One way would be to join monthly small group seminars where students in all stages of the dissertation meet together to give each other moral and academic support. Guests should include recent graduates who provide recommendations from their experience as well as emotional support.

Participants also mentioned that they would like to see a more lengthy "boot camp" dedicated to writing the proposal where students would be located away from their jobs and family thus dedicating all their time to academic writing. Tinto (1997) wrote that the classroom is the only place where involvement may arise for many if not most students and that it is important to promote involvement, especially in non-residential settings such as the satellite campus. Collaborative learning groups (such as seminars and "boot camps") enable students to develop a network of support outside the classroom.

Changes could be made in the required dissertation courses to address some of these recommendations. Participants reported the need for deadlines during the dissertation phase. By the time students successfully complete the comprehensive exam, they are no longer novice students and should have ideas for possible topics. Freshly admitted candidates could meet in small groups once a month with advisers during the first dissertation credit stage to work on the topic selection and literature review and/or proposal. At the end of that term, a pass-fail grade would be given for the completion of the review and/or proposal. By the second term in the dissertation credits, a draft of the 
first three chapters would be required, the committee selected and the study would have begun. So, by the end of the first half of the dissertation credits, doctoral students would be well on their way to completion.

5. The participants indicated doctoral students need to focus on the dissertation from the first class by considering "manageable" topics, reading related research studies, completing projects on the idea and even conducting a mini project or pilot study if possible. Since their research experience was limited to coursework and the comprehensive exam, the participants said that students need to use writing assignments in their classes as "dissertation practice."

Because women who completed their dissertation in a timely manner used the workplace to conduct their studies, the work site should be conducive to that approach if appropriate. When employed, the women indicated they needed to have supervisors who encouraged their pursuit of the degree, both emotionally and financially. Students should request an adjustment to work hours if necessary to attend class or during the dissertation writing stage by applying for grants or sabbaticals.

\section{Recommendations for Future Research}

The interpretation of the data indicates that more studies should be conducted in the following areas:

1. Research should explore the relationship between the level of research training and dissertation completion. The women in this study all reported they felt that they were hampered because they had little practical research experience. Empirical research should be conducted to ascertain if, in fact, a relationship exists between a doctoral students' participation in research projects and their dissertation completion rates. 
2. Since All But Dissertation (ABD) women were not interviewed, it would be valuable to study their self-perceptions and self-efficacy in relation to dissertation completion.

3. Because the successful women in this study had high self-efficacy, studies should be conducted to see if providing additional opportunities during the coursework that strengthen self-efficacy positively affects dissertation completion rates.

4. Since men were not interviewed for this study, research should compare how the self-perceptions and self-efficacy of male and female doctoral students compare in relation to dissertation completion.

5. Since non-completers were not interviewed, a study should compare and contrast completers and non-completers as to the strategies they used during their dissertation research and writing.

\section{Conclusion}

The road to the advanced doctoral degree is affected by both personal characteristics and structural resources. The women in this study began the journey with "baggage that they had to shift and repack" throughout their trip. They articulated a need for relationships, cooperation and caring also noted by many feminist researchers (Belenky, et al., 1986; Chodorow, 1972; Gilligan, 1986; Noddings, 2003). For these women, educational experiences and accomplishments strengthened their self-efficacy (Bandura, 1986) and academic resilience. They found success through developing strategies to work with the structural resources that were provided by the university and to generally seek opportunities that supported them. 
Although students are unable to control programmatic offerings and restrictions, they can set their own priorities and learn to focus on the job at hand, the completion of the dissertation. Unforeseen roadblocks may occur such as illness or family issues, but these successful doctoral completers developed and utilized personal strategies to overcome individual and programmatic roadblocks. Overall, this study indicated that a woman's academic resilience works with the structural sources to determine the strategies that help her cope and succeed in a doctoral program. 


\section{References}

Baird, L. L. (1997). Completing the dissertation. New Directions for Higher Education, $25,99-105$.

Bandura, A. (2000). Cultivate Self-efficacy for personal and organizational effectiveness. In E. A. Locke (Ed.), Handbook of principles of organizational behavior (pp. 120-136). Oxford, UK: Blackwell.

Bandura, A. (1994). Self-efficacy. In V. S. Ramachaudran (Ed.) Encyclopedia of human behavior (Vol. 4, pp. 71-81). New York: Academic Press.

Bandura, A. (1997). Self-efficacy: The exercise of control. New York: Freeman.

Bandura, A. (1986). Social foundations of thought and action: A social cognitive theory. Englewood Cliffs, NJ: Prentice-Hall, Inc.

Belenky, M. F., Bond, L. A., \& Weinstock, J. S. (1997). A tradition that has no name: Nurturing the development of people, families, and communities. New York: Basic Books.

Belenky, M. F. Clinchy, B. M., Goldberger, N. R., \& Tarule, J. M. (1986). Women's ways of knowing: New York: Basic Books, Inc.

Berg, H. M., \& Ferber, M. A. (1983). Men and women graduate students: Who succeeds and why? Journal of Higher Education, 54(6), 29-48.

Boes, S. R., Ullery, E. K., Millner, V. S., \& Cobia, D. C. (1999). Meeting the challenges of completing a counseling doctoral program. Journal of Humanistic Education and Development, 37, 130-144.

Bogdan, R. C., \& Bicklen, S. K. (1998). Qualitative research for education: An introduction to theory and methods $\left(3^{\text {rd }}\right.$ ed.). Needham Heights, MA: Allyn \& Bacon.

Bowen, W. G., \& Rudenstein, N. L. (1992). In pursuit of the PhD. Princeton, NJ: Princeton University Press.

Brunner, C. C. (1997). Women's way of succeeding in educational administration, ERS Spectrum, Fall, 25-31.

Brunner, C. C. (1998). Women superintendents: Strategies for success. Journal of Educational Administration, 36, 160-182. 
Burnett, P. C. (1999). The supervision of doctoral dissertations using a collaborative cohort model. Counselor Education and Supervision, 39, 1, 46-52.

The Carnegie Foundation for the Advancement of Teaching. (2002). Our Work: Carnegie Classification of Institutions of Higher Learning. Retrieved December 1, 2002, from http://CarnegieFoundation.org/Classification/Index.html

Cesari, J. P. (1990). Thesis and dissertation support groups: A unique service for graduate students. Journal of College Student Development, 31, 375-6.

Chodorow, N. (1974). Family structure and feminine personality. In M. Z. Rosaldo \& L. Lamphere (Eds.) Women, culture and society (pp.43-66). Stanford, CA: Stanford University Press.

Clark, M. C., \& Watson, D. B. (1998). Women's experience of academic collaboration. New Dimensions for Adult and Continuing Education, 79, 63-75.

Conrad, L., \& Phillips E. M. (1995). From isolation to collaboration: A positive change for postgraduate women? Higher Education, 30, 313-322.

Cooper, J. E. (2002). Gender equity in the academy. In J. Koch \& B. Irby (Eds.).

Defining and redefining gender equity in education (pp. 59-80). Greenwich, CT: Information Age Publishing.

Creswell, J. W. (1998). Qualitative inquiry and research design: Choosing among five designs. Thousand Oaks, CA: Sage Publications, Inc.

Cuetara, J., \& LeCapitaine, J. E. (1991). The relationship between dissertation writing experiences and doctoral training environments. Education, 112, 233-241.

Deakins, A. (1992). The tulvous dilemma: Gender, power and solidarity in Perry, L., Turner, L. and Sterk, H. (Eds.). Constructing and reconstructing gender: The links among communication, language, and gender (pp. 151-161). Albany: SUNY Press.

Denzin, N. K., \& Lincoln, Y. S. (Eds.). (2003). Strategies of qualitative inquiry. Thousand Oaks, CA: Sage Publications, Inc.

Eisner, E. (1998). The enlightened eye. New York: Macmillan.

Ellis, E. M. (2001). The impact of race and gender on graduate school socialization, satisfaction with doctoral study, and commitment to degree completion. The Western Journal of Black Studies, 25, 30-45. 
Fogg, P. (2002). Number of PhDs Awarded in U.S. declines, but American women gain in share of U.S. total. Retrieved November 12, 2002 from http://chronicle.com/daily/2002/11/2002111101n.htm

Garcia, M. E. (1987). Preventing the "all but thesis" phenomenon. (Doctoral dissertation Western Michigan University, 1987). Dissertation Abstracts International-B 48/07, 2089.

Gilligan, C. (1982). In a different voice. Cambridge, MA: Harvard University Press.

Golde, C. M., \& Dore, T. M. (2001). At cross purposes: What the experiences of today's doctoral students reveal about doctoral education, (www.phdsurvey.org). Philadelphia, PA: A report prepared for The Pew Charitable Trusts.

Green, K.E. (1997) Psychosocial factors affecting dissertation completion, New Directions for Higher Education, 99, 57-64.

Heinrich, K. T. (1995). Doctoral advisement relationships between women: On friendship and betrayal. Journal of Higher Education, 66, 447-469.

Jacoby, B. (2000a). Why involve commuter students in learning? New Directions for Higher Learning, 109, 3-12.

Jacoby, B. (2000b). Involving commuter students in learning: Moving from rhetoric to reality, New Directions for Higher Learning, 109, 81-87.

Janesick, V. J. (1998). “Stretching” exercises for qualitative researchers. Thousand Oaks CA: SAGE Publications, Inc.

Johnsrud, L. K. (1995). Women in graduate education: Reviewing the past, looking to the future. New Directions for Student Services, 72, 69-80.

Koch, J. and Irby, B. (Eds.). (2002). Defining and redefining gender equity in education. Greenwich, CN: Information Age Publishing.

Kluver, R. C. (1997). Students' attitudes toward the responsibilities and barriers in doctoral study. New Directions for Higher Education, 25, 47-56.

Kluver, R. C., \& Green, K. E. (1998). The responsibility scale: A research note on dissertation completion. Educational and Psychological Measurement, 58, 520531.

Le-Doux, C. (1996). Career patterns of African-American and Hispanic social work doctorates and ABDs. Journal of Social Work Education, 32, 245-52. 
Lenz, K. S. (1997). Nontraditional-aged women and the dissertation: A case study approach. New Directions for Higher Education, 99, 65-74.

Louque, A. (1999). Factors influencing academic attainment for African-American women Ph.D. recipients: an ethnographic study of their persistence. Educational Review, 50, 101-108.

Maher, M. A., Ford, M. E., \& Thompson, C. M. (2004). Degree progress of women doctoral students; Factors that constrain, facilitate, and differentiate. The Review of Higher Education, 27, 385-408.

Mariano, C, (1993). A Study of Ed.D.s, Ph.D.s and ABDs in education administration. (Doctoral dissertation Boston College, 1993). Dissertation Abstracts International-A, 54/06, 2069.

Martin, J. R. (1999). Women, schools and cultural wealth (In Titone, C. \& Maloney, K.E. (Eds.). Women's philosophies of education: Thinking through our mothers (pp. 149-177). Upper Saddle River, NJ: Merrill, an imprint of Prentice Hall.

Maslow, A. H. (1943). A theory of human motivation. Psychological Review, 50, 370396.

Merriam, S. B. (1988). Case study research in education: A qualitative approach. San Francisco: Jossey-Bass.

Monsour, M., \& Corman, S. (1991). Social and task function of the dissertation partner: One way of avoiding terminal ABD status. Communication Education, 40,180186.

Nerad, M., \& Miller, D. S. (1997). The institution cares: Berkeley's efforts to support dissertation writing in the humanities and social sciences. New Directions for Higher Education, 25, 75-90.

Neumark, D., \& Gardecki, R. (1998). Women helping women? Role model and mentoring effects on female $\mathrm{PhD}$ students in economics. Journal of Human Resources, 33, 220-246.

Noddings, N. (2003). Caring: A feminine approach to ethics and moral education $\left(2^{\text {nd }}\right.$ ed.). Berkley, CA: The University of California Press.

O'Connor, C. O. (2002). Black women beating the odds from one generation to the next: How the changing dynamics of constraint and opportunity affect the process of educational resilience. American Educational Research Journal, 39, 855-903. 
Patton, M. Q. (1990). Qualitative evaluation and research methods. Newbury Park, CA: Sage.

Pistole, M. C. (1994). Mentoring women's academic careers: Using a family model to enhance women's success. Initiatives, 56(2), 29-36.

Rode, W. H. (1998). Role of a learning community-based program in doctoral dissertation completion: A case study of program factors related to dissertation completion in a professional development program. (Doctoral dissertation University of Maryland, 1998). Dissertation Abstracts International, 60(2-A), 0325 .

Rudolph, F. (1990). The American College and University: A history. Athens, GA: The University of Georgia Press.

Schroeder, D. S., \& Mynatt, C. R. (1993). Female graduate students' perceptions of their interactions with male and female professors. Journal of Higher Education, 64, 5, 555-573.

Shelburn, M. R., \& Lewellyn, P. G. (1995). Gender bias in doctoral programs in economics. Journal of Economic Education, 26, 373-382.

Smeby, J. (2000). Same-gender relationships in graduate supervision. Higher Education, $40,53-67$.

Smallwood, S. (2004). Doctor dropout. The Chronicle of Higher Education, L, 19, 10-12.

Stake, R. E. (1998). Case studies. In N. K. Denzin and Y.S. Lincoln (Eds.), Strategies of qualitative inquiry (pp. 86-109). Thousand Oaks, CA: Sage Publications, Inc.

Sternberg, D. (1981). How to complete and survive a doctoral dissertation. New York: St. Martin's Press.

Tetreault, M. K. T. (1985). Feminist phase theory: An experience-derived evaluation model. Journal of Higher Education, 56, 363-384.

Tinto, V. (1997). Classrooms as communities: Exploring the educational character of student persistence. The Journal of Higher Education, 68, 599-623.

Titone, C., \& Maloney, K. E. (Eds.). (1999). Women's philosophies of education: Thinking through our mothers. Upper Saddle River, NJ: Merrill, an imprint of Prentice Hall.

Turner, C. S. V., \& Thompson, J. R. (1993). Socializing women doctoral students:

Minority and majority experiences. Review of Higher Education, 16, 355-370. 
Twombly, S. B. (1991). New directions for studying women in higher education: Lessons from the feminist phase theory. Initiatives, 54, 9-17.

Twombly, S. B. (1998). Women academic leaders in a Latin American university: Reconciling the paradoxes of professional lives. Higher Education, 35, 367-397.

Ulku-Steiner, B., Kurts-Costes, B., \& Kinlaw, C. R. (2000). Doctoral student experiences in gender-balanced and male-dominated graduate programs. Journal of Educational Psychology, 92, 296-307.

U.S. Department of Education. National Center for Educational Statistics. (2001). The condition of education 2001. Retrieved May 27, 2002, from http://nces.ed.gov/programs/coe/2001section3/indicator $30 / \mathrm{html}$

U.S. Department of Education. National Center for Educational Statistics. (2002). The condition of education 2002. NCES 2002-025. Washington, DC: U.S. Government Printing Office. Retrieved May 27, 2002, from http://nces.ed.gov/programs/coe/2002.

U.S. Department of Education. National Center for Educational Statistics. (2003). Postsecondary institutions in the United States: Fall 2002 and degrees and other awards conferred 2001-02 (NCES-154). Retrieved March 14, 2004, from http://nces.ed.gov.fastfacts/display.asp?id=72.

U.S. Department of Education. (1997). Title LX: 25 Years of Progress. Washington DC: U. S. Government Printing Office. Retrieved November 24, 2002, from http://www.ed.gov/pubs/Title IX.

Weil, R. L. (1990). Factors affecting doctoral students' time to degree. (Doctoral dissertation Claremont Graduate School, Claremont, CA, 1989). Dissertation Abstracts International-A, 55/12, 3714.

Wilson, A. H. (2000). Serving the quiet majority: The Drexel commuter program. About Campus, 8(4), 23-35.

Witte, J. E., \& James, W. B. (1998). Cohort partnerships: A pragmatic approach to doctoral research. New Directions for Adult and Continuing Education, 79, 53-62.

Wolf-Wendel, L. E. (2000). Women-friendly campuses: What five institutions are doing right. The Review of Higher Education, 23, 319-345.

Women's studies at Marshall University. Retrieved January 19, 2003 from http://www.marshall.edu/womenstu/why.htm 
Zeldin, A. L., \& Pajares, F. (2000). Against the odds: Self-efficacy beliefs of women in mathematical, scientific, and technological careers. American Educational Research Journal, 37, 215-246. 
APPENDIXES 
Appendix A

Broward Doctoral Program

College of Education

Admissions/Enrollment Summary by Cohort and Year

COHORT 1

Fall, 1993

\begin{tabular}{|l|c|c|c|c|c|c|}
\hline & Applicants & Admitted & Matriculated & $\begin{array}{c}\text { Dissertation } \\
\text { Stage }\end{array}$ & Inactive & Graduated \\
\hline AE/HRD & 9 & 7 & 6 & 0 & 1 & 6 \\
\hline C \& I & 17 & 10 & 10 & 1 & 0 & 9 \\
\hline HE & 7 & 3 & 2 & 0 & 0 & 1 \\
\hline TOTAL & 33 & 20 & 18 & 1 & 1 & 16 \\
\hline
\end{tabular}

COHORT 2

Fall, 1994

\begin{tabular}{|l|c|c|c|c|c|c|}
\hline & Applicants & Admitted & Matriculated & $\begin{array}{c}\text { Dissertation } \\
\text { Stage }\end{array}$ & Inactive & Graduated \\
\hline AE/HRD & 11 & 3 & 3 & 1 & 1 & 1 \\
\hline C \& I & 17 & 8 & 7 & 4 & 2 & 1 \\
\hline HEI & 8 & 3 & 3 & 2 & 0 & 1 \\
\hline HEA & 0 & 0 & 0 & 0 & 0 & 0 \\
\hline TOTAL & 36 & 14 & 13 & 7 & 3 & 3 \\
\hline
\end{tabular}

COHORT 3

Fall, 1995

\begin{tabular}{|l|c|c|c|c|c|c|}
\hline & Applicants & Admitted & Matriculated & $\begin{array}{c}\text { Dissertation } \\
\text { Stage }\end{array}$ & Inactive & Graduated \\
\hline AE/HRD & 18 & 5 & 5 & 2 & 2 & 0 \\
\hline C \& I & 17 & 7 & 7 & 6 & 1 & 0 \\
\hline HEI & 1 & 1 & 1 & 0 & 0 & 1 \\
\hline HEA & 10 & 6 & 6 & 5 & 0 & 0 \\
\hline TOTAL & 46 & 19 & 19 & 13 & 3 & 1 \\
\hline
\end{tabular}

COHORT 4

Fall, 1996

\begin{tabular}{|l|c|c|c|c|c|c|}
\hline & Applicants & Admitted & Matriculated & $\begin{array}{c}\text { Dissertation } \\
\text { Stage }\end{array}$ & Inactive & Graduated \\
\hline AE/HRD & 14 & 8 & 8 & 3 & 1 & 0 \\
\hline C \& I & 10 & 5 & 5 & 2 & 0 & 2 \\
\hline HEI & 3 & 2 & 2 & 2 & 0 & 0 \\
\hline HEA & 4 & 0 & 0 & 0 & 0 & 0 \\
\hline TOTAL & 31 & 15 & 15 & 7 & 1 & 2 \\
\hline
\end{tabular}

(Revised 10/09/00) Page 1 of 2 
COHORT 5

Fall, 1997

\begin{tabular}{|l|c|c|c|c|c|}
\hline & Applicants & Admitted & Matriculated & $\begin{array}{c}\text { Dissertation } \\
\text { Stage }\end{array}$ & Inactive \\
\hline AE/HRD & 10 & 6 & 6 & 3 & 1 \\
\hline C \& I & 5 & 4 & 4 & 2 & 1 \\
\hline HEI & 6 & 5 & 5 & 2 & 2 \\
\hline HEA & 6 & 5 & 5 & 2 & 0 \\
\hline
\end{tabular}

COHORT 6

Fall, 1998

\begin{tabular}{|l|c|c|c|c|}
\hline & Applicants & Admitted & Matriculated & Inactive \\
\hline AE/HRD & 11 & 7 & 6 & 0 \\
\hline C \& I & 7 & 4 & 4 & 0 \\
\hline HEI & 9 & 2 & 2 & 0 \\
\hline HEA & 19 & 11 & 10 & 2 \\
\hline TOTAL & 45 & 24 & 22 & 2 \\
\hline
\end{tabular}

COHORT 7

Fall, 1999

\begin{tabular}{|l|c|c|c|}
\hline & Applicants & Admitted & Inactive \\
\hline AE/HRD & 10 & 5 & 0 \\
\hline C \& I & 10 & 6 & 1 \\
\hline HEI & 5 & 3 & 1 \\
\hline HEA & 5 & 7 & 0 \\
\hline TOTAL & 30 & 21 & 19 \\
\hline
\end{tabular}

Entry Year 2000

January 2000-September 2000

\begin{tabular}{|l|c|c|}
\hline & Applicants & Admitted \\
\hline AE/HRD & 31 & 7 \\
\hline C \& I & 13 & 1 \\
\hline HEI & 9 & 1 \\
\hline HEA & 9 & 5 \\
\hline TOTAL & 62 & 14 \\
\hline
\end{tabular}

(Revised 10/09/00) Page 2 of 2

KEY:

AE/HRD

Adult Education/Human Resource Development

$C \& I$

Curriculum and Instruction

HEI

Higher Education Instruction

HEA

Higher Education Administration 
February 28, 2003

Name

Address

City, State, Zipcode

Dear

It is a pleasure to invite you to become a part of a qualitative study I am conducting for my doctoral dissertation. The purpose of the study is to examine women's experiences as they complete an advanced graduate degree. Your participation in this study is requested because you have received your degree from the satellite program.

Participation in this study will require approximately one to two hours of your time for an in-depth interview, which (with your permission) will be audiotaped and transcribed. To maintain confidentiality, you will not be identified by name on the tape. I will transcribe the tapes and keep them in locked in a cabinet at my residence. Each participant will be offered a copy of her tape and her transcription. Only the participants, the members of the dissertation committee and myself will have access to the tapes. The results of the research may be presented at a professional conference.

In the next week I will contact you to answer any questions that you may have concerning your participation in this study. At that time we can arrange the details of the interview if you agree to participate.

I congratulate you on your successful completion of the doctoral degree, and I look forward to your participation in this study.

Sincerely,

Alyce S. Culpepper 


\section{Appendix C}

\section{Participant Informed Consent Form}

Ed.D. candidate Alyce S. Culpepper - under the supervision of Dr. Janice Sandiford in the College of Education - from Florida International University is conducting research examining the experiences of women in graduate school. Ten women will be interviewed at a time and location (at their convenience) in sessions lasting for at least one hour on audiotape which will be transcribed and analyzed later. During the interviews, the women will tell their personal stories as they studied for their doctoral degree. Participants may receive copies of the tapes and transcriptions if they wish.

The risks involved as a participant are minimal; they are no greater than participation in a normal conversation. Benefits of participation include assisting the researcher in gathering knowledge in this area of study as well as providing suggestions for other students to be successful Ed.D. recipients. No cost is involved for the participants of this study nor is any compensation given to the participants in return for their interviews.

Participants may withdraw their consent and discontinue participation in this research project at any time with no negative consequences. All information pertaining to this study including tapes will be kept in a locked cabinet at the researcher's home. The interviews are confidential; files will only be identifiable by subject number. The content of the tapes is only available to the researcher, the three members of the dissertation team and for possible presentation at a professional conference. The research will be presented with pseudonyms; no real names will be disclosed unless required by law.

Participants may ask questions concerning the interviews, and if any new findings are developed during the time of this study which may affect a willingness to continue to be in the study, participants will be informed as soon as possible. For any questions concerning the rights of human subjects that may have incurred related to this study, participants may contact Institutional Review Board Chairperson Dr. Bernard Gerstman at 305-348-3115 or 305-348-2494 (Florida International University, University Park, MARC 430, Miami, Florida 33199).

For more information contact the principal investigator Alyce Culpepper at 954-587-3060 or her advisor Dr. Janice Sandiford at 305-348-3996.

By signing this form, you agree to participate in this study: to be interviewed, to have the interview recorded, to be included in a dissertation and to have the results presented at a scholarly conference.

Signature of Participant

$$
\text { Printed Name of Participant }
$$

Date

The research procedure has been explained to the participant, and a copy of this consent form has been offered to her. 


\section{Sample Interview Questions}

\section{Questions for Qualitative Interview}

\section{Grand Tour - What was happening in your life when you decided to pursue a doctoral degree?}

a. How did you arrive at the South Florida off-campus program?

b. How did it affect your doctoral study?

c. Why did you want the degree? What value did you see in it?

d. What about yourself made you feel you could complete the degree?

\section{Grand Tour - Walk me through your degree program.}

a. Course work, qualifying exam and defense, dissertation and defense

b. What courses or activities contributed to your confidence that you could complete this goal?

c. Along the way, what kept you going?

d. For you, what was the easiest part? The most difficult?

e. Who or what supported you through this process?

f. What influence did your personal/family responsibilities have on completion?

g. Describe any unusual event that happened during your doctoral study that affected your time to completion - positively and negatively.

\section{Grand Tour: Let's chat about the dissertation.}

a. When did you choose the topic you decided to stay with? What influenced you with this?

b. What influence did your work/job responsibilities have on your completion?

c. What influence did your personal/family responsibilities have on completion?

d. Tell me about your adviser. Committee members.

e. What research experience did you have prior to completing the dissertation and how did that affect your completion?

IV. Grand Tour: Talk with me about the major outcomes for you professionally, personally and intellectually now that you have finished. How do you view yourself at this point in your life now that you have been successful?
a. Tell me about the significant event when you knew you were going to finish.
b. How did you feel when you first heard your name as doctor?
c. What has happened to you since you earned your degree? (professional and personal)

\section{V: Grand tour: Let's talk about the program.}

a. What in the program was helpful to you? What did you consider a hindrance?

b. Discuss with me how the cohort format affected your completion.

c. What issues about the doctoral program do you perceive to be undisscussable?

d. What advice would you give to women about completing the doctoral degree?

e. What do you think hinders other students' chances for doctoral success?

f. Looking back at your doctoral experience, what would you do differently now? 


\section{Appendix E \\ Sample Interview Transcription}

Interview 6 - Dissertation

"Nora" Workplace Site

AC: Thank you for this interview. Your name was mentioned quite often. I was just so grateful that you agreed to do this. What was happening in your life when you decided to pursue the doctoral degree?

NORA: Actually it happened to me. I was the principal at -..- Elementary and I had worked with -... -.-- in some reading projects at my school. And then they kinda got bounced out of their home at BCC where FAU is now. FIU had a home there, and they had to find themselves a place to go. So they... and I think the state politics was that FAU had the undergraduate programs in Broward and they could control and so FIU had to get out of the undergraduate business, so they desperately had to get their graduate program beefed up. So she had come and talked to my staff; one, they wanted a room to teach in; and two, they wanted people to go into their graduate degrees. So they came to talk to them about master's in reading, etc. and the doctoral program was a brand new doctoral program they were to get off the ground in Broward County. And so there were some of us that... and I was the principal and so I thought I had to model a behavior and sign up never knowing how much work it was.

$A C$ : So you were in the first cohort then?

NORA: Yes.

$A C$ : That was the most successful one.

NORA: Because, and it's true of any reform movement, they were the visionaries. They were the ones who dreamed it up. They were very invested in its success. And as that strength dissipates so does the enthusiasm I think.

$A C$ : What was happening in your personal life at that time?

NORA: Well, my children were, I think they were in middle and high school, so they weren't babies so also I was... some time in my life so I could devote the time and not have the time... It was a busy time. I was a principal and a fairly new principal so it wasn't necessarily the ideal time but there never is.

$A C$ : So you were married? So did you have any financial assistance?

NORA: Did I take loans? I probably took loans out. I'm sure for some of it. Some I could pay. As the semesters roll along it gets expensive. My son was at St. Thomas. So, yea, but that never is an issue for me. I can always pay the money back at sometime. I would never let money stop me from doing it you know.

$A C$ : What about yourself in your background, your training made you feel you could complete the degree?

NORA: Um, I just felt it was probably a persistence issue. I was the leader of the school I had guidance counselors and people under me who went into it with me. So I knew I could do it if they could do it. I know the college was very committed to having people graduate because it doesn't count if you never finish it. So I knew... and it was a small group, and it was experimental in nature. So I knew they had a real strong 
investment to help us finish it. They had confidence that we would. And I had confidence... especially once I started paying the money. Once I plunk in that much money I would never just say, "Oh, well, let me just chalk up that $\$ 5,000 . "$

$A C$ : How long had it been since you'd been in school?

NORA: I had my master's in the mid 70s so it was a good 15 years. But you know I had to get certified in administration supervision. I had a lot of training as an assistant principal and principal. I had a lot of training as an assistant principal and a principal. So when you're an educator you're always taking something.

$A C$ : Walk me through your degree program. We can start with the coursework.

NORA: Well, my course work... the very first course, and that was the deal that it was going to be right in my school. So that was the other thing... here's my office and next door is the conference room and that was where the first course was offered. So you couldn't really use the excuse you had to get to Miami or anything. So the first courses were actually housed in my school, and then because more people joined that wasn't convenient for them. They diverted to downtown to where BCC is now. But that was a place here FIU was. So that wasn't too bad. And then there's a little tug of war. But you promised. It was going to be at Nova and now it's downtown. But of course they had to get other people to join or it wouldn't have survived. I think the master's in reading stayed at my school the whole time. And then they modeled teaching and everything and it was great for the teaching staff. So that's how it started... small class, nine or ten people. It was exciting at first you know. Getting back into the groove and those intellectual conversations and those books. It gets long after a while. But the first semester I thought this is really great. I feel energized again. I feel like am working with people who need to have those conversations and an intellectual dialogue, which sometimes you don't have as a principal because you do a lot of teaching and mentoring. But there's is not a lot of places to get it at your level across the board. Principals tend to be... they don't provide a lot of opportunities for you to have those learning communities among principals so it was really like energy for me to have it.

$A C$ : How fast did you take your courses?

NORA: We took two a semester. Now cohort one was designed that they would always have the courses you needed when you needed them in order, and if you kept up, you know... if you sign up as you were supposed to and you didn't have to play catch up, you would finish in four years. So that was their promise to us. And it worked pretty well. But if you said, "Oh, gee, I'm going away this summer, I can't take this course or I can't handle three or two" and you fell behind then you had some work to do. And some people um had weaker backgrounds that they needed some prerequisite courses, and so they had to take extra courses to be eligible. And I never majored in education in college. My undergraduate was not in education so I never took a lot of those things. My master's was but I just went for it. If there was a curriculum course and the prereq. was something else but this was the one that counted, I thought well I'm going to try it. If I read the book and if I don't do well, if then I will take but I wasn't going to pay for an extra course I didn't have to. So I just did it, that's all.

$A C$ : And the qualifying exam?

NORA: My qualifying exam was um... the comprehensive exams were two days, eight hours each of questions. Now the interesting thing is they were still using blue book 
when I... This was 1995 we're not talking 30 years ago. And they were just teaching us email and technology was just really coming in full steam. So we asked to take our comps on the computer instead of writing them because we heard that it writer's cramp that got you more than not knowing the stuff. And they had a big issue with that. And we challenged them. How can you talk about technology, and we should be on email doing all this research when you are still making us write in blue books for 16 hours? They said there was some concern that the clicking of computer keys (laughing) would be a distraction. And we said how about the groaning of people who are dying. They finally allowed us... we could choose to take it on the computer or take in the blue book, and some people chose the blue books. They didn't want to do it. I took it on the computer. But we were the first class to take comps on the computer.

AC: Cool. Your dissertation. Your topic... When did you decide...

NORA: What happened to me was I got promoted to elementary curriculum supervisor downtown, and so it took me out of my element of where I was going to do all my work. The smart think I did which I passed along was... they told me whatever you pick do something where you are... that you have access to do. My friend chose to do... she got promoted out of ---- too but she had her work going on at ----. Once you're gone and those teachers don't have to do because it's a reform initiative in your school and the new administration comes in. She lost her whole project because they just didn't have time to do it, and the new principal had other initiatives and things like that. So she had to redo her whole thing. So I was smart enough to say, "Okay what is it I have to do in this job? Who are the people I have contact with everyday that's part of my work anyway?" and not trying to go back and do some kind of school-based thing when I didn't have a school. So what happened to me was... I got that job and within three months the critically low schools thing hit in the newspaper and there were these schools named. So I ended up doing it on that because it became my job to go out to try and help these schools get off the ground and all that stuff. So I though why not? That's what I have to do. And I have access to the superintendent and all the district people and everything. So why not do that? And that was a godsend because I got it done on time.

$A C$ : What classes or activities helped you improve your confidence or complete the dissertation?

NORA: Um... Well, we had research courses. We had a lot. That was part of the cohort one. I don't know if it's still in the program, but part of the desire that we would have a lot more research background than most doctoral programs. So I think we had about five research courses and that I guess was unusual; most have only one or two. So that gave me some help. But someone... the key for me that someone said really the dissertation is just a giant term paper. It's longer, but it's the same format, and you know its not to get freaked out, it's methodical, and to make sure your committee likes each other. That was the other big tip.

AC: You spoke about the research classes. Any one in particular help you? What methodology did you use?

NORA: I used qualitative and that was a course I took, qualitative. I did it because we had number crunchers downtown that were crunching all the numbers so there was no need for me to do that. But really the process of what it was doing to people, and how teachers were reacting and all the way down, that was what was interesting to me, 
understanding the impact of these initiatives on people that were charged in implementing them. So...

$A C$ : Were you able to use some of that in your class?

NORA: We had to do a mini project, and they recommended that you do it on the same thing you wanted to do your dissertation on. Smaller sample, shorter project but it gets the kinks out of it. And all the mistakes you make you make there. What helps is when you know what you want to do your dissertation on, which a lot of people didn't and a lot of people you know have a lot of 'anxt' about what to do it on. And one teacher... one of our professors was just finishing his and I think he had been working on his four or five years, and he said, "You know, you just have to realize, you're not going to save the world. It's not going to make... You think it's the most important find that's ever come through humanity, but the truth is it's probably going to sit on a shelf somewhere and very few people will read it. So don't spend years trying to find the perfect topic. Just find something that you can do, that you like, that you don't mind living with for two years and just do it. And just begin." I'm very pragmatic when it comes to that you know. And when it came to spending extra money or being in the program longer... because you kinda wear out, you wear down. It's like your going to get this thing done or you're going to belabor it forever. You known how many people drop out after they've done all their course work and they've been working on their dissertation a year or two, and they never quite get it done and they kinda give up.

$A C$ : What is your background contributed to your pragmatism?

NORA: It's just my personality I think. I'm flaky and fluid in a lot ways (laughing) but the big things you know... When I signed up... I never would have signed up and spent my family's money without an intention of finishing it. And I never would... just because $I$ procrastinated... would not cost myself and my family thousands of extra dollars because I knew that it was never going to be easier six... or you always think, oh, I just can't do it this month, I'll get... But the truth is life's busy all the time. And uh, it's really procrastination. So I just had to suck it up and say... You had to sign up for 24 doctoral credits for dissertation. And the good advice I got was... some people are going to rush through, and they sign up for nine credits at once. And unless you steam roll it, you can use up those... in a year and a half you have used up those 24 credits and you're not done yet. And now you have to sign up for more. And the other advice I got was just go... just sign up for six at a time. You had to sign up for six. Sign up for the minimum, you're paying for the minimum credits; it gives you a longer time. Oh, gee, if you are farther ahead than you think, at the end you can always sign up for nine or whatever. So I did it six at a time and figured out how long that would be if I stayed on track, and just kind of made myself do it. I was rushing at the end like everybody just to get it done. Thanksgiving holiday... just doing gobs of work... at once and then doing nothing for a few months but I just didn't want...

$A C$ : What was the easiest part of this whole process?

NORA: The easy part, which people will tell you although you don't believe it, is really the course work. You know the structure. You show up for class, you have conversations, you have a paper or something to do. The hard part, maybe not for some people, but I'm not naturally a highly concrete sequential person, that's not me... so the hard part is when the structure's off, there's no help unless you seek it. It's there if you 
want it you know but no one's calling you every week calling to see how you're coming, have you got the next chapter done. You have to do that yourself. It's all about selfmotivation and self-discipline. And that's the hard part.

\section{$A C$ : Who or what supported you through this process?}

NORA: Well, I think you'll find that cohort one... they did a lot to bond us. They did a lot of simple little ice breakers and things like that so they invested heavily on us knowing and caring about each other. They provided a lot of time for that and a lot of group activities. That was in the design of the cohort. So when it came to crunch we were very supportive of each other. Of course it helped that people from my own school, that I saw everyday were in it. And even when I left the school I was still close to them. But truly when one got discouraged and didn't think they could go on, there was always someone to say, "Yea, you can, you know. How can I help you? Just do this." So we really did, even when we finished and there were some that finished several years after us, we were there to help then and support them. That was by design and it works when it's nurtured, but it has to be nurtured.

AC: How fast do you think you finished in comparison to others?

NORA: The stunning thing is I was one of the first to finish which is not.... If you were to take a poll, you would not expect that because there are some really some concrete sequential driven kind of people that always had things done on time and when we were in groups to organize. We had group work, small group work. I was never the group leader to organize everybody. But those kind of people you just knew that they... I just felt they would be done first. Where I think some people get hung up is in their perfectionism if its not the best or the absolute right topic or if it's... I know people who left the doctoral program because they did not get an A on their paper. I remember clearly one she was a brilliant woman and we were well through. We were not too far from the end of our course work. She had to rewrite... It was a research paper and he said she did not have the right references, and she did not do this and than. She got highly insulted, and said "I have never not gotten an A on my paper" and she dropped out. I found that... You just have to say "Who cares if you get straight As or straight Bs?" No one knows. That's the degree. (Points to framed degree on the wall and laughs). It looks good.

$A C$ : It looks great (laughing together).

NORA: I'm just saying, no one knows whether... like I used to go out and say, "Do you know what the superintendent got in his coursework for his doctorate?" They would say, "No, what?" That's the point. You don't know, nobody knows, who cares, you could've got straight As, you could've got straight Bs, get over just get it done.

AC: How did you family responsibilities affect your degree?

NORA: My family... because my kids were on their own little world because I was always going classes. It does cut your social life down. All day Saturday you are in class. You have to be willing to do that. My husband was very supportive just as far as not expecting a lot of picking up. And then I got highly organized. Like I realize if I just knew what was in the house for dinner, that was the whole thing. So I would get up like 7 o'clock Saturday morning I learned to be in Publix with the menu for the week and everything I needed and whether my husband was going to cook it or my kids and we were ordering pizza, I had that organized. And when I did that one thing, that made all the difference in the world. You know working and coming home and knowing what $I$. 


\section{Appendix F}

Summary of Coding Procedures

\section{Method used for coding}

- Print out all transcripts

- Read transcripts and circle words and phrases indicating internal factors and mark in the left margin, underline external and write in the right margin

- Circle words and ideas that begin to appear in a regular fashion

- Reread transcripts and identify the themes with colored post it notes

- Review and revise list of themes until it captures the transcript content

- Use colored highlighter to identify sub themes with each primary theme

\section{Themes for Coding \\ Internal \\ - Family (pink) Children, spouse, parent \\ - Motivation (hot orange) Goals, Pride, embarrassment \\ - Self-discipline (mottled blue) Finish what started, set deadlines \\ - Strategy \\ - Finances (own) (green) \\ - Self-advocacy (blue) Speak up, change committee \\ - Love of learning (light yellow) Goal in life, lifelong learning \\ - Juggle responsibilities}

Time Management

\section{External}

- Finances (bright green) Assistantships, scholarships, loans, not spend more than needed

- Committee (purple) Faculty, changes, support

- Research (hot pink) Statistics, courses, study

- Convenience (pale green) Location, time, met with small group

- Cohort (gold) Collaboration, small group, boot camp

- Topic (teal) Proposal, selection, comprehensive exam

- Work (lavender) Tuition reimbursement, grant, sabbatical, supervisor support, research study location 


\section{Appendix G \\ Sample of Journal Entry}

\section{October 30}

Met with registrar about the chart she did that I saw. She said it was an internal chart for professors and not an official publication of the university. We discussed the women who have completed the dissertation, and we discovered that 16 have finished since 1993. I still think that is very few.

The research I have been reading says it now is taking people longer and longer to finish the paper. The last article reported that universities may need to rethink the process because the clientele has changed - demographics are different. No longer are people just in college to complete the degree, but they are working professionals. As the older generation retires there will be fewer professors and doctors to replace them. Academia will be less so the intellectual quality of the university may lessen. All of this is not good. It is much like the public schools lowering standards so students can graduate. Now schools must raise the bar. I think the bar can be high we just need to add support vehicles along the way - not expect people to do it alone because there are too many distractions along the way.

\section{November 7}

Met with the off-campus support group. I will continue to find supporting reasons why my study is important. So far, most of my research is why people have not finished their dissertations and nearly all are quantitative. Few have even interviewed successful students. I think I will use the metaphor "The glass is half full" since I want my study to be optimistic and positive. Have set up the first interview next Tuesday. I want to have the time to transcribe and code the information before I do the second interview. It takes me a long time to transcribe and analyze, which I discovered from my in class interviews.

\section{November 13}

When I walked in the room, Lil was very busy. She was working on her computer, talking with students and greeting me. Her classroom was a buzz with activity, and she was going a mile-a-minute. I was grateful she allowed me to chat with her....

I've completed my first interview. I really like talking with people and found the follow-up and probing questions easy to do since I was carefully listening to the participant. My questions seem repetitive so I had to be careful not to keep asking the same things. Sometimes the participant would answer a couple of questions in one answer. She suggested (since she did a qualitative study for her dissertation) that I share some of the questions before hand with the participant. She did and she said her interviews were more thorough. I will try that for the next interview.

It was interesting to hear how her husband pushed her for the degree. It is so much like my husband. If I am daydreaming he will say, "That doesn't look like research to me." He is doing the laundry and never complains about leftover food. When I have class he takes my son to dinner or they order in.

She also talked about the camaraderie of her classmates and how powerful the cohort idea was. It seems her group had and action research class that permitted some 
advanced work on the dissertation. I wonder if others had that too. Pride was an important reason for her to finish. I will try to investigate that in a question with other interviewees. I will have to listen to see if I can use a follow-up question and not put ideas in to the participant's mouth. I want to be as non-biased as I can be.

\section{November 18}

It took over 12 hours to transcribe the interview. I am exhausted. I did allow my participant time to answer questions, which made the transcription easier. I did not butt in too much and left long pauses so the participant could think. I will begin the coding and see how it works. Other women have the same frustrations that I do. I liked her idea of the "zone." She would put her headsets on and listen to music and go to work. I put headsets on only to listen to the interviews and boy do my ears hurt today.

I have set up the next interview. I want to keep things fresh but will reread the first interview for hints of themes. I am splitting the transcription into internal on the left side and external on the right side. I am using post-it notes in different colors as the themes appear.

\section{November 22}

Just finished my interview. It was just as nice as the first one. People who complete their dissertations are so happy and pleasant. Maybe that is one reason they finish! They all like the satellite program and feel it helps them complete. The area we spoke in was noisy. I hope I can transcribe this one okay. She also said how the cohort part was very helpful. She took a sabbatical for part of her dissertation and that gave her time off to devote totally to the paper. She was able to complete in a very short time.

I changed jobs, left the classroom and went to more administrative type work but my job now is more demanding since I am now responsible for an entire school. Before I only was concerned about my journalism program and not 250 staff members for grants, volunteers, newsletters, partners and so on. I used to stay up all night until the wee hours of the morning grading papers and now I just work on my research and transcriptions. I find I am working or thinking about it nearly every day.

\section{November 21}

I knew nothing about the next participant, just picked her name out of the Doctoral Directory - she finished her dissertation in 1997 and started with the first cohort. I was interested in finding out what that cohort did that was different from the more recent groups. She went through a great deal - one of the people on her committee was terminally ill. I found out it was the woman who wrote one of the textbooks we used in a class.

I discovered the first cohort had action research in which they began their literature review, formulated questions and worked on proposals. When I got to the program, action research was abolished. We still had the CIS Saturday seminars but even those are no longer offered. I wonder if this will hurt the program.

Maybe part of the dissertation credits should include a monthly meeting with a group. Perhaps my professor is testing this idea. It will be interesting to see if people in the groups complete. My second participant was in my support group for only two times. 
She was able to gather the information she needed and then went full steam ahead and wrote the paper. I must be careful in my interviewing and analysis and keep reminding myself I am a researcher and not a participant.

Again this woman was so optimistic and peppy. These graduates have an inner energy, a passion to finish. I guess you need energy to do the paper. I think I have the energy and desire to finish the paper so I found a self-efficacy survey and completed it. I saw I have the belief to be successful.

As a person said a long time ago in one of my last classes, "The paper is what we have been working toward; it is the culmination of all our classes and should be fun." I don't know... So many people have tried and failed. The first cohort was successful but the first two I interviewed were not in that cohort and they made it so I think I can too.

\section{November 22}

Again two full days to transcribe my third interview. It was in the camera. (I taped with the lens cap on because the audio was so good. I did not want the women to feel insecure about a camera in the interview but the audio is so much better.) I will have more than 30 pages when I finish.

It is Thanksgiving, and I am thankful I have this time off to do the transcription. I am taking a break and writing in my journal before I finish. Tomorrow, instead of going shopping I will finish the last transcription always do my Christmas shopping the day after Thanksgiving but not this year.

All the participants so far mentioned how the cohorts helped them through the classes. Not too many mentioned the cohorts after completing the orals. Only one person spoke about her "horrible" orals. Her dissertation went smoothly just the mix up in her orals was bad. All have mentioned how their husbands helped them. Two of the three had children and wrote the dissertation after their children went off to college - interesting. All three are so optimistic, loved the program. "The glass is half full" for all of them.

The cohorts were disbanded by the time I enrolled so I can eliminate myself from this part of the discussion and be a researcher.

\section{December 2}

Continued to transcribe the last of the interviews. I don't understand how anyone could do this project unless they transcribed all the interviews. The participants are grouping themselves into similar categories although they each approached the writing differently. One just wrote some in each area, another did only a chapter at a time and the third gave herself goals each week. One still had a life, another had no life for four years, not even a movie and the third had a life after she completed the weekly goal. Interesting. All the participants seemed to have writing skills. I probably should have asked more about the writing.

As I am now becoming part of the group that is taking longer to finish the dissertation I tend to listen more carefully to the reasons of those I interview and look for myself. I have to remind myself to stand back and be a researcher, not a participant. When I took the self-efficacy survey, I realized that my dedication to working out shows that I do possess the characteristics of self-efficacy. I just have to keep reminding myself and apply them to getting this thing done. 


\section{ALICE S. CULPEPPER}

February, 26, 1945

1967

$1967-1997$

1970

1978

$1990-1997.1$

$1997-2000$

2000-present
Born, Beaumont, Texas

BEd, Language Arts Education

University of Florida

Gainesville, Florida

Language Arts Teacher

Hallandale Jr. High, Miramar High, South Plantation High

School Board of Broward County, Florida (SBBC)

Fort Lauderdale, Florida

MEd, Curriculum and Instruction

Florida Atlantic University

Boca Raton, Florida

First Woman Athletic Director for a Florida High School

Creator, Executive Producer

Broward Teen News

SBBC Instructional Television Center

Assistant Professor, Communications

Lynn University

Boca Raton, Florida

Magnet Coordinator, SBBC

Environmental Science and Everglades Restoration

South Plantation High School

Plantation, Florida

\section{PUBLICATIONS/PRESENTATIONS/AWARDS}

Culpepper, A. S. (1994). Broward Teen News Staff Manual and TV Production Guide. Manhattan, KS: Journalism Education Association.

Culpepper, A. S. (1976). Journalism Center of Excellence. Tallahassee, FL: Florida Council of Teachers of English.

Sandiford, J. R., \& Culpepper, A. S. (2003, November). The Road to the EdD:

Successful Women Graduates. Poster session presented at the annual meeting of the Association for the Study of Higher Education, Portland, OR. 
Gold Medallion Award

Florida Scholastic Press Association (F.S.P.A.)

Gainesville, Florida

1994

Professional Impact Award

Journalism Education Association

Manhattan, Kansas

1996

Pioneer Award

National Scholastic Press Association

Minneapolis, Minnesota

1996

Gold Key

Columbia University

New York, New York

1997-present

Executive Director

Culpepper Journalism Foundation

Plantation, Florida

1998-Present

1998

Nationally Certified Master Journalism Educator Journalism Education Association

1998

Lifetime Achievement Award

Journalism Education Association

F.S.P.A. Lifetime Achievement Award

Gainesville, Florida

1999

Phi Kappa Phi, Graduate Honor Society

2004

Broward County Newspaper Adviser of the Year Sun-Sentinel Newspaper (Tribune Corporation)

Fort Lauderdale, Florida

Environmental Educator of the Year

Broward County Environmental Education Council Fort Lauderdale, Florida 